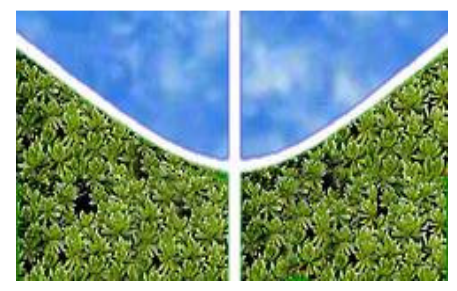

Universidade de Brasília

Instituto de Biologia

Departamento de Botânica

Programa de Pós-graduação em Botânica

Crescimento inicial das gramíneas Paspalum atratum (Swallen) e Urochloa brizantha (Hochst. Ex A. Rich) Stapf. e seus efeitos na rebrota de espécies lenhosas do do Cerrado

Giovanna Masson Conde Lemos Caramaschi 
Universidade de Brasília

Instituto de Biologia

Departamento de Botânica

Programa de Pós-graduação em Botânica

\title{
Crescimento inicial das gramíneas Paspalum atratum (Swallen) e Urochloa brizantha (Hochst. Ex A. Rich) Stapf. e seus efeitos na rebrota de espécies lenhosas do do Cerrado
}

\author{
Giovanna Masson Conde Lemos Caramaschi \\ Orientador: Prof. Fabian Borghetti
}

Tese apresentada ao Programa de Pós-Graduação do Instituto de Biologia, Departamento de Botânica da Universidade de Brasília, como requisito parcial para a obtenção do título de Doutora em Botânica. 
Banca Examinadora:

\begin{tabular}{c}
\hline $\begin{array}{c}\text { Prof. Dr. Fabian Borghetti } \\
\text { Membro Titular - Unb }\end{array}$ \\
\hline Prof. Dr. Augusto César Franco \\
Membro Titular - UnB \\
\end{tabular}

Dra. Dulce Alves da Silva

Membro Titular - EMBRAPA - Cenargem

Dr. Eduardo Rogério Moribe Barbosa

Membro Titular - Universidade de Brasília

Dr. Carlos Romero Martins

Membro Titular - IBAMA

Dr. José Felipe Ribeiro

Suplente - EMBRAPA 
À vida e seus encantos... 
"Nada é impossível para quem tem força de vontade e não desiste nunca".

Giovanna Caramaschi 


\section{AGRADECIMENTOS}

À Universidade de Brasília e ao Instituto de Biologia pela estrutura oferecida.

Ao Departamento de Botânica pela oportunidade de fazer parte de um programa de pós-graduação de qualidade.

A todos os professores do Departamento de Botânica pela amizade e disposição em ajudar.

Ao meu orientador Fabian Borghetti pelos ensinamentos e apoio.

À Capes e ao CNPq pela bolsa de doutorado, fomento à pesquisa e financiamento dos meus estudos na Holanda.

Aos membros da banca examinadora pela disposição em me ajudar a aprimorar a pesquisa e meus conhecimentos.

Ao grupo de pesquisa GEST de Wageningen University pela oportunidade, por todo aprendizado, e pela experiência, em especial ao PhD. Kyle Tomlinson, ao meu orientador externo PhD. Frank Van Langeveld.

Ao meu amigo Eduardo Barbosa pelo companheirismo e ajuda em todos os momentos que precisei no Brasil e na Holanda.

A todos os alunos de graduação e pós-graduação que participaram da coleta de dados do projeto GEST. Sem vocês, certamente eu não teria conseguido terminar o projeto.

Aos funcionários do Laboratório de Termobiologia, em especial Dona Odete, Seu Manoel, Seu Francisco e Seu Antônio. Vocês são maravilhosos! Tenho um carinho especial por vocês.

Aos meus queridos amigos do Laboratório de Termobiologia e aos meus colegas do PPG-Bot.

A minha família e amigos, em especial ao meu marido Marquinhos, meu irmão Emiliano, minha cunhada Júlia, minha sogra Walmíria e meus sobrinhos, Martha e Raul, pela compreensão das ausências, reclamações e incentivos.

Aos meus alunos e amigos que sempre me incentivaram e me deram forças para continuar. Obrigada por ouvirem minhas brincadeiras em relação ao doutorado.

A alguns amigos em particular, que vivenciaram momentos difíceis, e se fizeram muito presentes e dispostos a me ajudar. Obrigada Letícia, Bárbara, David, Ioná, Juliana, Dulce, Nilda!

Aos meus gatos Pepe, Ghost, Gorducha e Luna. Estiveram comigo em todas as jornadas frente ao computador e aos "papers". Meus companheiros de todos os dias, noites e madrugadas!

A uma amiga especial que incentivou toda a jornada e nunca desistiu de mim. Obrigada pela amizade, companheirismo e por toda a ajuda!

Muito obrigada do fundo do meu coração!!!! 


\section{Sumário}

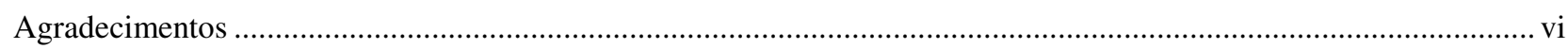

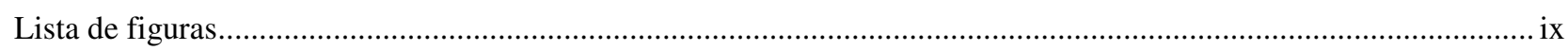

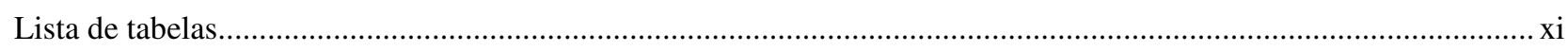

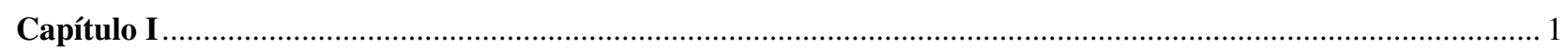

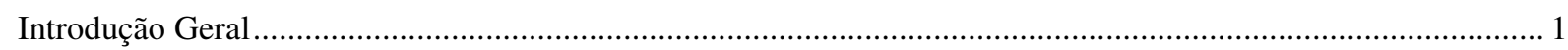

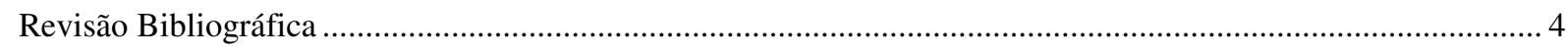

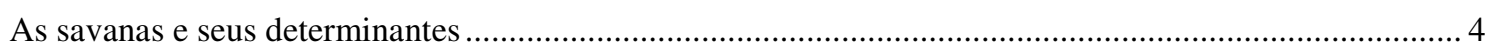

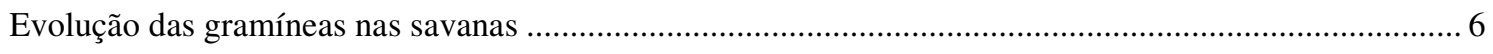

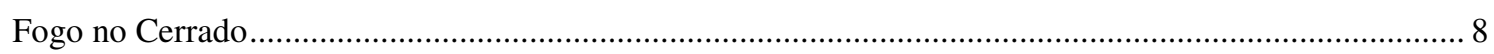

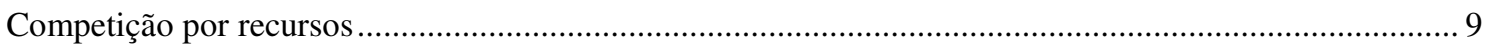

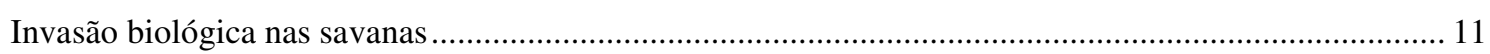

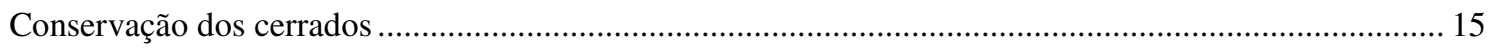

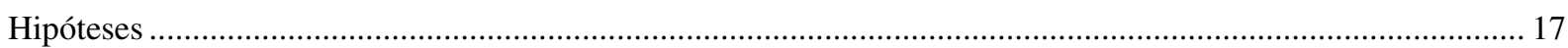

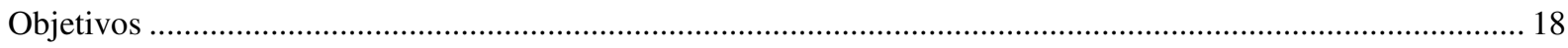

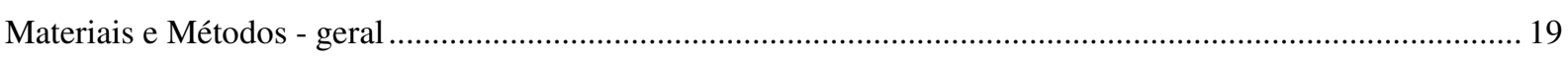

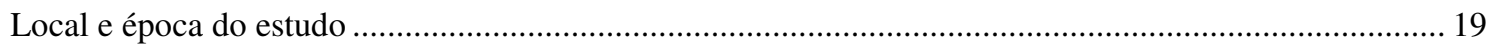

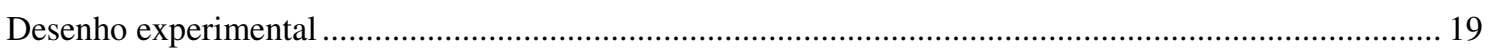

Experimento 1 - Biomassa da cobertura graminosa …............................................................... 22

Experimento 2 - Defoliação e rebrota de espécies lenhosas .............................................................. 23

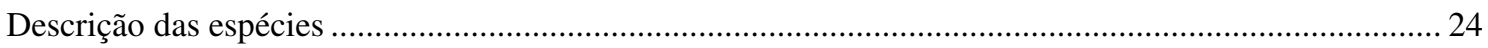

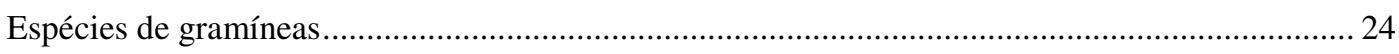

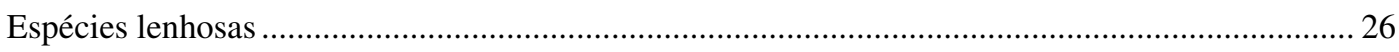

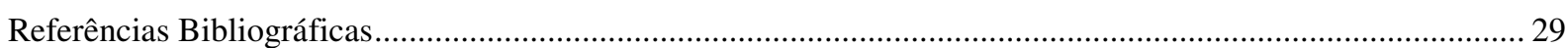

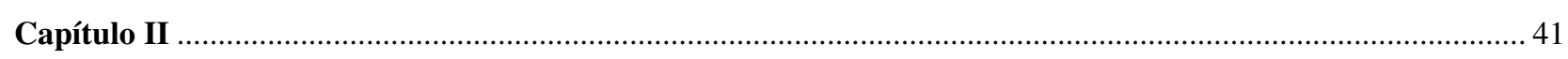

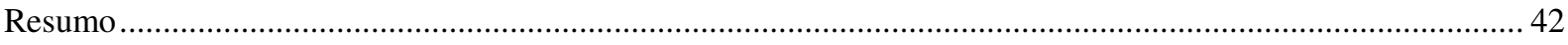

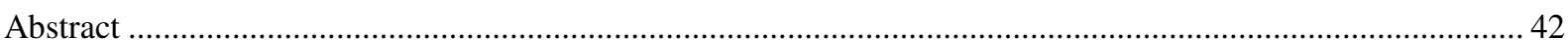

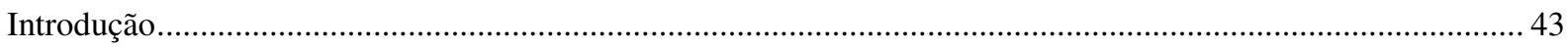

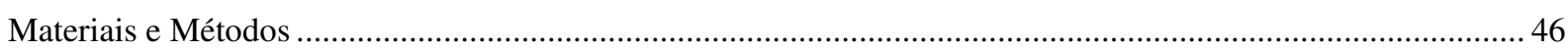

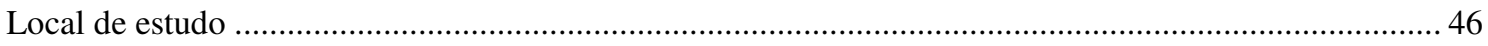

Preparo das parcelas e plantio das gramíneas........................................................................................ 46

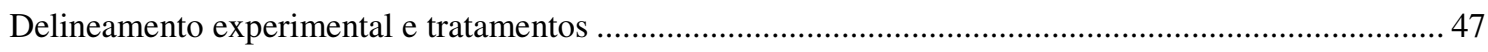

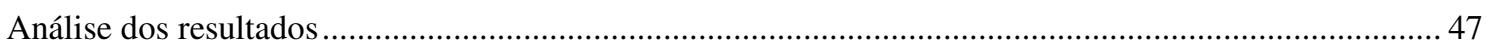

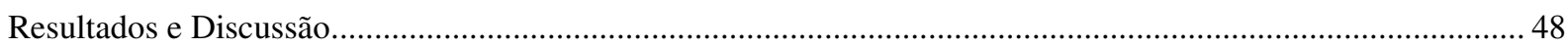

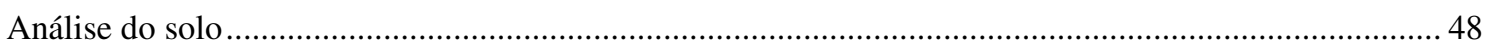

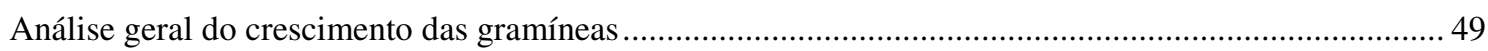

Efeito do sistema de irrigação e da adição de nutrientes no crescimento das gramíneas ...........................52

Efeito da luz e da adição de nutrientes no crescimento das gramíneas ......................................................55

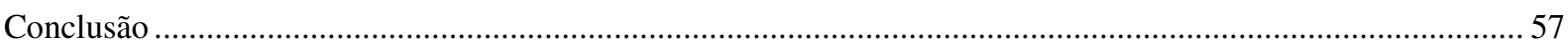

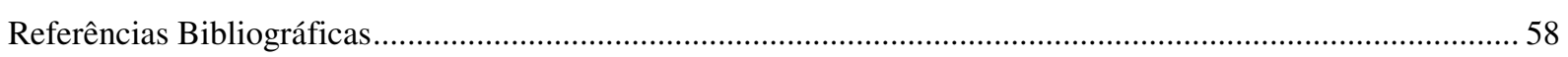


Capítulo III 65

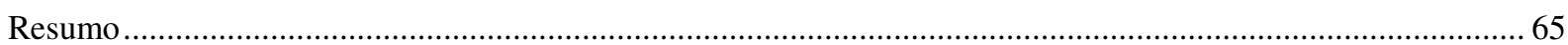

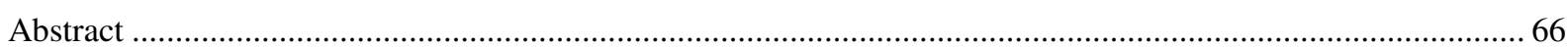

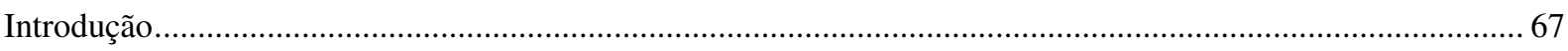

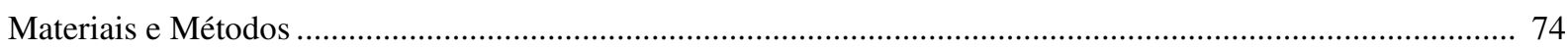

Preparo da área experimental, espécies selecionadas e delineamento experimental ................................... 74

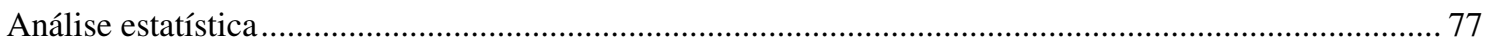

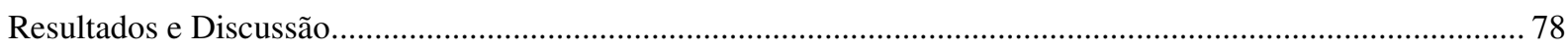

Biometria e biomassa das plantas que foram levadas ao campo - dados iniciais....................................... 78

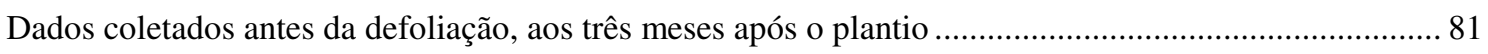

Dados coletados após a defoliação, aos 14 meses após o plantio no campo ……………............................ 85

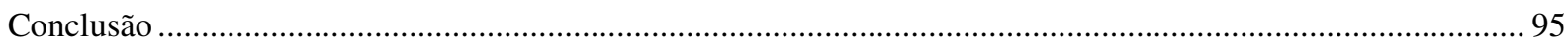

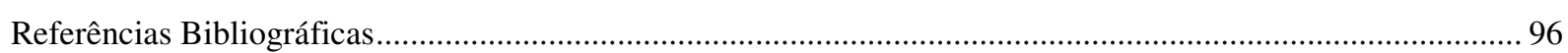




\section{Lista de Figuras}

\section{Capítulo I}

Página

Figura 1. Representação dos blocos experimentais. Os retângulos cobertos com pontos representam casas de vegetação com coberturas para exclusão de chuva, aqueles com linhas verticais coberturas para exclusão de chuva e sombreamento de $80 \%$ e aqueles em branco representam as parcelas sem nenhuma cobertura.

Figura 2. Desenho esquemático dos tratamentos de um único bloco experimental. Água (W), Luz (L) e defoliação (D) foram tratamentos de uma parcela, enquanto que gramíneas (G) e nutrientes (N) foram tratamentos de uma subparcela.

\section{Capítulo II}

Página

Figura 1. Biomassa média (g) das gramíneas Paspalum atratum e Urochloa brizantha produzida durante as estações seca (maio a outubro) e chuvosa (outubro a abril). Experimento conduzido em área experimental do Laboratório de Termobiologia, UnB/Brasília, entre maio de 2011 e abril de 2012. Barras de erros indicam o desvio padrão das amostras.

Figura 2. Média das taxas de crescimento absoluto (TCA) das gramíneas Paspalum atratum e Urochloa brizantha, ao longo da estação de crescimento (início - entre os meses de outubro e dezembro de 2011; meio - entre os meses dezembro de 2011 e fevereiro de 2012; fim entre os meses de fevereiro e abril de 2012). Barras de erros indicam intervalo de confiança de $95 \%$.

Figura 3. Média das taxas de crescimento absoluto (TCA) de Paspalum atratum e Urochloa brizantha, ao longo da estação chuvosa (início - out a dez/2011; meio - dez/2011 a fev/2012; fim - fev a abr/2012), nos tratamentos com (N1) e sem (N0) adição de nutrientes. Barras de erros indicam intervalo de confiança de $95 \%$.

Figura 4. Média das taxas de crescimento absoluto (TCA) de Paspalum atratum e Urochloa brizantha, ao longo da estação chuvosa (início - out a dez/2011; meio - dez/2011 a fev/2012; fim - fev a abr/2012), nos tratamentos luz natural (sombreamento=0) e sombrite $80 \%$ (sombreamento=1). Barras de erros indicam intervalo de confiança de $95 \%$.

\section{Capítulo III}

Figura 1. Biomassa seca média (g) de dez amostras retiradas ao acaso das amostras de plantas utilizadas no experimento (antes do plantio das mudas na área experimental). Plantas das espécies: Copaifera langsdorffii, Dalbergia miscolobium, Eriotheca pubescens, Eugenia dysenterica, Myracrodruon urundeuva e Stryphnodendron adstringens. Plantas, com aproximadamente 120 dias de vida, produzidas a partir de sementes, entre os meses de out/2010 a jan/2012, em condições relativamente controladas. Barras de erros indicam o intervalo de confiança de $95 \%$.

Figura 2. Comprimento médio do caule $(\mathrm{mm})$ de dez indivíduos retirados ao acaso das amostras de plantas utilizadas no experimento (antes do plantio das mudas na área experimental). Plantas das espécies: Copaifera langsdorffii, Dalbergia miscolobium, Eriotheca pubescens, Eugenia dysenterica, Myracrodruon urundeuva e Stryphnodendron adstringens. Plantas, com aproximadamente 120 dias de vida, produzidas a partir de sementes, em condições relativamente controladas. Barras de erros indicam o intervalo de confiança de $95 \%$. (Obs.: letras diferentes sobre as colunas indicam diferenças estatísticas significativas entre os tratamentos, de acordo com o teste de Tukey, $\mathrm{p} \leq 0,05$ ). 
Figura 3. Porcentagem de plantas de lenhosas sobreviventes e biomassa aérea média para cada uma das espécies plantadas na área experimental, após 3 meses de crescimento em condições de campo. Plantas das espécies: Copaifera langsdorffii, Dalbergia miscolobium, Eriotheca pubescens, Eugenia dysenterica, Myracrodruon urundeuva e Stryphnodendron adstringens. Barras de erros indicam intervalo de confiança de 95\%. Obs. Plantas com aproximadamente 210 dias de vida. (Obs.: letras diferentes sobre as colunas indicam diferenças estatísticas significativas entre as espécies).

Figura 4. Gráficos de correlação entre biomassa aérea média antes do plantio (y) e porcentagem de plantas de lenhosas sobreviventes, após 3 meses de crescimento em condições de campo (z), Biomassa aérea média antes do plantio (y) e após 3 meses de crescimento em condições de campo (z), entre as plantas das espécies: Copaifera langsdorffii, Dalbergia miscolobium, Eriotheca pubescens, Eugenia dysenterica, Myracrodruon urundeuva e Stryphnodendron adstringens.

Figura 5. Sobrevivência e biometria média dos indivíduos de espécies de lenhosas plantados nos diferentes tratamentos com e sem gramíneas nativa (Paspalum atratum) e exótica (Urochloa brizantha), após 3 meses de crescimento em condições de campo. Barras de erros indicam o desvio padrão das amostras. Obs. Plantas com aproximadamente 210 dias de vida.

Figura 6. Sobrevivência e biometria média dos indivíduos de espécies de lenhosas plantados nos diferentes tratamentos com e sem gramíneas nativa (Paspalum atratum) e exótica (Urochloa brizantha), após 11 meses da defoliação. Barras de erros indicam o intervalo de confiança de 95\%. Obs. Plantas com aproximadamente 540 dias de vida.

Figura 7. Porcentagem de sobrevivência de plantas de lenhosas nos diferentes tratamentos, ao longo do tempo. Experimento conduzido em área experimental do Laboratório de Termobiologia, UnB/Brasília, entre fevereiro de 2011 e abril de 2012. (Obs.: letras diferentes entre tratamentos indicam a existência de diferenças significativas). G0=sem gramíneas; $\mathrm{G} 1=\mathrm{com}$ Paspalum atratum; G2=com Urochloa brizantha; N0 = sem adição de nutrientes; N1 = com adição de nutrientes.

Figura 8. Biometria média dos indivíduos de espécies de lenhosas plantados nos diferentes tratamentos, após 11 meses da defoliação. Barras de erros indicam o intervalo de confiança de $95 \%$. Obs. Plantas com aproximadamente 540 dias de vida.

Figura 9. Biometria média dos indivíduos de espécies de lenhosas plantados nos diferentes tratamentos, após 11 meses da defoliação. Barras de erros indicam o intervalo de confiança de $95 \%$. Obs. Plantas com aproximadamente 540 dias de vida. 


\section{Lista de Tabelas}

\section{Capítulo I}

Página

Tabela 1. Espécies lenhosas utilizadas no experimento de defoliação e rebrota.

\section{Capítulo II}

Página

Tabela 1. Análises físico-químicas dos solos da área experimental: solo nu e solo no qual cresceram as gramíneas Paspalum atratum e Urochloa brizantha. Experimento conduzido em área experimental do Laboratório de Termobiologia, UnB/Brasília, entre maio de 2011 e abril de 2012.

Tabela 2. Análise foliar de Paspalum atratum e Urochloa brizantha, após a conclusão do experimento. Experimento conduzido em área experimental do Laboratório de Termobiologia, UnB/Brasília, entre maio de 2011 e abril de 2012.

Tabela 3. Análise estatística (modelo linear misto) - efeito da irrigação e da adição de nutrientes no crescimento de Paspalum atratum e Urochloa brizantha. (Obs.: variável dependente = taxa de crescimento absoluto).

Tabela 4. Análise estatística (modelo linear misto) - efeito do sombreamento e da adição de nutrientes no crescimento de Paspalum atratum e Urochloa brizantha. (Obs.: variável dependente = taxa de crescimento absoluto).

\section{Capítulo III}

Tabela 1. Espécies lenhosas utilizadas no experimento de defoliação e rebrota e suas características

Tabela 2. Biometria média (média $(\mathrm{g}) \pm$ desvio padrão) de dez indivíduos retirados ao acaso das amostras de plantas utilizadas no experimento (antes do plantio das mudas na área experimental). Plantas das espécies: Copaifera langsdorffii, Dalbergia miscolobium, Eriotheca pubescens, Eugenia dysenterica, Myracrodruon urundeuva e Stryphnodendron adstringens. Plantas, com aproximadamente 120 dias de vida, produzidas a partir de sementes, em condições relativamente controladas.

Tabela 3. Peso médio das sementes de espécies de lenhosas do Cerrado (Copaifera langsdorffii, Dalbergia miscolobium, Eriotheca pubescens, Eugenia dysenterica, Myracrodruon urundeuva e Stryphnodendron adstringens). Adaptado de Almeida et al. (1998).

Tabela 4. Análise estatística (ANOVA - Modelo linear geral) dos dados coletados a partir das plantas que rebrotaram, após 3 meses do plantio no campo. Experimento conduzido em área experimental do Laboratório de Termobiologia, UnB/Brasília, entre fevereiro de 2011 e abril de 2012.

Tabela 5. Sobrevivência $(\%)$ e biometria (média \pm desvio padrão) de mudas de lenhosas plantadas na área experimental, nos diferentes tratamentos, após 3 meses de crescimento em condições de campo. Plantas das espécies: Copaifera langsdorffii, Dalbergia miscolobium, Eriotheca pubescens, Eugenia dysenterica, Myracrodruon urundeuva e Stryphnodendron adstringens. Obs. Plantas com aproximadamente 210 dias de vida.

Tabela 6. Análises estatísticas dos dados coletados a partir das plantas que rebrotaram, após 11 meses da defoliação. Experimento conduzido em área experimental do Laboratório de Termobiologia, UnB/Brasília, entre fevereiro de 2011 e abril de 2012.

Tabela 7. Sobrevivência (\%) e biometria média (média \pm desvio padrão) de mudas de lenhosas plantadas na área experimental, nos diferentes tratamentos, após 11 meses da defoliação. Plantas das espécies: Copaifera langsdorffii, Dalbergia miscolobium, Eriotheca pubescens, Eugenia dysenterica, Myracrodruon urundeuva e Stryphnodendron adstringens. Obs. Plantas com aproximadamente 540 dias de vida. 


\section{Capítulo I}

\section{INTRODUÇÃO GERAL}

As savanas são ecossistemas caracterizados pela coexistência de espécies lenhosas e herbáceas, formando um mosaico de combinações destes dois componentes (Scholes \& Archer, 1997; Pivello et al., 1999a; Specht \& Specht, 1999; Van Langevelde et al., 2003; Sankaran et al., 2005; Laris, 2011; Barbosa, 2013; Holdo et al., 2013; Rossatto et al., 2014). Constituem um dos maiores biomas terrestres do mundo nas quais se pode encontrar desde formações florestais mais densas até campos totalmente graminosos (Bond et al., 2005; Sankaran et al., 2005; Ribeiro \& Walter, 2008; Laris, 2011; Silva \& Batalha, 2011; Wakeling et al., 2012; Rossatto et al., 2014). Pivello et al. (1999a) cita que a cobertura arbórea pode variar desde menos de 1\% nos campos até $60 \%$ no Cerradão ou mais densa nas formações florestais do bioma Cerrado.

Estes ecossistemas se encontram amplamente distribuídos (Scholes \& Archer, 1997; Pinheiro et al., 2010), ocupam uma área de cerca de 33 milhões de quilômetros quadrados (Hoffmann et al., 2002) e são encontrados em praticamente todos os continentes do mundo (Scholes \& Archer, 1997).

Apesar de todas as savanas terem espécies vegetais distribuídas em dois estratos (graminoso-herbáceo e arbóreo), existe uma grande diversidade de características bióticas e abióticas, de composição florística e de história evolutiva quando as comparamos (Cole, 1986; Solbrig et al., 1996).

O Cerrado, a savana brasileira, é o segundo maior bioma do Brasil, ocupando cerca de dois milhões de $\mathrm{Km}^{2}$. O cerrado brasileiro é considerado um dos maiores hotspots de biodiversidade mundial (Myers et al., 2000; Silva \& Bates, 2002; Ministério do Meio Ambiente - MMA, 2014). 
Possui mais de 11 mil e 500 espécies vegetais nativas catalogadas (MMA, 2014) e tem sido vista como a savana tropical mais diversa do mundo com $44 \%$ de endemismo em sua flora (Klink \& Machado, 2005).

Nas savanas e, consequentemente no Cerrado, os principais fatores ambientais que influenciam e determinam a estrutura da comunidade vegetal e a composição da florística são: solo, topografia, clima, disponibilidade de água e nutrientes, pluviosidade, fogo e herbivoria (OliveiraFilho \& Martins, 1986; Pivello \& Coutinho, 1996; Moreira, 2000; Bond \& Keeley, 2005; Kraaij \& Ward, 2006; Bond, 2008; Ribeiro \& Walter, 2008; Sankaran et al., 2008; Hirota et al., 2011; Staver et al., 2012). É importante salientar que os distúrbios (fogo e herbivoria) também são considerados determinantes da vegetação e, desta forma, alterações em sua freqüência e intensidade podem causar modificações na comunidade vegetal das savanas (Scholes \& Archer, 1997; Higgins et al., 2000; Bond \& Keeley, 2005; Bond et al., 2005; Martins et al., 2006; Sankaran et al., 2008; Foxcroft et al., 2010; Masocha et al., 2010).

As formas de vida, arbórea e graminosa, interferem no crescimento uma da outra (Foxcroft et al., 2010), inclusive a cobertura graminosa pode interferir diretamente no recrutamento de espécies arbóreas e vice-e-versa (Cramer et al., 2007; Hoffmann \& Haridasan, 2008; Kambatuku et al., 2011;). De acordo com Kraaij e Ward (2006), um dos principais fatores que afeta a dinâmica árvores/gramíneas das savanas é a habilidade competitiva de cada planta em adquirir recursos.

As interações entre árvores e gramíneas tem sido analisadas principalmente em função da competição por água e nutrientes do solo (Walter 1971; Knoop \& Walker 1985; Kambatuku et al., 2011), baseado na hipótese sugerida por Walter da separação vertical de nichos das raízes de árvores e gramíneas (Walter 1971; Kambatuku et al., 2011). Segundo Walter (1971), gramíneas são mais eficientes na captação de recursos superficiais do solo, enquanto as plantas lenhosas conseguem buscar recursos nas camadas mais profundas do solo. No entanto, este modelo proposto por Walter é simplificado e não admite a estratificação das raízes e não considera a presença de arbustos e outras ervas. Vários estudos mostram que gramíneas, de maneira geral, exercem uma 
influência negativa na sobrevivência e estabelecimento de plântulas de lenhosas (Walker et al., 1981; Scholes \& Archer, 1997; Higgins et al., 2000; Roques et al., 2001; Van Langevelde et al., 2003; Ludwig et al., 2004; Bond, 2008; Riginos, 2009; Kambatuku et al., 2011).

Esta interação também pode ser afetada pela invasão e/ou substituição das gramíneas nativas por exóticas, já que gramíneas exóticas, como Melinis minutiflora, Panicum maximum, Andropogon gayanus, Hyparrhenia rufa e Urochloa spp., tem se tornado cada vez mais abundantes nas savanas neotropicais, inclusive no Cerrado (Parsons, 1972; Klink \& Joly, 1989; Rossiter et al., 2003; Hoffmann \& Haridasan, 2008; Brooks et al., 2010; Foxcroft et al., 2010; Mworia, 2011; Horowitz et al., 2013).

Outro grande problema enfrentado pelo Cerrado atualmente é o crescimento urbano e a conversão de suas áreas nativas em áreas de agricultura e pastagens (MMA, 2014). Klink e Machado (2005) estimam que cerca de $55 \%$ da vegetação nativa já tenha sido convertida em monoculturas e pastos. Estas atividades são responsáveis por importantes alterações no bioma, como desmatamento e uso freqüente e irregular de fogo (Mworia, 2011).

A intensa fragmentação de ambientes de cerrado, nos quais pequenas áreas de vegetação nativa são circundadas por pastagens e áreas agrícolas, favorecem ainda mais a disseminação de gramíneas exóticas (Pivello et al., 1999a). Praticamente todo fragmento de cerrado aberto existente atualmente já apresenta gramíneas africanas (Pivello et al., 1999b).

Em suma, muitas savanas, como é o caso do Cerrado, se encontram ameaçadas devido ao impacto de diversas mudanças ambientais: o aumento da população nessas áreas, a substituição da vegetação natural por monoculturas e/ou pastagens, mudanças climáticas (redução pluviométrica em algumas regiões e aumento em outras), o aumento da intensidade e/ou freqüência de distúrbios tais como queimadas e herbivoria (Hoffmann, 1996; Solbrig et al., 1996; Hoffmann \& Jackson, 2000; Klink \& Machado, 2005; Saha \& Howe, 2006).

Apesar do fato do Cerrado não ter muitos grandes mamíferos herbívoros, há a presenca de uma enorme quantidade de insetos herbívoros (Marquis et al., 2002; Silva, 2010). De acordo com 
Costa et al. (2008), a herbivoria no Cerrado é maior ou comparável a outras comunidades terrestres, incluindo savanas. No entanto, pouco se sabe sobre qual seria o impacto da herbivoria nas comunidades vegetais do Cerrado (Marquis et al., 2002; Van Langevelde et al., 2003; Silva, 2010).

\section{REVISÃO BIBLIOGRÁFICA}

\section{As savanas e seus determinantes}

A diversidade em savanas está presente em todas as escalas. Na escala inter-continental, as grandes diferenças observadas na estrutura da vegetação e na composição florística são função de diferentes tipos de solo e regimes climáticos. Desta forma, em uma escala regional, as diferenças em solo e clima determinam os principais tipos de savanas, já em uma escala local são as diferenças em topografia e geomorfologia os principais fatores determinantes da estrutura da vegetação e composição florística (Solbrig, 1993).

Inicialmente, ecólogos associaram a distribuição das savanas ao clima, solo e topografia (Solbrig, 1993; Bond \& Keeley, 2005; Beckage et al., 2009; Kambatuku et al., 2011; Laris, 2011; Staver et al., 2012). Associava-se a existência de savanas em locais com baixa precipitação anual e a presença de florestas mais densas em regiões com muitas chuvas. Entretanto em locais com precipitação intermediária, as diferenças em textura e profundidade do solo e na sazonalidade seriam os responsáveis pela formação ou não das savanas (Staver et al., 2012). Estudos posteriores revelaram a existência de savanas em locais onde o clima, o solo e a topografia seriam compatíveis com a existência de florestas (Staver et al., 2012). Em muitas savanas, outros fatores como herbivoria e fogo podem afetar a cobertura arbórea da comunidade determinando a cobertura vegetal (Van Langevelde et al., 2003; Bond, 2008; Sankaran et al., 2008; Beckage et al., 2009; Kambatuku et al., 2011; Laris, 2011). 
Ainda não há consenso sobre quais seriam realmente os fatores limitantes e por que as savanas não são substituídas por florestas mais densas ou vice-versa (Bond, 2008), mas muitos pesquisadores acreditam que os distúrbios, como fogo e herbivoria, sejam os responsáveis por isso (Van Langevelde et al., 2003; Beckage et al., 2009; Beckage et al., 2011; Kambatuku et al., 2011; Laris, 2011; Dohn et al., 2013)

Esse é um antigo e grande debate na ecologia: a coexistência de árvores e gramíneas nas savanas e a ausência de um modelo mundialmente aceito que possa explicar a grande variabilidade de fisionomias que compõem as savanas (Walter, 1971; Bond, 2008; Holdo et al., 2013).

De maneira geral, a ocorrência de árvores e gramíneas nas savanas é primeiramente determinada por fatores edáficos e climáticos e sua relação de competição entre os grupos vegetais, aparentemente representando um falso estado de "equilíbrio" (Bond, 2008; Beckage et al., 2009; Kambatuku et al., 2011; Laris, 2011). Entretanto, a manutenção da composição florística e a ausência de conversão em outro tipo de fitofisionomia é função da presença de distúrbios, como fogo e herbivoria, o que representa um estado de "não-equilíbrio" (Jeltsch et al., 2000; Van Langevelde et al., 2003; Sankaran et al., 2004; Kraaij \& Ward, 2006; Bond, 2008; Beckage et al., 2009; Beckage et al., 2011; Kambatuku et al., 2011; Laris, 2011; Dohn et al., 2013;).

Desta forma, muitos modelos foram propostos para se explicar o balanço entre árvores e gramíneas nas savanas (Higgins et al., 2000; D’Odorico et al., 2006; Accatino et al., 2010; Calabrese et al., 2010; Beckage et al., 2011). A diferença entre estes modelos é o que cada um considera como sendo o fator mais importante na determinação da vegetação (Holdo et al., 2013).

Alguns modelos principais foram estabelecidos e podem ser divididos em dois grupos: modelos competitivos (“competition models") e modelos baseados nos distúrbios ("demographic bottleneck models") (Jeltsch et al., 2000; Beckage et al., 2011; Kambatuku et al., 2011; Mworia, 2011).

No primeiro caso, a coexistência dos dois grupos vegetais é basicamente determinada pelo potencial de cada um adquirir recursos em locais diferentes; é a teoria da separação de nichos, 
baseada no modelo proposto por Walter, em 1971 (Mworia, 2011). Desta forma, apenas os recursos são considerados determinantes primários da vegetação, sendo os distúrbios apenas modificadores (Walker et al., 1981; Scholes \& Archer, 1997; Higgins et al., 2000; Kambatuku et al., 2011; Mworia, 2011). No segundo tipo de modelo, os distúrbios e seus efeitos diretos (pós-distúrbio) são considerados determinantes da estrutura da vegetação, assim como os recursos (Van Langevelde $e t$ al., 2003; Sankaran et al., 2005; Beckage et al., 2009; Kambatuku et al., 2011; Mworia, 2011).

Pesquisadores tem inclusive verificado a importância dos freqüentes distúrbios antropogênicos na manutenção das savanas na África (Bond et al., 2005; Sankaran et al., 2005; Almeida-Neto et al., 2010; Laris, 2011).

Bond (2008) dividiu os limitantes da cobertura arbórea em savanas em fatores "bottom-up" e fatores "top-down”. Os primeiros são aqueles conhecidos globalmente por influenciar a dinâmica das vegetações, como clima, solo, topografia, pluviosidade. Já os últimos são herbivoria, fogo e nutrientes, fatores conhecidos por influenciar a dinâmica de populações vegetais localmente.

Os modelos variam na proporção que consideram os fatores "top-down" ou "bottom-up" como sendo determinantes do balanço árvores/gramíneas (Sankaran et al., 2004; Holdo et al., 2013).

\section{Evolução das Gramíneas nas Savanas}

A maior parte das gramíneas presente nas savanas tropicais e subtropicais do mundo é de gramíneas $\mathrm{C}_{4}$, chegando a $90 \%$ ou mais da cobertura graminosa, em ambientes nos quais a temperatura e a intensidade luminosa são altas (Keeley \& Rundel, 2005). A rota fotossintética $\mathrm{C}_{4}$ fornece vantagens frente à rota $\mathrm{C}_{3}$, por diminuir a perda de água por tranpiração e favorecer a sobrevivência em ambientes mais quentes (Keeley \& Rundel, 2005).

Acredita-se que o metabolismo $\mathrm{C}_{4}$ tenha surgido durante o Oligoceno $(\approx 36$ a $23 \mathrm{Ma})$ com um declínio nos níveis de $\mathrm{CO}_{2}$ atmosféricos, mas que os campos dominados por gramíneas $\mathrm{C}_{4}$ tenham evoluído apenas durante o período final do Mioceno $(\approx 8 \mathrm{Ma})$, em função da mudança 
climática e da intensa atividade do fogo ocorrida naquela época (Keeley \& Rundel, 2005; Beerling \& Osborne, 2006).

Savanas com domínio de gramíneas $\mathrm{C}_{4}$, como é o caso do Cerrado (Klink \& Joly, 1989), são os ecossistemas com maior freqüência de queimadas do mundo, com incêndios ocorrendo a cada dois ou três anos e algumas vezes até duas vezes por ano (Hoffmann et al., 2002). Devido a estes aspectos, Keeley e Rundel (2005) acreditam que a expansão e a manutenção dos campos graminosos como eles estão desde então, se deve à presença periódica do fogo e que, a frequência do fogo controlaria o estabelecimento de lenhosas.

Incêndios recorrentes evitam a transformação da vegetação em formações florestais mais fechadas, em função do empobrecimento do solo, do aumento do déficit hídrico, durante a estiagem, e o consequente controle do estabelecimento de lenhosas (Miranda et al., 2002; Oliveira-Filho \& Ratter, 2002).

De acordo com Accatino et al. (2010), o fogo pode determinar dois tipos de savanas: as fogo-dependentes, que são aquelas nas quais o fogo não permite que as árvores cresçam o suficiente para fechar a copa. Neste caso, as gramíneas geram um feedback positivo para o fogo, produzindo mais biomassa e combustível para queimadas subsequientes. No segundo tipo, na ausência de perturbações como as queimadas, as savanas são dependendentes da precipitação, e a vegetação é determinada pela disponibilidade de água (Accatino et al., 2010).

Durante a estação de crescimento, as gramíneas produziriam grande quantidade de biomassa que serviria de combustível para o fogo na estação seca subseqüente (D’Antonio \& Vitousek, 1992; Miranda et al., 1993; Keeley \& Rundel, 2005; Beerling \& Osborne, 2006). Além de formarem densa camada de biomassa, altamente inflamável na época da seca, ainda reduzem a luminosidade na superfície do solo, podendo impedir os processos de germinação e recrutamento de espécies nativas presentes no banco de sementes (Hughes \& Vitousek, 1993). Ainda podem alterar os ciclos de nutrientes, como o ciclo de nitrogênio, devido à intensa captura de nutrientes (Asner \& Beatty, 1996). 


\section{Fogo no Cerrado}

O fogo, apesar de natural e frequente no Cerrado, é um drástico agente de distúrbio na vegetação do bioma com grande impacto na dinâmica das populações de plantas (Henriques, 2005).

O fogo é considerado um dos elementos que aparentemente definem e mantém a formação savânica, juntamente com clima, solo, topografia, sazonalidade e herbivoria (Miranda et al., 2002; Van Langevelde et al., 2003; Bond, 2008; Sankaran et al., 2008; Beckage et al., 2009; Beckage et al., 2011; Kambatuku et al., 2011; Laris, 2011; Dohn et al., 2013).

Muitas espécies vegetais do Cerrado apresentam características morfológicas que conferem resistência ao fogo, como intensa suberização do tronco e galhos, que resulta em um efetivo controle térmico dos tecidos internos (Miranda et al., 2002). Mesmo assim, incêndios em intervalos muito curtos desfavorecem a camada lenhosa (Hoffmann, 1998; Moreira, 2000; Felfili et al., 2005), até porque plantas diferem enormemente em sua tolerância ao fogo e sua capacidade de rebrota (Miranda et al., 2002). O fogo causa diminuição da altura da vegetação e uma maior mortalidade de plantas lenhosas (Sato \& Miranda, 1996; Miranda et al., 2002).

Logicamente, fogo e biomassa de gramíneas estão intimamente correlacionados, já que a biomassa das gramíneas, produzida durante a estação de crescimento, serve de combustível para o fogo na estação seca subseqüente (Miranda et al., 1993; Keeley \& Rundel, 2005; Beerling \& Osborne, 2006; Accatino et al., 2010). Com maior freqüência de queimadas, em regiões tropicais, as taxas anuais de crescimento populacional favorecem os arbustos e gramíneas em detrimento das árvores (Hoffmann, 1999).

Por outro lado, o fogo, em geral, é insuficiente para promover efeitos significamente negativos em plantas lenhosas já maduras (Higgins et al., 2000). O impacto negativo do fogo no estabelecimento de lenhosas é bastante reconhecido na literatura. Apesar de menos comum nas savanas, o fogo, dependendo de sua intensidade, pode atuar abrindo clareiras, diminuindo a 
biomassa aérea das gramíneas, quebrando a dormência de sementes e acabar favorecendo o estabelecimento das lenhosas (Kraaij \& Ward, 2006).

Acredita-se também que a herbivoria por grandes mamíferos, nas savanas africanas, promoveria o mesmo efeito do fogo, limitando o crescimento das espécies lenhosas (Van Langevelde et al., 2003; Bond \& Keeley, 2005; Staver et al., 2012). A diferença é que a herbivoria age de maneira muito mais seletiva que o fogo, sendo que apenas algumas espécies são as mais atacadas pelos herbívoros (Marquis et al., 2002; Van Langevelde et al., 2003)

A proteção contra o fogo, ou mesmo contra a herbivoria, pode determinar mudanças graduais na fitofisionomia de uma savana desde, uma formação mais aberta até uma formação florestal mais fechada, com maior número e densidade de espécies lenhosas (Moreira, 2000).

Diversos estudos mostram que a proteção contra fogo por um período superior a 15 anos de áreas de savanas favorece o recrutamento de espécies lenhosas, aumentando a densidade de espécies arbóreas na região, o que comprova a influência negativa do fogo no recrutamento de espécies arbóreas em savanas (Coutinho, 1990; Bowman \& Fensham, 1991; Hoffman, 1999; Moreira, 2000; Oliveira-Filho \& Ratter, 2002; Hoffman et al., 2012).

\section{Competição por recursos}

A teoria clássica da competição por recursos prevê que a competição intraespecífica deve ser maior que a competição entre espécies, visto que indivíduos da mesma espécie compartilham recursos similares (Tilman, 1982; Goldberg \& Barton, 1992; Mangla et al., 2011).

No entanto, a competição não acontece apenas entre espécies ou entre indivíduos da mesma espécie; ela pode ocorrer em estágios diferentes da vida da planta (Mangla et al., 2011). Segundo Goldberg et al. (2001), nas fases da germinação e durante os estágios iniciais de crescimento, as plântulas são bem mais sensíveis à competição que quando adultas. Inclusive, a competição durante o estabelecimento inicial pode influenciar na biomassa da planta adulta (Goldberg et al., 2001). 
As interações competitivas são afetadas pela disponibilidade dos recursos naturais (Grime, 1977; Tilman, 1988). Existem dois grandes modelos para analisar a competição por recursos: o modelo de Grime prevê que a competição exercerá maior influência na comunidade vegetal em ambientes com maior abundância de recursos, enquanto que o modelo de Tilman prevê que a competição será similar em ambientes ricos ou com escassez de recursos (Grime, 1977; Tilman, 1988).

Desta forma, de acordo com Grime (1977), grande parte da variação nas respostas adaptativas das plantas pode ser explicada se for considerada a produtividade do habitat e a frequência e severidade de distúrbios. Grime (1977) propõe que a competição, que pode ser definida como a habilidade de capturar recursos na presença de outros organismos, atinge seu máximo de importância em circunstâncias nas quais a quantidade de recursos não é limitante e permite que indivíduos cresçam rapidamente. Desta forma, eles têm a capacidade de captar recursos, redistribuindo-os de maneira a permitir uma alta dinâmica de suas raízes e partes aéreas. Com a escassez dos recursos, as estratégias selecionadas serão aquelas para promover a conservação e preservação dos recursos já capturados.

Já, segundo Tilman (1982, 1985), a competição atinge seu maior nível de importância quando os recursos são escassos, e neste caso as plantas atingiriam seu maior sucesso quando conseguirem reduzir a quantidade os nutrientes do solo para níveis nos quais outras espécies (mais exigentes) não possam obtê-los de maneira suficiente para sobreviver. Tilman (1985) denominou de "R”, a concentração mínima de nutrientes para a qual uma espécie reduz os recursos, tornando inviável a manutenção de outras espécies.

A competição por recursos envolvem alocações de energia e investimentos que acabam gerando "trade-offs" inevitáveis: para captar mais de um recurso, é necessário alocar mais energia para uma determinada região da planta deixando de investir em outras partes que poderiam estar envolvidas na aquisição de outros recursos (Tilman, 1985). 
As teorias de Tilman (1982) e Grime (1977) envolvem a alocação de biomassa e aquisição e perda de recurso, envolvidas no processo de competição e "trade-offs" evolutivos entre as espécies (Craine, 2005). As duas teorias sozinhas não são suficientes para explicar a competição por recursos na natureza, mas se complementam na tentativa de se compreender parte do processo de coexistência das espécies (Craine, 2005; Zupo, 2010).

Outra forma de se avaliar a competição por recursos é a sugerida por Wilson (1988). Neste caso, a competição subterrânea entre plântulas e gramíneas seria primordial quando fatores como água e nutrientes fossem limitantes e a competição aérea, basicamente controlada pela luz, se iniciaria quando os outros fatores estivessem abundantes (Wilson, 1988).

Estudos mais recentes sobre competição por recursos tem considerado a importância de interações positivas entre organismos vizinhos na determinação da estrutura da comunidade vegetal, de forma que estresses abióticos severos podem interferir na relação competitiva entre as espécies (Dohn et al., 2013). Dohn et al. (2013) encontraram espécies lenhosas facilitando o crescimento de gramíneas, em regiões mais secas, e suprimindo-as, quando as condições estavam mais úmidas.

Várias são as formas que as árvores podem facilitar o aparecimento das gramíneas: aumento dos nutrientes do solo pelas fezes de animais ou pela serrapilheira, redução da irradiação solar e da transpiração, aumentando a disponibilidade de água no solo (Dohn et al., 2013).

\section{Invasão Biológica nas Savanas}

Espécies não nativas, trazidas geralmente a partir de um outro continente e introduzidas na região com boas intenções (medicinais, agro-pastoris ou florestais) (Davis et al., 2000; Myers \& Bazely, 2003), tem invadido as savanas do mundo inteiro (Foxcroft et al., 2010). Enquanto as savanas tropicais e subtropicais da África, Australia e de algumas ilhas do Pacifico são frequentemente invadidas por espécies de arbustos, principalmente Cactaceae, as savanas tropicais 
da América do Sul e da Australia são principalmente invadidas por gramíneas africanas $\mathrm{C}_{4}$ (Foxcroft et al., 2010).

Muitas destas espécies, inicialmente dependiam do homem para se propagar, mas acabaram se estabelecendo, multiplicando e se expandindo rapidamente, dominando o ambiente e gerando diversos impactos ambientais negativos (Davis et al., 2000; Myers \& Bazely, 2003; Lockwod et al., 2007; Mworia, 2011).

Somente espécies exóticas, ou seja, originárias de fora da comunidade, podem ser consideradas invasoras (Matos \& Pivello, 2009). No entanto, espécies nativas (originárias da própria comunidade) podem se comportar como espécies invasoras, ou seja, por algum desequilíbrio ambiental, essas espécies passam a crescer e a se multiplicar demasiadamente. Neste caso, estas plantas são denominadas de superdominantes (Richardson et al., 2000).

Charles Darwin, em 1860, já havia alertado para o crescimento explosivo das espécies invasoras. Com o passar dos anos, a comunidade científica, ao verificar a dimensão do problema, chegou a cogitar a hipótese de que poderia haver uma homogeneização de todos os ecossistemas terrestres do mundo, com a substituição das espécies nativas pelas invasoras por competição, grande perda da biodiversidade e descaracterização da superfície da Terra (Matos \& Pivello, 2009). Desde então, muito tem sido estudado no intuito de se conhecer um pouco mais sobre a ecologia de espécies invasoras e sobre técnicas de manejo destas espécies (Matos \& Pivello, 2009).

O sucesso no estabelecimento e multiplicação de uma espécie não-nativa em uma comunidade vegetal tem sido associado às características biológicas de cada espécie além de vários fatores ambientais, muitos inclusive ligados à atividade humana, como o revolvimento ou a fertilização do solo, a eliminação de espécies indesejáveis, mudanças climáticas e disturbios ambientais (Sala et al., 2000; Myers \& Bazely, 2003; Lockwod et al., 2007; Matos \& Pivello, 2009; Almeida Neto et al., 2010).

Plantas potencialmente invasoras, em geral, apresentam características que as tornam melhores competidoras, como: altas taxas de crescimento, alta taxa fotossintética (a grande maioria 
heliófita, com metabolismo $\mathrm{C}_{4}$ ), ciclo reprodutivo rápido, intensa produção de sementes, alta eficiência no uso de nutrientes, tolerância ao desfolhamento, ao sombreamento e à herbivoria, alta capacidade de rebrota (D'Antonio \& Vitousek, 1992; Rejmanek \& Richardson, 1996; Williamson \& Fitter, 1996; Everett, 2000; Brooks et al., 2004; Matos \& Pivello, 2009; Foxcroft et al., 2010).

Estas plantas invasoras também apresentam outras características que podem diminuir o recrutamento de espécies lenhosas (Hoffmann \& Haridasan, 2008). Além de grande produção de biomassa que acaba gerando bastante combustível para o fogo, promovem sombreamento das plântulas de lenhosas (D'Antonio et al., 1998; Rossiter et al., 2003; Freitas \& Pivello, 2005; Hoffmann \& Haridasan, 2008; Setterfield et al., 2010) e, em alguns casos, podem liberar aleloquímicos no solo (Martins et al., 2006; Barbosa et al., 2008;). Estudos comprovam também que muitas gramíneas invasoras são resistentes ao fogo, competindo e ganhando das gramíneas nativas na ocupação da área após a passagem do fogo (D’Antonio \& Vitousek, 1992; Pivello et al., 1999a; Foxcroft et al., 2010).

Já que a invasão biológica está intimamente associada a distúrbios ambientais (naturais ou não), além é claro das características intrínsecas das espécies invasoras e à sua capacidade de multiplicação, as savanas são alvo de invasões (Sala et al., 2000; Williams \& Baruch, 2000; Myers \& Bazely, 2003; Lockwod et al., 2007; Foxcroft et al., 2010). Nas savanas, os distúrbios, como fogo e herbivoria, são fatores chaves na determinação da estrutura da vegetação e, consequentemente a interação destes fatores irá determinar o sucesso de uma espécie invasora na savana (Scholes \& Archer, 1997; Higgins et al., 2000; Bond \& Keeley, 2005; Bond et al., 2005; Sankaran et al., 2008; Foxcroft et al., 2010; Masocha et al., 2010).

Nas savanas neotropicais, gramíneas exóticas, como Melinis minutiflora (capim-gordura) e Urochloa spp. (braquiárias), tem se tornado cada vez mais abundantes (Klink \& Joly, 1989; William \& Baruch, 2000; Rossiter et al., 2003; Rejmánek et al., 2005; Durigan et al., 2007; Hoffmann \& Haridasan, 2008;). Já nas savanas brasileiras, além destas, pode-se encontrar com frequência Hyparrhenia rufa (capim-jaraguá), Megathyrsus maximus (capim-colonião) e 
Andropogum gayanus (Klink, 1996; Pivello et al., 1999a; Pivello et al., 1999b; Klink \& Machado, 2005; Rejmánek et al., 2005; Matos \& Pivello, 2009; Horowitz et al., 2013; Gorgone-Barbosa et al., 2014).

De acordo com Freitas e Pivello (2005), diversas foram as formas de introdução das gramíneas africanas no continente americano. Algumas gramíneas, como Hyparrhenia rufa (capimjaraguá), Panicum maximum (capim-colonião) e Brachiaria mutica (capim-pará), que eram utilizadas como cama de escravos em viagens, devem ter vindo acidentalmente nos navios negreiros, segundo Parsons (1972) e Filgueiras (1990). Outras gramíneas, como a Melinis minutiflora (capim gordura), foram introduzidas no Brasil acidentalmente ou para fins comerciais e se espalharam por grandes extensões (Pivello et al., 1999a; Pivello et al., 1999b; Matos \& Pivello, 2009). Algumas destas espécies também são plantadas como forrageiras para aumentar a produtividade do gado (Pivello et al., 1999b).

Gramíneas exóticas, em geral, possuem características que as deixam mais competitivas que as plantas nativas: possuem efetivo uso da água e dos nutrientes do solo, sementes facilmente dispersas, altas taxas de germinação e, muitas vezes, curtos ciclos de vida (D'Antonio \& Vitousek, 1992; Barbosa et al., 2008; Hoffmann \& Haridasan, 2008; Foxcroft et al., 2010; Zupo, 2010).

Gramíneas exóticas, aparentemente, substituem as gramíneas nativas (Pivello et al., 1999a; Rossiter et al., 2003; Hoffmann et al., 2004; Brooks et al., 2010; Foxcroft et al., 2010). Foxcroft et al. (2010) e Pivello et al. (1999a) afirmam também que muitas gramíneas invasoras são resistentes ao fogo, competindo e ganhando das gramíneas nativas na ocupação da área após a passagem do fogo.

Estas características também podem diminuir o recrutamento de espécies lenhosas (D’Antonio \& Vitousek, 1992; Rossiter et al., 2003; Barbosa et al., 2008; Bond, 2008; Riginos, 2009; Zupo, 2010; Kambatuku et al., 2011). As altas taxas de crescimento e a grande produção de biomassa acabam gerando bastante combustível para o fogo, promovem sombreamento das plântulas de lenhosas e podem muitas vezes liberar aleloquímicos no solo e, como consequência, 
podem promover alta mortalidade de espécies arbóreas (Martins et al., 2006; Hoffmann \& Haridasan, 2008).

Apesar de seu comportamento considerado agressivo, no que diz respeito à reprodução, estabelecimento e disseminação, o plantio destas gramíneas exóticas continua a ser promovido em pastagens, no sentido de aumentar a produtividade das forragens (Pivello et al., 1999b).

Entretanto, muitas delas acabam se espalhando enormemente e invadindo, inclusive, áreas de conservação (Klink, 1996; Baruch \& Bilbao, 1999; Pivello et al., 1999a; Pivello et al., 1999b; Martins et al., 2006; Hoffmann \& Haridasan, 2008).

Apesar de algumas espécies exóticas terem seu processo de invasão desacelerado com técnicas de manejo adequadas (Horowitz et al., 2013), em geral, são plantas difíceis de difícil controle, sendo que o uso de herbicidas para minimizar o crescimento destas gramíneas pode não ser muito adequado ao ambiente (Pivello et al., 1999a).

\section{Conservação dos Cerrados}

Nas últimas décadas, o Cerrado vem sofrendo várias alterações, com redução da biodiversidade, como conseqüências de atividades antrópicas: alterações no regime de queimadas, fragmentação de habitats, freqüentes atividades agropastoris, remoção de lenho e de espécies medicinais e invasão biológica por espécies exóticas (Ratter et al., 1997; Klink \& Machado, 2005; Pivello, 2006; MMA, 2014).

Silva \& Bates (2002) e Klink \& Machado (2005) e também afirmam que grandes áreas do cerrado brasileiro já foram convertidas em pastagens com gramíneas africanas, especialmente braquiárias (do gênero Urochloa) e monoculturas de soja e arroz (Klink \& Moreira, 2002). Em muitos dos casos, técnicas básicas de manejo e conservação do solo não foram tomadas acarretando muitas vezes em erosão e assoreamento de rios (Klink \& Moreira, 2002; Silva \& Bates, 2002).

Durante muitos anos, o difícil acesso a muitas áreas da região do cerrado aliado ao solo ácido e pobre em nutrientes, restringiu o uso de suas áreas (Zupo, 2010). Estas regiões passaram a 
ser intensamente ocupadas, com a construção das estradas no Centro-Oeste do Brasil e a mecanização da agricultura, a partir de 1950 (Cavalvanti \& Joly, 2002). Pivello (2006) afirma que o Cerrado, a partir de 1970, foi submetido a uma política governamental de incentivo à produção agrícola que acarretou em um grande desenvolvimento urbano, que vem descaracterizando e ocupando toda a região. A ausência de propostas eficazes paralelas de proteção ambiental tem destruído a flora e a fauna original do cerrado (Pivello, 2006).

Apesar do reconhecimento de sua importância biológica, o Cerrado é o que possui a menor porcentagem de áreas sobre proteção integral (MMA, 2014). O Bioma apresenta 8,21\% de seu território legalmente protegido por unidades de conservação; desse total, 2,85\% são unidades de conservação de proteção integral e 5,36\% de unidades de conservação de uso sustentável, incluindo RPPNs (0,07\%). De acordo com Machado et al. (2004), resta somente cerca de $34 \%$ da vegetação nativa original do Cerrado. Estimativas indicam ainda que, se o modelo atual de desenvolvimento continuar sendo mantido, o Cerrado deverá desaparecer no ano de 2030 (Machado et al., 2004).

A primeira grande iniciativa de conservação dos cerrados foi iniciada apenas em 1997, com um workshop do Ministério do Meio Ambiente, o qual reuniu cerca de 200 cientistas especialistas da região com o intuito de promover discussões sobre as metas prioritárias para a conservação da biodiversidade do Cerrado (Silva \& Bates, 2002).

Essas mudanças ambientais têm um impacto negativo na biodiversidade (Klink \& Moreira, 2002) e acredita-se que também tenham um impacto negativo no estabelecimento de plântulas de lenhosas, gerando uma redução na densidade de árvores nesses ecossistemas (Van Langevelde et al., 2003). Embora seja difícil afirmar o que seria um impacto negativo se não for feita uma comparação dos efeitos entre cobertura graminosa nativa e exótiva, aparentemente existe um potencial competitivo maior das espécies de gramíneas exóticas frente às gramíneas nativas. Além disto, estudos mostram que gramíneas exóticas são espécies de maior produtividade (Hoffmann et al., 2004), mas existe uma carência de estudos que avaliem os efeitos das variações abióticas no crescimento inicial das mesmas. De que forma as modificações no meio abiótico podem interferir 
nos efeitos que gramíneas nativas e exóticas geram no recrutamento e manutenção de populações de arbóreas nativas no Cerrado.

Diante dessas modificações ambientais, tendo em vista que os cerrados brasileiros são constituídos por gramíneas e lenhosas, e que a dinâmica de populações gramíneas/lenhosas é controlada por vários fatores incluindo disponibilidade de água, nutrientes e sombreamento e que a própria presença da gramínea ou mesmo a presença de uma gramínea exótica pode alterar toda a estrutura da comunidade, acredita-se que os resultados produzidos por este trabalho poderão contribuir para futuras projeções nas áreas de: estrutura de comunidades, para a elaboração de programas de recuperação de áreas degradadas, para revegetação e conservação do Cerrado.

Além disto, a compreensão das estratégias competitivas de plântulas de lenhosas pode ainda colaborar para uma melhor avaliação da susceptibilidade de diferentes ecossistemas em que coexistem lenhosas e gramíneas, à invasão de espécies exóticas.

\section{HIPÓTESES}

- Por ser uma espécie de ampla distribuição e forte potencial invasivo, a adição de recursos naturais ao solo, como água e nutrientes, deve favorecer mais o crescimento da gramínea exótica do que a gramínea nativa.

- Por serem potencialmente tolerantes ao sombreamento, gramíneas exóticas deverão crescer mais que gramíneas nativas, nos tratamentos sombreados.

- A presença das gramíneas nativa e exótica deve influenciar negativamente a sobrevivência e a rebrota das plantas de lenhosa.

- Por apresentar maior potencial competitivo que a gramínea nativa, a gramínea exótica deve exercer influência mais negativa sobre a sobrevivência e a rebrota das plantas de lenhosa.

- A abundância de recursos naturais, como luz e nutrientes deve favorecer o crescimento das gramíneas, prejudicando o cresscimento das plantas. 
- Espécies lenhosas características de diferentes fitofisionomias devem responder de maneira diferente à escassez de recursos e à presença das gramíneas.

\section{OBJETIVOS}

Objetivos Gerais:

- Verificar a influência do sombreamento, da irrigação e da adição de nutrientes no ganho de biomassa de gramíneas nativa e exótica.

- Verificar a influência da adição de nutrientes e da competição por estes recursos com gramíneas nativas e exóticas na rebrota de plantas lenhosas nativas do Cerrado.

Objetivos Específicos:

- Comparar o ganho de biomassa entre as gramíneas nativa e exótica crescidas sob condições naturais durante as estações seca e chuvosa.

- Verificar a influência da irrigação e da adição de nutrientes no ganho de biomassa das gramíneas nativa e exótica.

- Testar a influência da adição de nutrientes na rebrota de plantas lenhosas do Cerrado.

- Verificar a influência das gramíneas nativa e exótica na rebrota de plantas de lenhosas do Cerrado crescendo sob diferentes condições de disponibilidade de nutrientes.

- Investigar a existência de variação nas respostas de rebrota entre as espécies de lenhosas do Cerrado. 


\section{MATERIAL E MÉTODOS - GERAL}

\section{Local e época de Estudo}

Este trabalho foi realizado durante o período compreendido entre o início da estação chuvosa de 2009 (outubro de 2009) e o início da estação seca em 2012 (junho de 2012).

O presente estudo foi realizado em casas de vegetação construídas em área próxima ao laboratório de Termobiologia, no Campus Universitário Darcy Ribeiro (15 $48^{\circ} 00^{\prime}$ ' $\mathrm{S}$ e $47^{\circ} 51^{\text {' }}$ 50' O), em local de vegetação de campo sujo, que é um tipo fisionômico herbáceo-arbustivo, com arbustos e subarbustos esparsos e indivíduos menos desenvolvidos das espécies arbóreas do Cerrado (Sano et al., 1998).

Com o auxílio de um trator, tanto a camada herbácea, como a arbustiva e arbórea da vegetação nativa foram removidas. Posteriormente, com o uso de enxadas, a biomassa e as raízes foram retiradas e o solo foi revolvido. A área foi cercada, as casas de vegetação com estrutura de bambu foram construídas, o sistema de irrigação foi estabelecido e todas as parcelas experimentais foram delimitadas.

\section{Desenho experimental}

O experimento consistia de cinco blocos experimentais, sendo que cada um representava uma réplica do desenho experimental (Figura 1). Cada um dos blocos era constituído por 4 parcelas (casas de vegetação), com seis subparcelas de $4 \mathrm{~m}^{2}$ cada (Figura 1). Cada bloco experimental foi constituído por quatro casas de vegetação: uma casa de vegetação sem nenhuma cobertura (controle), uma coberta por sombrite (cobertura de 80\%) e plástico transparente para exclusão de chuva e duas cobertas por plástico transparente, sendo que uma destas foi usada para o experimento de defoliação e rebrota a ser descrito posteriormente. 
Todas as casas cobertas com plástico transparente foram irrigadas durante o período chuvoso, enquanto que a casa sem cobertura foi submetida às chuvas ocorridas no período. $\mathrm{O}$ fornecimento de água durante a irrigação ocorreu semanalmente ao longo de seis meses durante a estação chuvosa. O volume de água adicionado foi de $37,5 \mathrm{~L} / \mathrm{m}^{2}$ (equivalente a $37,5 \mathrm{~mm}$ de pluviosidade) a cada semana. A irrigação foi realizada a partir de gotejadores espalhados uniformemente em toda a área plantada da casa de vegetação de modo a irrigá-la completamente. $\mathrm{O}$ volume de água foi estabelecido com base na precipitação média durante a estação chuvosa para a região dos Cerrados. (900 mm por ano) dividido ao longo dos seis meses da estação chuvosa (150 mm), sobrando então 37,5 mm a cada semana. O período de irrigação foi de outubro de 2011 a abril de 2012.

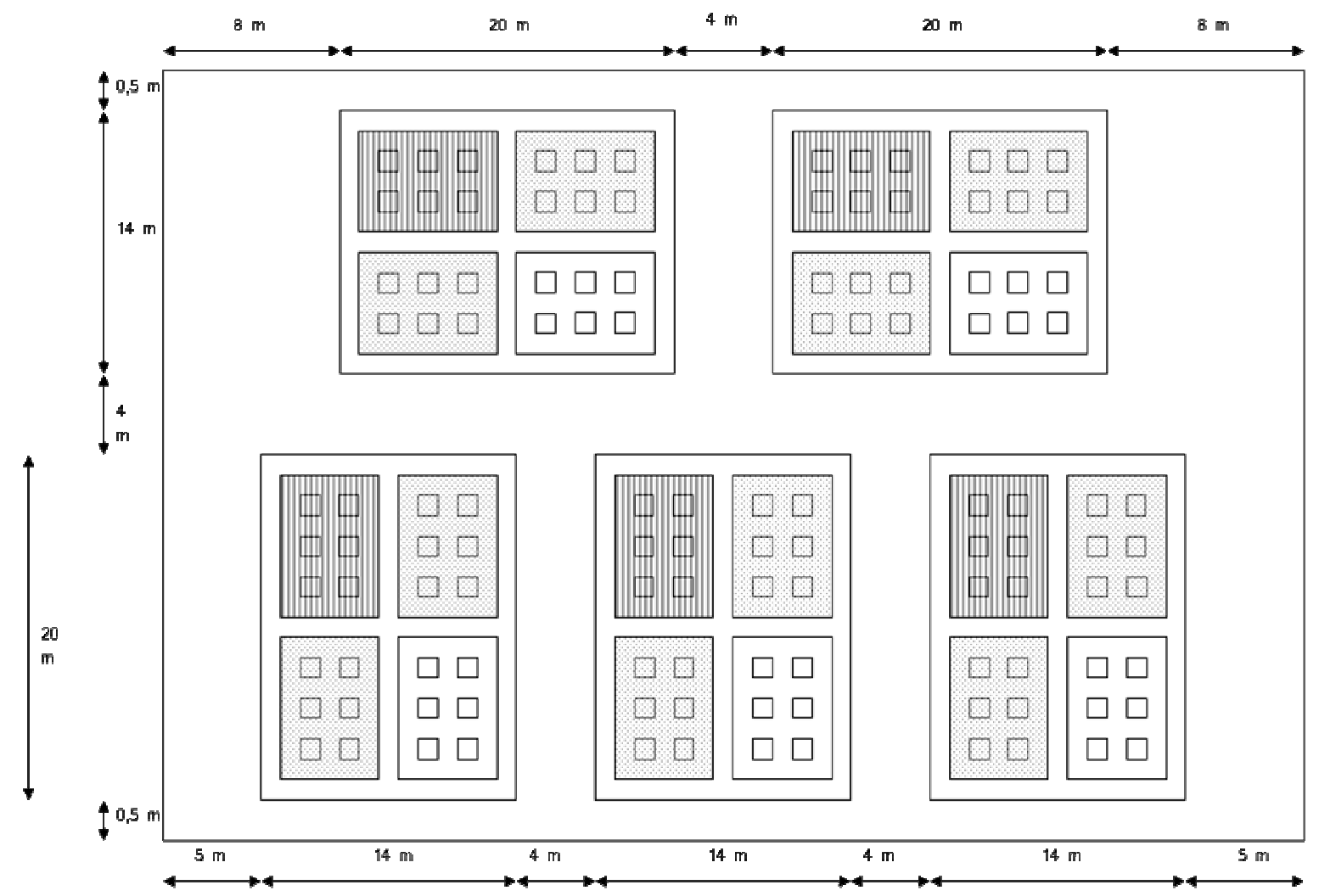

Figura 1. Representação dos blocos experimentais. Os retângulos cobertos com pontos representam casas de vegetação com coberturas para exclusão de chuva, aqueles com linhas verticais coberturas para exclusão de chuva e sombreamento de $80 \%$ e aqueles em branco representam as parcelas sem nenhuma cobertura.

Cada parcela (casa de vegetação) foi subdividida em seis subparcelas de $4 \mathrm{~m}^{2}$, sendo que em dois deles foram plantadas sementes de uma gramínea nativa do Cerrado (Paspalum atratum Swallen) (G1), em outros dois foram plantadas sementes de uma gramínea exótica (Urochloa 
brizantha (Hochst. ex A. Rich.) Stapf) (G2) e os outros dois permaneceram sem gramíneas (G0) (Figura 2).
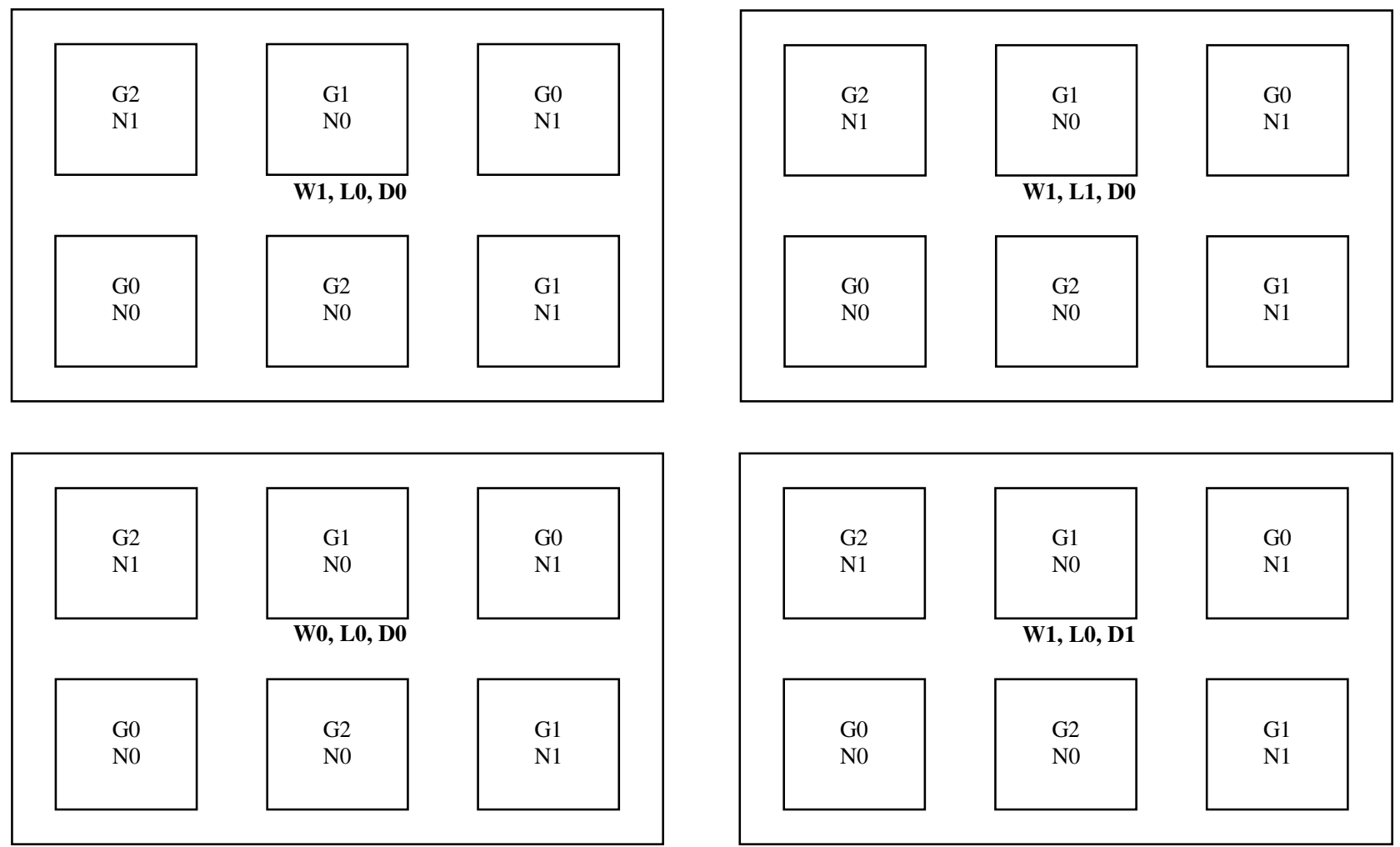

Figura 2. Desenho esquemático dos tratamentos de um único bloco experimental. Água (W), Luz (L) e defoliação (D) foram tratamentos de uma parcela, enquanto que gramíneas $(\mathrm{G})$ e nutrientes $(\mathrm{N})$ foram tratamentos de um subparcela.

Em três das seis subparcelas, foram adicionados nutrientes (N1) e as outras permaneceram sem a adição de fertilizantes (N0) (Figura 2). A adição de fertilizante foi realizada com o objetivo de aumentar a disponibilidade de nutrientes para as lenhosas e gramíneas. Fertilizante inorgânico $\left(\right.$ Osmocote $\left.^{\circledR}\right)$ do tipo granular de liberação lenta foi adicionado mensalmente por três meses, totalizando 4 aplicações. A aplicação de fertilizantes em diferentes datas ao longo da estação chuvosa teve a finalidade de prevenir possível lixiviação de nutrientes.

A quantidade de fertilizante aplicada foi determinada com base na adição de 4 g.N.m ${ }^{-2}$, 1,33 g.P.m ${ }^{-2}$, 2,67 g.K.m ${ }^{-2}$ (3:1:2 NPK) por aplicação, vista com uma alta concentração de nitrogênio em diversos estudos (Tilman, 1987; Walker \& Knoop, 1987; Kraaij \& Ward, 2006; Tomlinson et al., 2012; Vadigi \& Ward, 2014). A quantidade de nitrogênio utilizada (4 g/m² por mês) é quase o dobro da mais alta concentração utilizada por Kraaij e Ward (2006) (2,8 g/mês) e 
por Tilman (1987) (2,3 g/mês) (Vadigi \& Ward, 2014). Kozovits et al., 1996, em áreas de cerrado sentido restrito, encontraram concentrações de nitrato no solo variando entre 2,7 a $4,4 \mathrm{mg} / \mathrm{Kg}$ e de amônia entre 17 e $8,6 \mathrm{mg} / \mathrm{kg}$, antes das queimadas.

\section{Experimento 1 - Biomassa da cobertura graminosa}

Entre o início da estação chuvosa de 2009 e fevereiro de 2011, as gramíneas foram sendo estabelecidas na área experimental para formar uma cobertura graminosa uniforme nas respectivas subparcelas.

Para o início do experimento e avaliação dos efeitos dos tratamentos no crescimento das gramíneas, todas tiveram cortadas suas partes aéreas a dois centímetros do solo, em fevereiro de 2011, buscando uniformizar seus tamanhos aéreos antes do inicio do experimento.

Para avaliar o crescimento das gramíneas submetidas aos diferentes tratamentos ao longo do tempo, foram realizadas coletas da biomassa das gramíneas aos 3, 8, 10, 12 e 14 meses após o início do experimento. Para que o corte anterior não interferisse na medida seguinte, as parcelas foram subdivididos em 32 subparcelas de $0,125 \mathrm{~m}^{2}$, e os cortes de gramíneas eram sempre feitos em partes diferentes, evitando-se as subparcelas cortadas anteriormente.

Após o corte, as partes aéreas foram secas em estufa a $70^{\circ} \mathrm{C}$ por 48 horas antes da pesagem final.

Para a análise dos resultados, a biomassa e a taxa de crescimento absoluta foram calculadas:

$\mathrm{TCA}=(\mathrm{M} 2-\mathrm{M} 1) \div(\mathrm{T} 2-\mathrm{T} 1)$, sendo $\mathrm{TCA}=$ taxa de crescimento absoluta, $\mathrm{M} 2=$ massa seca no tempo $2(\mathrm{~T} 2)$ e $\mathrm{M} 1=$ massa seca no tempo $1(\mathrm{~T} 1)$.

Os dados foram analisados estatisticamente usando modelos lineares mistos, sendo a variável dependente, taxa de crescimento absoluto, e as variáveis independentes, espécies (G1 e 
G2), irrigação (W0 e W1) ou luz (L0 e L1), adição de nutrientes (N0 e N1) e tempo (T - meses dentro da estação de crescimento).

\section{Experimento 2 - Defoliação e rebrota de espécies lenhosas}

Este experimento foi realizado nas casas de vegetação com coberturas plásticas e irrigação artificial (L0,W1), especialmente designadas para este experimento (D1), nas quais não houve outro experimento (Figura 2).

Enquanto as espécies de gramíneas se estabeleciam no campo, mudas de espécies lenhosas do Cerrado foram produzidas.

Foram utilizadas seis espécies de lenhosas arbóreas nativas do Cerrado (Tabela 1). Os critérios de escolha dessas espécies foram: 1) representatividade nas comunidades de Cerrado; 2) disponibilidade, viabilidade e germinabilidade de suas sementes no ano de coleta; 3) estabelecimento e sobrevivência das plântulas em casa de vegetação.

Tabela 1. Espécies lenhosas utilizadas no experimento de defoliação e rebrota.

\begin{tabular}{lcc}
\hline \multicolumn{1}{c}{ Espécies } & Nome popular & Família \\
\hline Copaifera langsdorfii Desf. & Copaíba & Fabaceae -Caesalpinoideae \\
Dalbergia miscolobium Benth. & Jacarandá-do-cerrado & Fabaceae - Papilionoideae \\
Eriotheca pubescens (Mart \& Zucc)Schot & Paineira-do-cerrado & Bombacaceae \\
Eugenia dysenterica DC. & Cagaita & Myrtaceae \\
Stryphnodendron adstringens (Mart.) Cov. & Barbatimão & Fabaceae - (Mimosoideae) \\
Myracrodruon urundeuva Fr. All. & Aroeira & Anacardiaceae \\
\hline
\end{tabular}

As coletas de sementes de lenhosas foram realizadas tanto na estação chuvosa quanto na seca, desde maio de 2008. Diásporos foram dispostos em bandejas para secar, as sementes foram beneficiadas e armazenadas em sacos de papel identificados e guardadas em geladeira $\left(5^{\circ} \mathrm{C}\right)$.

Foram realizados experimentos para analisar a germinabilidade de cada espécie de lenhosa. Sementes de Copaifera langsdorffii, Eugenia dysenterica e Stryphnodendron adstringens foram escarificadas mecanicamente, para remover dormência tegumentar (Ferreira \& Borghetti, 2004). 
As sementes foram postas para germinar em placas de petri com água em câmaras de germinação com fotoperíodo de 12 horas e temperatura de $30^{\circ} \mathrm{C}$. Após a germinação, as plântulas foram transplantadas para sacos de mudas com latossolo vermelho, adicionado de 1/3 de areia para melhorar a aeração e mantidas em casa de vegetação, sem aplicação de fertilizantes. Somente após o seu estabelecimento, as plântulas em boas condições foram transplantadas para as parcelas do experimento no campo, com as gramíneas já totalmente estabelecidas nas parcelas.

Em cada subparcela das casas de vegetação foram plantadas quatro plântulas de cada espécie. Foram feitas medidas biométricas no momento do plantio das plantas no campo.

Após três meses do início do plantio no campo, as plantas tiveram suas partes aéreas cortadas, simulando efeitos de fogo ou mesmo de herbivoria. Quase toda a parte aérea foi suprimida, restando apenas o primeiro nó de cada planta. Dados de biomassa aérea foram coletados. As gramíneas foram cortadas concomitantemente a dois centímetros do solo.

As plantas que rebrotaram foram analisadas após 11 meses da defoliação. Dados como sobrevivência, altura e diâmetro do caule e número de folhas foram coletados.

Os dados coletados foram submetidos à análise de variância, quando possível, e a testes não paramétricos, como Kruskall Wallis e Mann Whitney U, para verificar possíveis diferenças entre os tratamentos.

\section{Descrição das espécies:}

\section{Espécies de gramíneas:}

Urochloa brizantha (Hochst. ex A. Rich.) Stapf

A braquiária (Urochloa brizantha (Hochst. ex A. Rich.) Stapf) é uma gramínea forrageira bastante plantada na América tropical, especialmente no Brasil (Dias-Filho, 2000; Dias-Filho, 2002). De acordo com Almeida Neto et al. (2010) e Lannes et al. (2012), as espécies de Urochloa 
representam as mais comuns e mais agressivas gramíneas exóticas encontradas nas áreas do Cerrado. Somente no Brasil, já existem 50 milhões de hectares de pastos constituídos por braquiária (Macedo, 2005). Podem diminuir drasticamente a abundância de gramíneas nativas (Pivello 1999a) e de Asteraceae (Almeida-Neto et al., 2010) e dominar a comunidade herbácea (Almeida-Neto et al., 2010; Gorgone-Barbosa et al., 2014;). Miles et al. (1996) relatam a existência de efeitos alelopáticos inibidores de Urochloa brizantha em espécies de Fabaceae.

É uma gramínea caracterizada por apresentar espécies facilmente adaptáveis a diferentes condições climáticas, como ambientes sombreados (Miles et al., 1996), e possuem a capacidade de sobreviver em variadas condições de solos, em particular solos ácidos e fracos e devastados (Miles et al., 1996; Andrade et al., 2004; Manzano et al., 2010). No entanto, tem baixo desempenho em solos mal drenados e com excesso de água (Miles et al., 1996; Andrade et al., 2004) e é sensível a temperaturas baixas (Cook et al., 2005). Apesar das espécies de braquiária serem capazes de se desenvolver em solos pobres em nutrientes, Urochloa brizantha foi a espécie reconhecida por responder de maneira mais positiva com incremento de biomassa à adição de nitrogênio ao solo (Miles et al., 1996). Urochloa brizantha apresenta alta produtividade, em média 6,5 toneladas de matéria seca aérea por hectare (Miles et al., 1996), e alto vigor de rebrota após defoliação (Valle \& Miles, 1994 In: Miles et al., 1996).

\section{Paspalum atratum Swallen}

O capim pojuca (Paspalum atratum Swallen) é uma gramínea nativa do Cerrado, que apresenta alta produção e grande velocidade de rebrota (Karia \& Andrade, 2001; Leite et al., 2001). Em função de seu rápido e vigoroso crescimento, tem sido utilizada como forrageira na diversificação de pastagens (Ramos et al., 2002). É uma espécie perene, com rizomas longos e profundos e com colmos de até $130 \mathrm{~cm}$ de comprimento, com alto potencial forrageiro (Maciel et al., 2009). A produtividade desta gramínea é maior em regiões com períodos chuvosos mais 
prolongados e secas menos severas (Ramos et al., 2002). Assim como outras espécies do mesmo gênero, esta espécie possui metabolismo fotossintético $\mathrm{C}_{4}$ (Klink \& Joly, 1989), sendo então bem adaptada a ambientes de pleno sol.

\section{Espécies lenhosas:}

\section{Copaifera langsdorffii Desf}

A Copaifera langsdorffii Desf. é uma árvore da família Fabaceae (Caesalpiniodeae) conhecida popularmente por copaíba, pau-d'óleo, podói, copaúba e cupiúva (Lorenzi, 2008). São plantas semidecíduas, heliófitas, características das formações de transição do cerrado para a floresta semidecídua (Lorenzi, 2008). No Brasil, as plantas desta espécie ocorrem nos estados de CE, MA, MG, MS, GO, MT, PA, TO, SP e PR e DF (Silva Junior et al., 2005), em áreas de mata de galeria, mata mesofítica, cerradão e cerrado (Proença et al., 2001).

Possuem de 10 a 15 metros, com tronco de 50 a $80 \mathrm{~cm}$ de diâmetro, folhas compostas paripinadas e madeira moderadamente pesada. Florescem de dezembro a março e os frutos amadurecem de agosto a setembro, com a planta quase sem folhas (Lorenzi, 2008) A folhação ocorre entre julho e setembro (Silva Junior et al., 2005).

\section{Dalbergia miscolobium Benth.}

A Dalbergia miscolobium Benth. é uma espécie arbórea da família Fabaceae (Faboideae), conhecida popularmente como jacarandá-do-cerrado. Ocorre no cerrado sentido restrido e cerradão distrófico, no DF, e também nos estados CE, GO, MA, MG, MT, MS, PA, SP e TO (Silva Júnior et al., 2005). Sua altura varia de 8 a 16 metros, com 30 a 50cm de diâmetro de tronco (Lorenzi, 2008). 
Possui folha composta pinada, com 15 a $22 \mathrm{~cm}$ de comprimento, contendo 4 a 8 pares de folíolos (Lorenzi, 2008).

Espécie perenifólia ou semidecídua, heliófita, pioneira e seletiva xerófita, característica de terrenos arenosos e bem drenados (Lorenzi, 2008). É mais freqüente em formações abertas secundárias, onde chega a formar grandes agrupamentos (Lorenzi, 2008). São plantas sensíveis ao sombreamente e características de solos mais arenosos e bem drenados (Barbieri Júnior, 2006).

Florescem normalmente entre novembro e maio, frutificando entre maio e julho (Silva Junior et al., 2005), porém os frutos podem ficar na árvore por mais um ano antes de serem dispersos de forma anemocórica (Lorenzi, 2008). A dispersão dos diásporos ocorre logo após as primeiras chuvas e suas sementes são ortodoxas e quiescêntes (Barbieri Júnior, 2006).

Eriotheca pubescens (Mart. \& Zucc.) Schott. \& Endl.

A Eriotheca pubescens (Mart. \& Zucc.) Schott. \& Endl. é uma espécie arbórea da família Malvaceae, conhecida popularmente como paineira-do-cerrado, embiriçu, colher-de-vaqueiro e embiruçu peludo (Silva-Júnior et al., 2005). No Brasil, ocorre nos estados BA, GO, MA, MG, MT, MS, PI, SP, TO e DF (Silva-Júnior et al., 2005), no cerrado sentido restrito, cerradão, campo cerrado e nas bordas das matas de galerias (Proença et al., 2001; Silva-Júnior et al., 2005). É uma planta decídua ou semidecídua, heliófita, característica de formações secundárias do cerrado e cerradões. Prefere solos arenosos e secos (Lorenzi, 2008). Essa espécie é amplamente adaptada a terrenos secos e pobres podendo ser incluída na composição de reflorestamentos destinados à reconstituição da vegetação de áreas degradadas e de preservação (Lorenzi, 2008).

Espécie arbórea com 6 a 10 metros do comprimento, dotada de copa aberta e irregular, com ramos curtos e grossos, tronco bastante ramificado e madeira macia, esponjosa e leve. Suas folhas são compostas, digitadas, contendo 3 a 5 folíolos (Lorenzi, 2008). A floração ocorre de julho a setembro e a frutificação de agosto a novembro (Silva-Júnior et al., 2005). 
Eugenia dysenterica DC.

A Eugenia dysenterica DC., popularmente conhecida como cagaita ou cagaiteira, é uma espécie da família Myrtaceae. Ocorre em áreas de cerradão e cerrado sentido restrito, nos estados do DF, BA, GO, MA, MT, MS, MG, PA, PI, SP e TO (Silva-Junior et al., 2005). É uma árvore que atinge de 4 a 8 metros de altura, possui tronco tortuoso e cilíndrico com 25 a 35cm de diâmetro e madeira é pesada e dura (Lorenzi, 2008). É planta decídua, heliófita, seletiva, xerófita, secundária e seu desenvolvimento é considerado lento (Lorenzi, 2008). De acordo com Lorenzi (2008), é exclusiva de cerrado de altitude (acima de 800 metros), onde é muito abundante, porém com dispersão descontínua e irregular. Ocorre preferencialmente em formações primárias e em capoeirões de terrenos elevados, com solo argiloso ou arenoso bem drenados. Floresce de agosto a setembro e frutifica durante as primeiras chuvas (Silva-Junior et al., 2005).

Myracrodruon urundeuva M. Allemao

Myracrodruon urundeuva M. Allemao uma espécie lenhosa de Anacardiaceae conhecida popularmente como aroeira, aroeira do campo, aroeira do sertão. Ocorre desde o Ceará até os estados do Paraná e Mato Grosso do Sul (Lorenzi, 2008). Pode ser encontrado em matas e cerradão (Proença et al., 2001). É uma árvore com 6 a 14 metros de comprimento no cerrado ou caatinga e até 20 ou 25 metros em solos mais férteis. O tronco possui de 50 a $80 \mathrm{~cm}$ de diâmetro e sua madeira é muito pesada (Lorenzi, 2008). É uma planta decídua, heliófita, seletiva xerófita, característica de terrenos secos e rochosos; ocorre tanto em formações abertas e muito secas (caatinga), como em formações muito úmidas e fechadas (com $2000 \mathrm{~mm}$ de pluviosidade anual) (Lorenzi, 2008). Floresce entre junho e julho, com a planta geralmente sem folhas, e a maturação dos frutos prolonga-se até o final de outubro (Lorenzi, 2008) 
Stryphnodendron adstringens (Mart.) Cov.

A Stryphnodendron adstringens (Mart.) Cov. é uma espécie arbórea da família Fabaceae (Mimosoideae), conhecida popularmente como barbatimão, barba-de-timão, charãozinho-roxo e casca-da-virgindade (Lorenzi, 2008). No Brasil, pode ser encontrada desde o estado do Pará até São Paulo e Mato Grosso do Sul (Lorenzi, 2008). É encontrada nos ambientes de cerrado, cerradão e campo cerrado do DF (Proença et al., 2001).

É uma planta decídua, heliófita, pioneira, seletiva xerófita, característica de formações abertas. Apresenta nítida preferência por solos arenosos e de drenagem rápida e ocorrem tanto em formações primárias como secundárias (Lorenzi, 2008).

Arvores de 4 a 5 metros, com troncos de 20 a $30 \mathrm{~cm}$ de diâmetro de madeira pesada e dura (Lorenzi, 2008). As folhas são alternas, compostas bipinadas, com 6 a 8 pares de foliólulos por pina (Lorenzi, 2008). As plantas florescem de setembro a novembro e frutificam de novembro a junho (Silva-Junior et al., 2005).

\section{REFERÊNCIAS BIBLIOGRÁFICAS}

Accatino, F.; De Michele, C.; Vezzoli, R.; Donzelli, D. \& Scholes, R. J.., 2010. Tree-grass coexistence in savanna: Interactions of rain and fire. Journal of Theoretical Biology, 267: 235242.

Almeida-Neto, M.; Prado, P. I.; Kubota, U.; Bariani, J. M.; Aguirre, G. H. \& Lewinsohn, T. M., 2010. Invasive grasses and native Asteraceae in the Brazilian Cerrado. Plant Ecology, 209: 109-122.

Andrade, C. M. S. de; Valentim, J. F.; Carneiro, J. C. \& Vaz, F. A., 2004. Crescimento de gramíneas e leguminosas forrageiras tropicais sob sombreamento. Pesquisa Agropecuária Brasileira, 39 (3): 263-270.

Asner, G. P. \& Beatty, S. W., 1996. Effects of an African grass invasion on Hawaian shrubland nitrogen biogeochemistry. Plant \& Soil, 186: 205-211. 
Barbieri Junior, C. A., 2006. Ecofisiologia da germinação e estabelecimento de plântulas de Dalbergia miscologium Benth. Dissertação de mestrado, Departamento de Ecologia e Recursos Naturais, Universidade Federal de São Carlos, São Carlos/SP. 63p.

Barbosa, E. R. M., 2013. Surviving and growing amidst others - the effect of environmental factors on germination and establishment of savanna trees. Tese de doutourado, Resorce Ecology Group, Wageningen University, Wageningen/ NL, 158p.

Barbosa, E. G.; Pivello, V. R. \& Meirelles, S. T., 2008. Allelopathic Evidence in Brachiaria decumbens and its potential to invade the Brazilian Cerrados. Brazilian Archives of Biology and Technology, 51 (4): 825-831.

Baruch, Z. \& Bilbao B., 1999. Effects of fire and defoliation on the life history of native and invader $\mathrm{C}_{4}$ grasses in a Neotropical savanna. Oecologia, 119: 510-520.

Beckage, B.; Platt, W. J. \& Gross, L. J., 2009. Vegetation, fire and feedbacks: a disturbance mediated model of savannas. The American Naturalist, 174 (6): 805-818.

Beckage, B.; Gross, L. J. \& Platt, W. J., 2011. Grass feedbacks on fire stabilize savannas. Ecological Modelling, 222: 2227-2233.

Beerling, D. J. \& Osborne, C. P., 2006. The origin of the savanna biome. Global Change Biology Journal, 12: 2023-2031.

Bond, W. J., 2008. What limits trees in $\mathrm{C}_{4}$ grasslands and savannas? Annual Review of Ecology, Evolution and Systematics, 39: 641-659.

Bond, W. J. \& Keeley, J. E., 2005. Fire as a global herbivore: the ecology and evolution of flammable ecosystems. Trends in Ecology and Evolution, 20 (7): 387 - 394.

Bond, W. J.; Woodward, F. I. \& Midgley, G. F., 2005. The global distribution of ecosystems in a world without fire. The New Phytologist, 165, 525-538.

Bowman, D. M. J. S. \& Fensham, R. J., 1991. Response of a monsoon forest-savanna boundary to fire protection. Australian Journal of Ecology, 16: 111-118.

Brooks, M. L.; D’Antonio, C. M.; Richardson, D. M.; Grace, J. B.; Keeley, J. E.; DiTomaso, J. M.; Hobbs, R. J.; Pellant, M. \& Pyke, D., 2004. Effects of invasive alien plants on fire regimes. Bioscience, 54: 677-688.

Brooks, K. J.; Setterfield, S. A. \& Douglas, M. M., 2010. Exotic Grass invasions: Applying a Conceptual Framework to the Dynamics of Degradation and Restoration in Australia's Tropical Savannas. Restoration Ecology, 18 (2): 188-197. 
Calabrese, J. M.; Vazquez, F.; Lopez, C.; San Miguel, M. \&Grimm, V., 2010. The independent and interactive effects of tree-tree establishment competition and fire on savanna structure and dynamics. The American Naturalist, 175 (3): E44-E65.

Cavalcanti, R. B. \& Joly, C. A., 2002. Biodiversity and conservation priorities in the Cerrado region. In: Oliveiras, P. S. \& Marquis, R. J. (Eds). The Cerrados of Brazil, Columbia University Press, New York, pp.351-367.

Cole, M. M., 1986. The Savannas: Biogeography and Geobotany. Academic Press, London, UK.

Cook, B.; Pengelly, B: Brown, S.; Donnelly, J.; Eadgles, D.; Franco, A.; Hanson, J.; Mullen, B; Partridge, P. \& Schultze-Kraft, M., 2005. Overview of tropical forages: interactive selection tool. Department of Primary Industries and Fisheries, Centro Internacional de Agricultura Tropical and International Livestock Research Institute. Disponível em: http://www.tropicalforages.info/key/Forages/Media/Html/Brachiaria_brizantha.htm.

Costa, A. N.; Vasconcelos, H. L.; Vieira-Neto, E. H. M. \& Bruna, E. M., 2008. Do herbivores exert top-down effects in Neotropical savannas? Estimates of biomass consumption by leaf cutter ants. Journal of Vegetal Sciences, 19:849-854.

Coutinho, L. M., 1990. Fire in the ecology of the Brazilian Cerrado. In: Goldmmer, J. G. (ed.). Fire in the Tropical Biota: ecossystem processes and global challenges. Springer Verlag, Berlin, pp. 82-105.

Craine, J. M., 2005. Reconciling plant strategy theories of Grime and Tilman. Journal of Ecology, 93: 1041-1052.

Cramer, M. D.; Chimphango, S. B. M.; Van Cauter, A.; Waldram, M. S. \& Bond, W. J., 2007. Grass competition induces $\mathrm{N}_{2}$ fixation in some species of African Acacia. Journal of Ecology, 95: 1123-1133.

D’Antonio, C. M. \& Vitousek, P. M., 1992. Biological invasions of alien grasses, the grass/fire cycle and global change. Annual review of ecology and Systematics, 23: 63-87.

D’Antonio, C. M.; Hugles, R. F.; Mack, M.; Hitchcock, D. \& Vitousek, P. M., 1998. The response of native species to removal of invasive exotic grasses in a seasonally dry Hawaiian woodland. Journal of Vegetation Science, 9 (5): 699-712.

Davis, M. A.; Grime, J. P. \& Thompson, K., 2000. Fluctuating resources in plant communities: a general theory of invasibility. Journal of Ecology, 88: 528-534.

D’Odorico, P.; Laio, F. \& Ridolfi, L., 2006. A probabilistic analysis of fire-induced tree-grass coexistence in savannas. The American Naturalist, 167: E79-E87. 
Dohn, J.; Dembélé, F.; Karembé, M.; Moustakas, A.; Amévor, K. A. \& Hanan, N. P., 2013. Tree effects on grass growth in savannas: competition, facilitation and the stress-gradient hypothesis. Journal of Ecology, 101: 202-209.

Durigan, G.; Siqueira, M. F. \& Franco, G. A. D. C., 2007. Threats to the Cerrado remnants of the state of São Paulo, Brazil. Scientia Agricola, 64: 355-363.

Everett, R. A., 2000. Patterns and pathways of biological invasions. Trends in Ecology \& Evolution, 15: $177-178$.

Felfili, J. M.; Sousa-Silva, J. C. \& Scariot, A., 2005. Biodiversidade, ecologia e conservação do Cerrado: avanços no conhecimento. In: Cerrado: ecologia, biodiversidade e conservação. A. Scariot; J. C. Sousa-Silva \& J. Felfili (orgs). Brasília, Ministério do Meio Ambiente. p. 25-44.

Ferreira, A. G. \& Borghetti, F. (Orgs.), 2009. Germinação: do básico ao aplicado. Porto Alegre: Artmed, 399 p.

Filgueiras, T. S., 1990. Africanas no Brasil. Gramíneas introduzidas da África. Cadernos de Geociências, 5: 57-63.

Foxcroft, L. C.; Richardson, D. M.; Rejmanek, M. \& Pysek, P., 2010. Alien plant invasions in tropical and sub-tropical savannas: patterns, processes and prospects. Biological Invasion, 12: 3913-3933.

Freitas, G. K. \& Pivello, V. R., 2005. A ameaça das gramíneas exóticas à biodiversidade. In: Pivello, V. R. \& Varanda, E. M. (Eds). O Cerrado Pé-de Gigante, ecologia e conservação. São Paulo, pp. 283-296.

Goldberg, D. E. \& Barton, A. M., 1992. Patterns and consequences of interspecific competition in natural communities: a review of field experiments with plants. American Naturalist, 139: 771801.

Goldberg, D. E.; Turkington, R.; Olsvig-Whittaker, L \& Dyer, A. R., 2001. Density dependence in an annual plant community: variation among life history stages. Ecological Monographs, 71: 423-446.

Gorgone-Barbosa, E.; Pivello, V. R.; Bautista, S.; Zupo, T.; Rissi, M. N. \& Fidelis, A., 2014. How can an invasive grass affect fire behavior in a tropical savanna? A community and individual plant level approach. Ecological Invasions, 17. Disponível em: http://link.springer.com/article/10.1007/s10530-014-0740-z

Grime, J. P., 1977. Evidence for the existence of three primary strategies in plant and its relevance to ecological and evolutionary theory. The American Naturalist, 111(982): 1169-1194. 
Henriques, R. P. B. 2005. Influência da história, solo e fogo na distribuição e dinâmica das fitofisionomias no bioma Cerrado. In: Cerrado: ecologia, biodiversidade e conservação. A. Scariot; J. C. Sousa-Silva \& J. Felfili (orgs). Brasília, Ministério do Meio Ambiente. p. 73-92.

Higgins, S. I.; Bond, W. J. \& Trollope, W. S. W., 2000. Fire, resprouting and variability: a recipe for grass-tree coexistence in savanna. Journal of Ecology, 88: 213-229.

Hoffmann, W. A., 1996. The effects of fire and cover on seedling establishment in a neotropical savanna. Journal of Ecology, 84: 383-393.

Hoffmann, W. A., 1998. Post-burn reproduction of woody plants in a neotropical savanna: the relative importance of sexual and vegetative reproduction. Journal of Apllied Ecology, 35: 422433.

Hoffmann, W. A., 1999. Fire and population dynamics of woody plants in a neotropical savanna: matrix model projection. Ecology, 80: 1354-1369.

Hoffmann, W. A. \& Haridasan, M., 2008. The invasive grass, Melinis minutiflora, inhibits tree regeneration in a Neotropical savanna. Australian Ecology, 33: 29-36.

Hoffmann, W. A. \& Jackson, R. B., 2000. Vegetation-climate feedbacks in the conversion of tropical savannah to grassland. Journal of Climate, 13: 1593- 1602.

Hoffmann, W. A; Schroeder, W. \& Jackson, R. B., 2002. Positive feedbacks of fire, climate and vegetation and the conversion of tropical savanna. Geophysical Research Letters, 29.

Hoffmann, W. A.; Lucatelli, V. M. P. C.; Silva, F. J. Azeuedo, I. N. C.; Marinho, M. S.; Albuquerque, A. M. S.; Lopes, A. O. \& Moreira, S. P., 2004. Impact of the invasive grass Melinis minutiflora at the savanna-forest ecotone in the Brazilian Cerrado. Diversity and Distributions, 10: 99-103.

Hoffmann, W. A.; Jaconis, S.; Mckinley, K. 1.; Geiger, E. L.; Gotsch, S. G. \& Franco, A. C., 2012. Fuels or microclimate? Understanding the drivers of fire feedbacks at savanna-forest boundaries. Australian Journal of Ecology, 37: 634-643.

Holdo, R., M.; Holt, R. D. \& Fryxell, J. M., 2013. Herbivore-vegetation feedbacks can expand the range of savanna persistence: insights from a simple theoretical model. Oikos, 122: 441-453.

Horowitz, C.; Martins, C. R. \& Walter, B. M. T., 2013. Flora exotica no Parque Nacional de Brasília: levantamento e classificação das espécies. Biodiversidade brasileira, 3(2): 50-73.

Hughes, F. \& Vitousek, P. M., 1993. Barriers to shrub establishment following to fire in the seasonal submontane zone of Hawaii. Oecologia, 29: 557-563. 
Jeltsch, F., Weber, G. E. \& Grimm, V., 2000. Ecological buffering mechanisms in savannas: a unifying theory of long-term tree-grass coexistence. Plant Ecology, 161: 161-171.

Kambatuku, J. R.; Cramer, M. D. \& Ward, D., 2011. Savanna tree-grass competition is modified by substrate type and herbivory. Journal of Vegetation Science, 22: 225-237.

Karia, C. T. \& Andrade, R. P., 2001 Cultivo do Capim Pojuca. Recomendação Técnica Embrapa Cerrados, 50: 1-2.

Keeley, J. E. \& Rundel, P.W., 2005. Fire and the Miocene expansion of $\mathrm{C}_{4}$ grasslands. Ecology Letters, 8: 683-90.

Klink, C. A., 1996. Germination and seedling establishment of two native and one invading African grass species in the Brazilian cerrado. Journal of Tropical Ecology, 12: 139-147.

Klink, C. A. \& Joly, C. A., 1989. Identification and Distribution of $\mathrm{C}_{3}$ and $\mathrm{C}_{4}$ grasses in open and shades habitats in São Paulo State, Brazil. Biotropica, 21 (1): 30-34.

Klink, C. A. \& Machado, R. B., 2005. Conservation of the Brazilian Cerrado. Conservation Biology, 19: 707-713.

Klink, C. A. \& Moreira, A., 2002. Past and current human occupation. In: Oliveira, P. S. \& Marquis, R. J. (Eds). The Cerrados of Brazil: Ecology and Natural History of a Neotropical Savanna. Columbia University Press, NewYork, pp. 69-88.

Knoop, W.T. \& Walker, B. H., 1985. Interaction of woody and herbaceous vegetation in the southern African savanna. Journal of Ecology, 73: 235-253.

Kozovits, A. R.; Bustamante, M. M. C.; Silva, L. F.; Duarte, G. F.; Castro, A. A. \& Magalhães, J. R., 1996. Nitrato e amônio no solo e sua assimilação por espécies lenhosas em uma área de cerrado submetida a queimadas prescritas. In: Miranda, H. S.; Saito, C. H. \& Dias, B. F. S. Impacto de queimadas em áreas de cerrado e restinga. Anais do Simpósio Impacto de queimadas sobre os ecossistemas e mudanças globais, Brasília, p. 137-147.

Kraaij, J. \& Ward, D., 2006. Effects of rain, nitrogen, fire and grazing on tree recruitment and early survival in bush-encroached savanna, South Africa. Plant Ecology, 186: 235-246.

Lannes, L. S.; Bustamante, M. M. C.; Edwards, P. J. \& Venterink, H. O., 2012. Alien and endangered plants in the Brazilian Cerrado exhibit contrasting relationships with vegetation biomass and N: p stoichiometry. The New Phytologist, 196: 816-823. 
Laris, P., 2011. Humanizing Savanna Biogeography: Linking Human Practices with Ecological Patterns in a Frequently Burned Savanna of Southern Mali. Annals of the Association of American Geographers, 101 (5): 1067-1088.

Leite, G. G.; Silveira, L. F.; Fernandes, F. D. \& Gomes, A. C., 2001. Crescimento e composição química do capim Paspalum atratum cv Pojuca. Boletim pesquisa e desenvolvimento (Embrapa cerrados), 19: 1-22.

Lockwood, J. L.; Hoopes, M. F. \& Marchetti, M. P., 2007. Invasion Ecology. Malden: Blackwell Publishing. Disponível em: http://www.planta.cn/forum/files_planta/invasion_ecology_185.pdf

Lorenzi, H., 2008. Árvores Brasileiras: manual de identificação e cultivo de plantas arbóreas do Brasil. Instituto Plantarum, Nova Odessa, 383p.

Ludwig, F.; De Kroon, H.; Berendse, F. \& Prins, H. H. T., 2004. The influence of savanna trees on nutrient, water and light availability and the understory vegetation. Plant Ecology, 170: 93-105.

Macedo, M. C. M., 2005. Pastagens no ecossistema Cerrados: evolução das pesquisas para o desenvolvimento sustentável. In: Anais da $42^{\mathrm{a}}$. Reunião Anual da Sociedade Brasileira de Zootecnia. Goiânia, Sociedade Brasileira de Zootecnia. p.56-84.

Machado, R. B., M. B. Ramos Neto, P. G. P., Pereira, E. F., Caldas, D. A., Gonçalves, N. S., Santos, K., T. \& Steininger., M. 2004. Estimativas de perda da área do Cerrado brasileiro. Relatório técnico não publicado. Conservação Internacional, Brasília, DF.

Maciel, J. R.; Oliveira, R. C. de \& Alves, M., 2009. Paspalum L. (Poaceae: Panicoideae: Paniceae) no estado de Pernambuco, Brasil. Acta Botanica Brasilica, 23 (4): 1145-1161.

Mangla, S.; Sheley, R. L.ç James, J. J. \& Radosevich, S. R., 2011. Intra and interspecific competition among invasive and native species during early stages of plant growth. Plant Ecology, 212 (4): 531-542.

Manzano, S. J. L.; Araújo, A. C. G.; Valle, C. B.; Santana, E. F. \& Carneiro, V. T. C., 2010. Histologia da embriogênese somática induzida em embriões de sementes maduras de Urochloa brizantha apomítica. Pesquisa Agropecuária Brasileira, 45 (5): 435-441.

Marquis, R. J.; Morais, H. C. \& Diniz, I. R., 2002. Interactions among Cerrado plants and their herbivores: unique or typical? In: Oliveira, P. S.; Marquis, R.J. (eds) The cerrados of Brazil. Columbia University, New York. p. $306-328$.

Martins, D.; Martins, C. C. \& Costa, N. V., 2006. Potencial alelopático de soluções de solo cultivado com Brachiaria brizantha: efeitos sobre a germinação de gramíneas forrageiras e plantas daninhas de pastagens. Planta Daninha, 24 (1): 61-70. 
Masocha, M. A.; Skidmore, K.; Poshiwa, X. \& Prins, H. H. T., 2010. Frequent burning promotes invasions of alien plants into a mesic African savanna. Biological Invasions, 13:1641-1648.

Matos, D. M. S. \& Pivello, V. R., 2009. O impacto das plantas invasoras nos recursos naturais de ambientes terrestres - alguns casos brasileiros. Ciência e Cultura, 61 (1): 27-30.

Ministério do Meio Ambiente, 2014. O Bioma Cerrado. Disponível em: http://www.mma.gov.br/biomas/cerrado.

Miles, J. W.; Maass, B. L.; Valle, C. B. \& Kumble, V., 1996. Brachiaria: biology, agronomy, and improvement. EMBRAPA/CNPGC, Cali. Disponível em: http://books.google.com.br/books/ about/Brachiaria.html?id=dMF6QpfVdjMC\&redir_esc=y

Miranda, A. C.; Miranda, H. S.; Dias, I. O. \& Dias, B. F., 1993. Soil and air temperatures during prescribed Cerrado fires in Central Brazil. Journal of Tropical Ecology, 9: 313-320.

Miranda, H. S.; Bustamante, M. M. C. \& Miranda, A. C., 2002. The Fire factor. In: Oliveira, P. S. \& Marquis, R. J. (Eds). The Cerrados of Brazil: Ecology and Natural History of a Neotropical Savanna. Columbia University Press, NewYork, pp. 51-68.

Moreira, A .G., 2000. Effects of fire protection on savanna structure in Central Brazil. Journal of Biogeography. 27:1021-1029.

Myers, N.; Mittermeir, R. A.; Mittermeir, C. G.; Fonsaeca, A. B. \& Kent, J., 2000. Biodiversity hotspots for conservation priorities. Nature, 403: 853-858.

Myers, J. H. \& Bazely, D. R., 2003. Ecology and Control of Introduced Plants. Cambridge: Cambridge University Press. 11p. Disponível em: http://assets.cambridge.org/97805213/55162/ frontmatter/9780521355162_frontmatter.pdf

Mworia, J. K., 2011. Invasive Plant Species and Biomass Production in Savannas, Biomass and Remote Sensing of Biomass. Dr. Islam Atazadeh (Ed.), ISBN: 978-953-307-490-0, InTech, Disponível em: http://www.intechopen.com/books/biomass-and-remote-sensing-of-biomass/ invasive-plant-species-andbiomass-production-in-savannas.

Oliveira-Filho, A. T. \& Martins, F. R., 1986. Distribuição, caracterização florística das formações vegetais da região da Salgadeira na Chapada dos Guimarães (MT). Revista Brasileira de Botânica, 9: 207-223.

Oliveira-Filho, A. T. \& Ratter, J. A., 2002. Vegetation physiognomies and Woody flora of the Cerrado bioma. In: Oliveira, P. S. \& Marquis, R. J. (Eds). The Cerrados of Brazil: Ecology and Natural History of a Neotropical Savanna. Columbia University Press, NewYork, pp. 91-120. 
Parsons, J. J., 1972. Spread of African Pasture Grasses to the American Tropics. Journal of Range Management, 25:12-17.

Pinheiro, M. H. O.; Azevedo, T. S. \& Monteiro, R., 2010. Spatial-temporal distribution of protected savanna physiognomies in Southeast Brazil. Annals of the Brazilian Academy of Sciences, 82: 379-395.

Pivello, V. R., 2006. Manejo de fragmentos do Cerrado: princípios para a conservação da biodiversidade. In: Cerrado: ecologia, biodiversidade e conservação. Scariot, A.; Sousa Silva, J. C. \& Felfili, J. M. (Eds). Ministério do Meio Ambiente, Brasília, DF, pp. 402-413.

Pivello, V. R. \& Coutinho, L. M., 1996. A qualitative successional model to assist in the management of Brazilian cerrados. Forest Ecology and Management, 87: 127-138.

Pivello, V. R.; Shida, C. N. \& Meirelles, S. T. 1999a. Alien grasses in Brazilian savannas: a threat to the biodiversity. Biodiversity and Conservation, 8: 1281- 1294.

Pivello, V. R.; Carvalho, V. M. C.; Lopes, P. F. Peccinini A. A. \& Rosso, S., 1999b. Abundance and distribution of native and alien grasses in a "Cerrado" (Brazilian savanna) biological reserve. Biotropica, 31: 71- 82.

Proença, C. E. B.; Munhoz, C. B. R.; Jorge, C. L. \& Nóbrega, M. G. G., 2001. Listagem e nível de proteção das espécies de fanerógamas do Distrito Federal, Brasil. In: Cavalcanti, T. B. \& Ramos, A. E. Flora do Distrito Federal. Volume I. Embrapa, Brasília, pp: 87-359.

Ratter, J. A.; Ribeiro, J. F. \& Bridgewater, S., 1997. The Brazilian Cerrado vegetation and threats to its biodiversity. Annals of Botany, 80: 223-230.

Rejmánek, M. \& Richardson, D. M., 1996. What attributes make some plant species more invasive? Ecology, 77:1655- 1661.

Rejmánek, M.; Richardson, D. M. \& Pysek, P., 2005. Plant invasions and invasibility of plant communities. In: Van Der Maarel, E. (Ed). Vegetation ecology. Blackwell, Oxford, pp. 332355.

Ribeiro, J. F. \& Walter, B. M. T., 2008. Fitofisionomias do bioma Cerrado. In: Sano, S. M. \& Almeida, S. P. Cerrado: ambiente e flora. Embrapa, CPAC, Planaltina, pp: 89-166.

Richardson, D. M.; Pyšek, P.; Rejmanek, M.; Barbour, M. G.; Panetta, D. \& West, C. J., 2000. Naturalization and invasion of alien plants: concepts and definitions. Diversity and distributions, 6: 93-107. 
Riginos, C., 2009. Grass competition suppresses savanna tree growth across multiple demographic stages. Ecology, 90: 335-340.

Rossatto, D. R.; Silva, L. C. R; Sternberg, L. S. L. \& Franco, A. C., 2014. Do woody and herbaceous species compete for soil water across topographic gradients? Evidence for niche partitioning in a Neotropical savanna. South African Journal of Botany, 91: 14-18.

Rossiter, N. A.; Setterfield, S. A.; Douglas, M. M. \& Hutley, L. B., 2003. Testing the grass-fire cycle: alien grass invasion in the tropical savannas of northern Australia. Diversity and Distributions, 9:169-176.

Roques, K. G.; O'Connor, T. G. \& Watkinson, A. R., 2001. Dynamics of shrub encroachment in an African savanna: relative influences of fire, herbivory, rainfall and density dependence. Journal of Applied Ecology, 38: 268-280.

Saha, S. \& Howe, H. F., 2006. Stature of juvenile trees in response to anthropogenic fires in a tropical deciduous forest of Central India. Conservation and Society, 4 (4): 619-627.

Sala, O. E.; Chapin, F. S.; Armesto, J. J.; Berlow, E.; Bloomfield, J.; Dirzo, R; Huber-Sanwald, E.; Huenneke. L. F.; Jackson, R. B.; Kinzig, A.; Leemans, R.; Lodge, D. M.; Mooney, H. A.; Oesterheld, M.; Poff, N. L; Sykes, M. T.; Walker, B. H.; Walker, M. \& Wall, D. H., 2000. Global biodiversity scenarios for the year 2100. Science, 287: 1770-1774.

Sankaran, M.; Ratnam, J. \& Hanan, N. P., 2004. Tree-grass coexistence in savannas revisited Insights from an examination of assumptions and mechanisms invoked in existing models. Ecological Letters, 7: 480-490.

Sankaran, M.; Hanan, N. P.; Scholes, R. J.; Ratnam, J.; Augustine, D. J.; Cade, B.S.; Gignoux, J.; Higgins, S. I.; Le Roux, X.; Ludwig, F.; Ardo, J.; Banyikwa, F.; Bronn, A.; Bucini, G.; Caylor, K. K.; Coughenour, M. B.; Diouf, A.; Ekaya, W.; Feral, C. J.; February, E. C., Frost, P. G. H., Hiernaux, P., Hrabar, H., Metzger, K. L.; Prins, H. H. T.; Ringrose, S.; Sea, W.; Tews, J.; Worden, J. \& Zambatis, N., 2005. Determinants of woody cover in African savannas. Nature, 438: 846-849.

Sankaran, M.; Ratnam, J. \& Hanan, N. P., 2008. Woody cover in African savannas: the role of resources, fire and herbivory. Global Ecology and Biogeography, 17: 236-245.

Sano, S. M.; Almeida, S. P. de \& Ribeiro, J. F. (Eds). 1998. Cerrado: ecologia e flora. Brasília, Embrapa Cerrados. 1279p.

Sato, M. N. \& Miranda, H. S. 1996. Mortalidade de plantas lenhosas do cerrado sensu stricto submetidas a diferentes regimes de queima. In: H. S. Miranda; C. H. Saito \& B. F. S. de Souza 
Dias (eds). Impactos de queimadas em áreas de cerrado e restinga. Brasília, Depto de Ecologia, Universidade de Brasília. pp. 102-111.

Scholes, R. J. \& Archer, S.R., 1997. Tree-Grass interactions in savannas. Annual Review of Ecology and Systematics, 28: 517-544.

Setterfield, S.; Rossiter-Ranchor, N. A.; Hutley, L. B.; Douglas, M. M. \& Williams, R. J., 2010. Turning up the heat: the impacts of Andropogon gayanus (gamba grass) invasion on fire behaviour in northern Australian savannas. Diversity and Distributions, 16: 854-861.

Silva, D. M., 2010. Defesas contra herbivoria no cerrado: síndromes de defesa e originalidades. Dissertação de Mestrado. Universidade Federal de São Carlos. São Carlos. 63p.

Silva, J. M. C. da \& Bates, J. M., 2002. Biogeographic patterns and conservation in the South American Cerrado: a tropical savanna hotspot. Bioscience, 52(3): 225-233.

Silva, I. A. \& Batalha, M. A., 2011. Plant functional types in Brazilian savannas: The niche partitioning between herbaceous and woody species. Perspectives in Plant Ecology, Evolution and Systematics, 13 (3): 201-206.

Silva Júnior, M. C.; Santos, G. C.; Nogueira, P. E.; Munhoz, C. B. R. \& Ramos, A. E., 2005. 100 Árvores do Cerrado - Guia de campo. Rede de sementes do Cerrado, Brasília, 278p.

Solbrig, O. T. 1993. Ecological constraints to savanna land use. In: Young, M. D. \& Solbrig, O. T. (eds) The world's savannas. Parthenon, Paris. pp 21-48.

Solbrig, O. T.; Medina, E. \& Silva, J. F., 1996. Biodiversity and Savanna Ecosystem Processes - A Global Perspective. Ecological Studies, 121. Berlin, Springer Verlag. 233p.

Specht, R. L. \& Specht, A. S., 1999. Australian Plant Communities - dynamics of structure, growth and biodiversity. Oxford University Press: Oxford.

Staver, A. C., Archibald, S. \& Levin, S. A., 2012. The global extent and determinants of savanna and forest as alternative biome states. Science, 334:230-232.

Tilman, D., 1982. Resource competition and community structure. Princeton University Press, New York.

Tilman, D., 1985. The resource-ratio hypothesis of plant sucession. American naturalist, 125: 827852.

Tilman, D., 1988. Plant strategies and the dynamics and structure. Princeton University Press, Princeton. 
Vadigi, S. \& Ward, D., 2014. Herbivory effects on saplings are influenced by nutrients and grass competition in a humid South African savanna. Perspectives in Plant Ecology, Evolution and Systematics, 16: 11-20.

Van Langevelde, F.; Van De Vijver, C. A. D. M.; Kumar, L., Van De Koppel, J., De Ridder, N., Van Andel, J., Skidmore, A. K., Hearne, J.W., Stroosnijder, L., Bond, W. J., Prins, H. H. T. \& Rietkerk, M., 2003. Effects of fire and herbivory on the stability of savanna ecosystems. Ecology, 84: 337-350.

Wakeling, J. L.; Cramer, M. D. \& Bond, W. J., 2012. The savanna-grassland 'treeline': why don't savanna trees occur in upland grasslands? Journal of Ecology, 100: 381-391.

Walker, B. H.; Ludwig, D.; Holling, C. S. \& Peterman, R. M., 1981. Stability of semi-arid savanna grazing systems. Journal of Ecology, 69: 473-498.

Walter, H., 1971. Ecology of tropical and subtropical vegetation. Oliver and Boyd, Edinburgh.

Williams, D. G. \& Baruch, Z., 2000. African grass invasion in the Americas: ecosystem consequences and the role of ecophysiology. Biological Invasions, 2: 123-140.

Williamson, M. H. \& Fitter, A., 1996. The characters of successful invaders. Biological conservation, 78: 163-170.

Wilson, J. B., 1988. Shoot competition and root competition. Journal of Applied Ecology, 25: 279 296.

Zupo, T. M., 2010. Invasão, competição e uso de recursos por uma gramínea nativa e uma gramínea invasora do cerrado. Dissertação de Mestrado, Departamento de Ecologia, Universidade de São Paulo, São Paulo/SP, 75p. 


\section{Capítulo II}

Efeitos do sombreamento, irrigação e adição de nutrientes na rebrota das

gramíneas Paspalum atratum (Swallen) e Urochloa brizantha (Hochst. ex A.

Rich.) Stapf.

Giovanna M. C. L. Caramaschi ${ }^{1}$, Eduardo R. M. Barbosa ${ }^{2}$, Dulce A. da Silva ${ }^{3}$, Violeta B. Braga ${ }^{4}$, Fabian Borghetti ${ }^{5,6}$

1. Departamento de Botânica, Universidade de Brasília, Brasília/Distrito Federal, Brazil

2. Resource Ecology Group, Wageningen University, The Netherlands

3. Embrapa Recursos Genéticos - Cenargen, Brasília/Distrito Federal, Brazil

4. Universidade Paulista - UNIP, Brasília/Distrito Federal, Brazil

5. Departamento de Botânica, Universidade de Brasília, Brasília/Distrito Federal, Brazil

6. Corresponding author: fborghett@unb.br; +5561-3107-1865

Artigo submetido ao periódico "Brazilian Journal of Botany” em novembro de 2014. 


\title{
Resumo
}

A competição por recursos é considerada um fator chave no processo regulatório da dinâmica da comunidade vegetal, sendo que plantas invasoras, em função de suas características morfo-fisiológicas e de sua plasticidade e tolerância à diferentes ambientes, normalmente beneficiam-se mais da aquisição dos recursos que as nativas. Distúrbios, como fogo e herbivoria, que promovem modificações na comunidade vegetal, frequentemente favorecem as invasões. $\mathrm{O}$ objetivo deste trabalho foi testar a adição de recursos como água e nutrientes, bem como a influência do sombreamento, na taxa de crescimento de gramíneas, após a simulação de distúrbio, buscando verificar diferenças no potencial competitivo de uma gramínea nativa do cerrado (Paspalum atratum) e de uma exótica (Urochloa brizantha). As espécies de gramíneas foram plantadas separadamente em um fatorial incompleto dos tratamentos: luz natural/sombreamento 80\%; adição ou não de nutriente inorgânico e irrigação artificial presente ou ausente. A biomassa aérea foi determinada ao longo do tempo e a taxa de crescimento absoluta calculada. Durante a rebrota, a gramínea exótica sempre apresentou maior biomassa aérea que a nativa. Urochloa brizantha também foi capaz de se beneficiar mais da adição de água e nutrientes ao solo que Paspalum atratum, sustentando seu crescimento até o fim da estação de crescimento. Também se mostrou mais tolerante ao sombreamento, apresentando crescimento mais uniforme ao longo da estação chuvosa. Desta forma, mesmo ao comparar a gramínea exótica com uma nativa que apresenta características morfo-fisiológicas similares, Urochloa brizantha ainda apresenta uma vantagem competitiva frente à gramínea nativa e um grande potencial de invasão.

Palavras chave: Cerrado; gramínea; invasão biológica; Paspalum atratum; savana; Urochloa brizantha

\begin{abstract}
The resource competition is considered a key regulatory process on plant community dynamics, and invasive plants, according to their morphological and physiological characteristics and its plasticity and tolerance to different environments, typically benefit more from the acquisition of resources that native ones. Disturbances, such as fire and herbivory, which promote changes in the plant community, often favor invasions. The objective of this study was to test the addition of resources, like water and nutrients, as well as the influence of shading, on the growth rate of grasses, after simulating a disturbance, in order to verify differences in the competitive hability of a native cerrado grass (Paspalum atratum) and an exotic (Urochloa brizantha). Grass species were planted separately in an incomplete factorial treatments: natural light / $80 \%$ shaded; with or without inorganic nutrients added and artificial irrigation present or absent. The biomass was determined over time and the absolute growth rate was calculated. During regrowth, the exotic grass has always been greater biomass than the native. Urochloa brizantha was also able to benefit more from the addition of water and nutrients to soil than Paspalum atratum, sustaining its growth until the end of the growing season. It was also more tolerant to shade, growing until the end of the rainy season. Thus, even when comparing the exotic with a morpho-physiological similar native grass, Urochloa brizantha still has a competitive advantage over the native grass and a great potential for invasion.
\end{abstract}

Key-words: biological invasion; Cerrado; grass; Paspalum atratum; savanna; Urochloa brizantha 


\section{Introdução}

Invasões por plantas exóticas representam uma das grandes ameaças à biodiversidade mundial (Vitousek et al. 1996). Plantas invasoras são conhecidas por promover modificações na composição florística e no funcionamento do ecossistema (Levine et al. 2003; Seabloom et al. 2003; Hedja et al. 2009; Giorgia et al. 2014), promovendo diferentes impactos nos meios biótico e abiótico (Vilà et al. 2011; Pysek et al. 2012; Giorgia e Osborbe 2014). O impacto de espécies invasoras em comunidades nativas pode ser manifestado de diversas formas, seja através da redução da riqueza e abundância da flora nativa, seja promovendo efeitos em relações como dispersão e polinização (Pysek et al. 2012).

Plantas invasoras possuem características morfo-fisiológicas que as confere vantagem na capacidade em adquirir recursos comparado às plantas nativas ou espécies não invasoras (Rejmanek 1996; Rejmanek 2000; Daehler 2003; Levine et al. 2003; Vilà et al. 2003; Vilà e Weiner 2004; Davidson et al. 2011; Funk 2013). Visto que a competição por recursos tem sido considerada como um fator chave no processo regulatório da dinâmica da comunidade vegetal (Grime 1977; Tilman 1982), esta capacidade é vista como determinante do sucesso de espécies exóticas, no caso das invasões biológicas (Levine et al. 2003; Vilà e Weiner 2004; Giorgia e Osborbe 2014). Plantas invasoras normalmente beneficiam-se mais da aquisição dos recursos naturais, levando a um crescimento destas em relação às nativas quando sujeitas a condições semelhantes (Daehler 2003; Davidson et al. 2011; Funk 2013).

A identificação de um conjunto de características associadas às plantas invasoras é difícil, já que existe uma relação entre a espécie e o ambiente invadido, principalmente a disponibilidade de nutrientes (Alpert et al. 2000; Daehler 2003; Tecco et al. 2010). Dentre as características frequentemente associadas às plantas invasoras, que podem torná-las melhores competidoras que as nativas, pode-se citar: altas taxas de crescimento, alta taxa fotossintética, ciclo reprodutivo rápido, intensa produção de sementes, alta eficiência no uso de nutrientes, tolerância ao desfolhamento, ao sombreamento e à herbivoria, alta capacidade de rebrota (D’Antonio e Vitousek 1992; Rejmanek e Richardson 1996; Williamson e Fitter 1996; Everett 2000; Foxcroft et al. 2010).

Além das características biológicas de cada espécie, o sucesso no estabelecimento e multiplicação de uma espécie não-nativa em uma comunidade vegetal tem sido associado a vários fatores ambientais, muitos inclusive ligados à atividade humana, como o revolvimento ou a fertilização do solo e a disponibilidade de água, o sombreamento, a eliminação de espécies indesejáveis, mudanças climáticas e distúrbios ambientais (Alpert et al. 2000; Dias-Filho 2000; Myers e Bazely 2003; Lockwod et al. 2007; Matos e Pivello 2009; Funk 2013).

Estudos sugerem que a fertilização do solo geralmente traz mais benefícios às espécies invasoras que às nativas (Daehler 2003; Lowe et al. 2003; Leishman e Thomson 2005; Abraham et al. 2009; Sharma et al. 2010). De acordo com Davis et al. (2000) e Davidson et al. (2011), espécies invasoras também possuem maior plasticidade na resposta à disponibilidade de nutrientes no solo que espécies não invasoras, seja na manutenção do crescimento com o aumento ou com a diminuição dos recursos ou em ambos os casos. Além disto, a dominância por espécies exóticas também pode ser conseguida através de sua habilidade em tolerar ambientes com baixa disponibilidade de recursos (Tilman 1982; Goldberg 1996; Craine et al. 2005; Funk 2013).

A competição por luz também é considerada um dos grandes determinantes do sucesso do estabelecimento de espécies invasoras. Muitas espécies invasoras, através de uma inerente habilidade em capturar mais luz, produzem mais biomassa, promovendo o sombreamento das nativas e uma consequente competição ainda maior (Hobbs e Mooney 1986). Segundo Dias-Filho (2000), diversas espécies exóticas são capazes de ajustar suas características morfofisiológicas em resposta à ambientes com baixa intensidade luminosa, o que seria determinante no seu potencial de invasão. 
A vulnerabilidade às invasões e o potencial de cada ambiente ser invadido depende de diversos fatores ainda não totalmente elucidados (Giorgia e Osborne 2014), e apenas alguns ecossistemas são alvo frequente de invasão por espécies exóticas (Vitousek et al. 1997). Estudos sugerem que ambientes pobres em recursos ou com pouco estresse abiótico, em geral, seriam os menos afetados pelas invasões (Daehler 2003; Funk e Vitousek 2007; Stohlgren et al. 2008; Moles et al. 2012; Funk 2013), visto que as espécies nativas, selecionadas para aquele ambiente ao longo da evolução, deveriam possuir uma vantagem competitiva frente às exóticas que não tiveram a oportunidade de crescer naquele ambiente (Alpert et al. 2000; Daehler 2003).

No entanto, o conjunto de características de muitas espécies invasoras as tem permitido invadir diversos ecossistemas inesperados (Giorgia e Osborne 2014), como solos vulcânicos, dunas, campos graminosos e regiões áridas (Funk e Vitousek 2007; Han et al. 2012). De fato, estudos revelam que ambientes pobres em recursos, como as savanas, tem sido frequentemente invadidos por espécies exóticas (Fowler 1986; Funk e Vitousek 2007; Funk 2013). Enquanto as savanas tropicais e subtropicais da África, Australia e de algumas ilhas do Pacifico são frequentemente invadidas por espécies de arbustos, principalmente Cactaceae (Foxcroft et al. 2010), as savanas tropicais da América do Sul e da Australia são principalmente invadidas por gramíneas africanas $\mathrm{C}_{4}$ (William e Baruch 2000; Rossiter et al. 2003; Rejmánek et al. 2005; Durigan et al. 2007; Foxcroft et al. 2010).

As savanas são caracterizadas por um mosaico de combinações entre espécies arbóreas e herbáceas, especialmente gramíneas, sendo esta complexa interação determinada pela disponibilidade de recursos (água e nutrientes) e a freqüência e/ou intensidade dos distúrbios, como fogo e herbivoria (Sankaran et al. 2004). Em savanas, os distúrbios, como fogo e herbivoria, são fatores chaves na determinação da estrutura da vegetação (Scholes e Archer 1997; Higgins et al. 2000) e, como a invasão biológica nestes ambientes intimamente associada aos distúrbios ambientais (naturais ou não), (Seabloom et al. 2003; Williams e Baruch 2000; Myers e Bazely 2003; Lockwod et al. 2007; Foxcroft et al. 2010; Masocha et al. 2010), a interação destes fatores irá determinar o sucesso de uma espécie invasora na savana (Scholes e Archer 1997; Higgins et al. 2000). Desta forma, as savanas, frequentemente sujeita às queimadas ou à herbivoria, são grande alvo de invasões. Em muitos casos, o homem é responsável por alterar a frequência e/ou intensidade dos distúrbios, seja através das queimadas induzidas ou da introdução de espécies exóticas (Hoffmann 1999; Kraaij e Ward 2006; Laris 2011).

Por ser um bioma que apresenta solos considerados pobres em nutrientes minerais necessários para o crescimento vegetal (Motta et al. 2002; Reatto et al. 2008), principalmente fósforo, cálcio e muitos micronutrientes (Motta et al. 2002), o Cerrado apresenta uma boa opção para o estudo dos efeitos de plantas invasoras no equilibrio das comunidades vegetais de savanas. Gramíneas africanas são as principais plantas a invadir o Cerrado, como Melinis minutiflora (capim-gordura), Hyparrhenia rufa (capim-jaraguá), Megathyrsus maximus (capim-colonião), Urochloa spp. (braquiárias) e Andropogum gayanus (Klink e Joly 1989; Pivello et al. 1999a e b; Matos e Pivello 2009; Horowitz et al. 2013).

Apesar de alguns estudos sugerirem que, em ambientes pobres em nutrientes, as espécies nativas deveriam possuir uma vantagem competitiva frente às exóticas (Alpert et al. 2000; Daehler 2003), outros autores associam as espécies invasoras a uma maior plasticidade na resposta à disponibilidade de nutrientes no solo (Davis et al. 2000; Davidson et al. 2011) e à sua habilidade em tolerar ambientes com poucos recursos (Tilman 1982; Goldberg 1996; Craine et al. 2005; Funk 2013). Desta forma, ainda é incerta a real interferência dos nutrientes na rebrota e no crescimento de gramíneas nativas e exóticas. Assim, experimentos incluindo tratamento com fertilização contribuiriam para entender até quanto a deficiência de nutrientes no solo poderia interferir na rebrota de nativa, e se a espécie exótica tem melhor desempenho sob condições de baixa e alta fertilidade do solo. 
Devido às características destas gramíneas exóticas que, em geral, possuem maiores taxas de germinação e de crescimento que as nativas, estas tem o seu potencial competitivo aumentado quando comparados com gramíneas nativas (Rossiter et al. 2003; Han et al. 2012). As gramíneas invasoras também possuem características que as faz conquistar mais espaços que as gramíneas nativas após as queimadas (D’Antonio e Vitousek 1992; Pivello et al. 1999a; Foxcroft et al. 2010). Gramíneas africanas também demostraram ter uma maior eficiência fotossintética e um uso mais eficiente da água e nutrientes (D'Antonio e Vitousek 1992; Firn et al. 2012).

A espécies de braquiária representam as mais comuns e mais agressivas gramíneas exóticas encontradas nas áreas do Cerrado (Almeida Neto et al. 2010; Lannes et al. 2012), sendo que somente no Brasil, já existem 50 milhões de hectares de pastos constituídos por braquiária (Macedo 2005). Podem diminuir drasticamente a abundância de gramíneas nativas (Pivello 1999a) e de Asteraceae (Almeida-Neto et al. 2010) e dominar a comunidade herbácea (Almeida-Neto et al. 2010; Gorgone-Barbosa et al. 2014).

Savanas com domínio de gramíneas $\mathrm{C}_{4}$, como o Cerrado (Klink e Joly 1989), são os ecossistemas com maior frequiência de queimadas do mundo, com incêndios ocorrendo a cada dois ou três anos e algumas vezes até duas vezes por ano (Hoffmann et al. 2002). Além do impacto em toda a cobertura vegetal e na abertura de clareiras na vegetação, as queimadas geram "inputs" temporários de nutrientes do solo (Miranda et al. 2002; Pivello et al. 2010), que poderiam favorecer o aparecimento ou o estabelecimento das invasoras em detrimento das nativas (Daehler 2003; Lowe et al. 2003; Leishman e Thomson 2005; Abraham et al. 2009; Sharma et al. 2010).

De fato, existem evidências de que gramíneas exóticas estão substituindo as gramíneas nativas e invadindo as savanas (Brooks et al. 2010). No Cerrado, Pivello et al. (1999b) observaram a influência negativa de duas espécies de gramíneas exóticas, Melinis minutiflora e Brachiaria decumbens, na abundância da maioria das gramíneas nativas. A presença da gramínea Melinis minutiflora também foi negativamente associada a um declínio na densidade de plântulas de lenhosas (Hoffman et al. 2004), além da abundância de espécies herbáceas de savanas (Pivello et al. 1999a).

O Cerrado é submetido a secas regulares anuais, associadas a altas temperaturas, baixa umidade relativa do ar e grande irradiação solar (Franco et al. 2008). Mesmo durante a estação chuvosa, períodos de duas ou mais semanas sem chuva são comuns, denominados veranicos (Assad e Evangelista 1994). Apesar de frequentes no Cerrado, pouco se sabe a respeito do impacto dos veranicos nas espécies vegetais, principalmente se eles influenciam na rebrota e no estabelecimento de gramíneas invasoras em detrimento das nativas.

$\mathrm{O}$ fato de muitas plantas invasoras apresentarem maior plasticidade nas respostas, além de sua capacidade em tolerar ambientes com baixa disponibilidade de recursos, como água (Levine et al. 2003; Vilà e Weiner 2004; Funk 2013; Giorgia e Osborbe 2014), poderia favorecer o surgimento de espécies invasoras na região. Em particular, a alta produtividade de gramíneas africanas $\mathrm{C}_{4}$ é frequentemente associada a sua alta tolerância a seca, altas temperaturas e sua habilidade de crescer em solos ácidos e pobres em nutrientes (D’Antonio e Vitousek 1992).

Apesar de muitas espécies invasoras serem consideradas tolerantes ao sombreamento (Hobbs e Mooney 1986; Riginos 2009; Foxcroft et al. 2010; Dohn et al. 2013; Funk 2013), faltam estudos comparativos sobre a rebrota de gramíneas nativas e exóticas sombreadas. A influência do sombreamento é frequentemente comparada entre plantas com diferentes ciclos de vida (anuais e perenes) ou de diferentes formas de vida (árvores e herbáceas).

Compreender o comportamento de gramíneas exóticas e nativas crescendo sob condições experimentais similares possui uma extrema importância para permitir o estabelecimento de um esquema de controle do crescimento e disseminação de espécies invasoras (Mangla et al. 2011; Giorgia e Osborne 2014). Também é interessante comparar as taxas de crescimento de gramíneas nativas e exóticas e a influência de distúrbios no seu desenvolvimento (Seabloom et al. 2003), já que as savanas tem sofrido o impacto de diversas mudanças ambientais, como o aumento da intensidade e/ou freqüência de distúrbios (queimadas e herbivoria), aumento populacional, substituição da vegetação por pastagens, 
mudanças climáticas (por exemplo, redução pluviométrica em algumas regiões e aumento em outras) (Hoffmann 1996; Solbrig et al. 1996; Hoffmann e Jackson 2000; Klink e Machado 2005; Saha e Howe 2006).

Estudos mostram que as vantagens competitivas das plantas invasoras frente às nativas são especialmente importantes durante as fases iniciais do crescimento ou no início do processo de invasão (Corbin e D'Antonio 2004; Sala et al. 2007; Mangla et al. 2011). Desta forma, este estudo visa verificar diferenças no potencial competitivo entre espécies graníneas de estrutura morfológica e funcional semelhantes, já estabelecidas, mas após a simulação de uma queimada ou intenso pastoreio. O objetivo principal deste trabalho foi avaliar a influência da adição de água e nutrientes ao solo, tanto sob condições de pleno sol, como sombreadas na produção de biomassa de uma gramínea nativa do cerrado (Paspalum atratum Swallen) e de uma gramínea exótica (Urochloa brizantha).

Em função das características gerais de espécies invasoras, é esperado que a gramínea exótica (Urochloa brizantha) tenha um crescimento superior que a gramínea nativa Paspalum atratum. A gramínea exótica também deve ter um incremento no crescimento superior ao da gramínea nativa, quando da adição de recursos, como nutrientes e água ao solo. Em função da maior plasticidade associada às espécies invasoras, espera-se que o sombreamento promova menor impacto no crescimento da gramínea exótica em comparação à nativa.

\section{Material e Métodos}

\section{Local de estudo}

O presente estudo foi realizado em casas de vegetação construídas em área próxima ao laboratório de

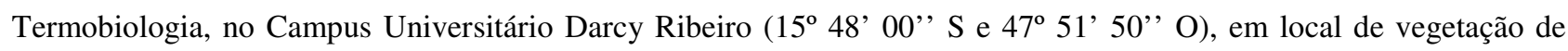
campo sujo, que é um tipo fisionômico herbáceo-arbustivo do Cerrado (Sano et al. 1998). Com o auxílio de um trator, toda a vegetação nativa foi removida para o estabelecimento das parcelas experimentais.

O clima no Cerrado é classificado como tropical (Koppen Aw), caracterizado por duas estações, uma seca e outra chuvosa (Eiten 1972). A temperatura média anual varia entre 18 to $28^{\circ} \mathrm{C}$ e a precipitação média entre 800 e 2000 mm anuais, sendo que as chuvas ocorrem principalmente entre os meses de outubro a abril (Dias 1992). Os solos característicos da região são distróficos, profundos, bem drenados, pobres em nutrientes, ácidos e com alto teor de alumínio (Motta et al. 2002).

\section{Preparo das parcelas e plantio das gramíneas}

Sementes da gramínea nativa (Paspalum atratum Swallen) (G1) e da gramínea exótica (Urochloa brizantha (Hochst. ex A. Rich.) foram semeadas separadamente em parcelas de $4 \mathrm{~m}^{2}$ nos diferentes tratamentos e ficaram se estabelecendo por um período de 15 meses (entre novembro de 2009 e fevereiro de 2011), antes da coleta dos dados.

Para o estabelecimento inicial das gramíneas, foram utilizadas aproximadamente 50 gramas de sementes por parcela, sendo estas irrigadas frequentemente. Em alguns casos, novas sementes foram acrescidas com o objetivo de formar uma cobertura graminosa o mais uniforme possível ao longo da parcela, visto que algumas sementes eram predadas por pássaros e formigas.

As gramíneas selecionadas possuem metabolismo $C_{4}$ (Klink e Joly 1989), são adaptadas a ambientes de pleno sol e possuem crescimento vigoroso e alta capacidade de rebrota (Miles et al. 1996; Karia e Andrade 2001; Leite et al. 2001; Andrade et al. 2004; Maciel et al. 2009; Manzano et al. 2010). Ambas são utilizadas como forrageiras, em função de sua alta produtividade e de suas características morfológicas (Dias-Filho 2000; Dias-Filho 2002; Maciel et al. 2009). São espécies perenes, com rizomas longos e se desenvolvem formando grandes touceiras (Miles et al. 1996; Maciel et al. 2009). 


\section{Delineamento experimental e tratamentos}

As espécies de gramíneas foram independentemente submetidas a seis tratamentos, sendo que em metade deles, houve a adição de fertilizantes inorgânicos (N1) e no restante não (N0): 1) casa de vegetação com sombrite (80\% de sombreamento) e plástico transparente para exclusão de chuva (W1, L1);2) casa de vegetação coberta somente com plástico transparente (W0, L1); 3)casa de vegetação sem nenhuma cobertura (W0, L0). Foram feitas cinco repetições por tratamento.

As parcelas cobertas foram mantidas sob irrigação artificial (W1), sendo irrigadas duas vezes ao dia, ao longo de seis meses durante a estação chuvosa. O volume de água adicionado foi de $37,5 \mathrm{~L} / \mathrm{m}^{2}(37,5 \mathrm{~mm})$ a cada semana. $\mathrm{O}$ período de irrigação foi de outubro de 2011 a abril de 2012 .O volume de água foi estabelecido com base na precipitação média, durante a estação chuvosa, para a região dos Cerrados (900 mm por ano).

A adição do o fertilizante inorgânico "Osmocote ${ }^{\circledR}$ 15:9:12" teve o objetivo de avaliar a influência da adição de nutrientes no crescimento das gramíneas. Este fertilizante foi adicionado mensalmente, totalizando 4 aplicações por ano, durante os meses abril a julho de 2011. A quantidade de fertilizante aplicada foi de 26,7 gramas por $\mathrm{m}^{2}$ por aplicação (3:1:2 NPK). Esta quantidade foi determinada com base na adição de 4 gramas de N.m ${ }^{-2}$ por aplicação, vista com uma alta concentração de nitrogênio em diversos estudos (Tilman 1987; Walker e Knoop 1987; Kraaij e Ward 2006; Tomlinson et al. 2012; Vadigi e Ward 2014).

Com o objetivo de simular um distúrbio, como a passagem do fogo, e tentar uniformizar a biomassa aérea inicial das gramíneas, para o início do experimento, em fevereiro de 2011, todas elas tiveram cortadas suas partes aéreas a dois centímetros do solo

Para avaliar o crescimento das gramíneas submetidas aos diferentes tratamentos ao longo do tempo, foram realizadas coletas das partes aéreas das gramíneas aos 3 meses (início da estação seca), 8 meses (fim da estação seca e início da chuvosa), 10, 12 e 14 meses (fim da estação chuvosa), após o início do experimento.

Para que o corte anterior não interferisse na medida seguinte, as parcelas foram subdivididas em 32 subparcelas de $0,125 \mathrm{~m}^{2}$, e os cortes de gramíneas eram sempre feitos em partes diferentes, evitando-se aquelas cortadas anteriormente. Após o corte, as partes aéreas foram secas em estufa a $70^{\circ} \mathrm{C}$ por 48 horas antes da pesagem final, para quantificação da biomassa seca total da parte aérea.

\section{Análise dos resultados}

Para a análise dos resultados, a biomassa aérea total e a taxa de crescimento absoluta foram calculadas. A taxa de crescimento absoluta foi calculada segundo a fórmula abaixo (Tomlinson et al. 2012; adaptado de Hoffmann e Poorter 2002):

$$
\mathrm{TCA}=\frac{\mathrm{M} 2-\mathrm{M} 1}{\mathrm{~T} 2-\mathrm{T} 1}
$$

Sendo,

$\mathrm{TCA}=$ taxa de crescimento absoluta,

M2= massa seca no tempo 2 (T2)

e M1= massa seca no tempo 1 (T1).

Os dados foram analisados usando modelos lineares mistos, sendo a variável dependente, taxa de crescimento absoluto, as variáveis randômicas (casa de vegetação e parcelas) e as variáveis independentes, espécies (G1 e G2), irrigação (W0 e W1) ou luz (L0 e L1), adição de nutrientes (N0 e N1) e tempo (T - meses dentro da estação de crescimento). O pacote estatístico utilizado nas análises foi o SPSS. 
Em função do experimento não ser um delineamento fatorial completo, foi necessário analisar estatísticamente as variáveis de maneira independente, ou seja, tratamentos com e sem sombreamento ou tratamentos com e sem irrigação, já que não havia um tratamento sombreado sem irrigação.

Como o período chuvoso do ano 2011 se iniciou em outubro e terminou em abril, tendo duração de 6 meses, a variável "tempo" foi dividida em três partes, dentro da estação de crescimento (estação chuvosa), a cada dois meses: início, meio e fim. O "início" foi representado pela taxa de crescimento absoluto entre os meses de outubro e dezembro de 2011; o "meio" pela taxa de crescimento absoluto entre os meses dezembro de 2011 e fevereiro de 2012; e o "fim" entre os meses de fevereiro e abril de 2012.

Amostras do solo nu e das parcelas onde haviam crescido as gramíneas Urochloa brizantha e Paspalum atratum foram levadas ao laboratório para análise. Análises físico-químicas e de macro e micronutrientes presentes no solo foram realizadas.

Amostras das folhas das gramíneas nativa e exótica também foram coletadas, após o término do experimento. Macro e micronutrientes foram analisados.

\section{Resultados e Discussão}

\section{Análise do solo}

A análise do solo da região revelou a presença de um solo franco-argilo-arenoso, ácido ( $\mathrm{pH}$ entre 4,5 e 4,8), com baixa disponibilidade de nutrientes e presença de alumínio, com baixo teor de silte (em torno de $16 \%$ ) e teor de argila que varia entre 23 e $30 \%$ (Tabela 1). Aparentemente, este tipo de solo representa o tipo mais comum existente no Cerrado, o latossolo, que corresponde a cerca de 49\% dos solos encontrados no bioma (Reatto et al. 2008).

Por apresentar boa estabilidade, latossolos tendem a ter boas características físicas mas são considerados pobres quimicamente para o crescimento vegetal (Motta et al. 2002). Possuem agregados argilosos com alto conteúdo de matéria orgânica e óxidos de ferro e alumínio, permitindo a entrada de ar e água, além de não oferecer grandes resistências ao crescimento das raízes (Motta et al. 2002). Latossolos são pobres em nutrientes (Motta et al. 2002; Reatto et al. 2008), principalmente fósforo, cálcio e muitos micronutrientes (Motta et al. 2002).

De acordo com uma revisão feita por Funk (2013), solos com concentrações de potássio inferiores a 1 mg.g $\mathrm{g}^{-1} \mathrm{e}$ de nitrogênio menores que $13 \mathrm{mg} \cdot \mathrm{g}^{-1}$ são considerados solos muito pobres em nutrientes e podem ser limitantes ao crescimento vegetal.

Tabela 1. Análises físico-químicas dos solos da área experimental: solo nu e solo no qual cresceram as gramíneas Paspalum atratum e Urochloa brizantha. Experimento conduzido em área experimental da Universidade de Brasília, entre maio de 2011 e abril de 2012.

\begin{tabular}{lccc}
\hline & Solo nú & Paspalum atratum & Urochloa brizantha \\
\hline Silte: Argila: Areia (\%) & $16: 23: 61$ & $17: 30: 53$ & $16: 23: 61$ \\
Classificação do solo & $\begin{array}{c}\text { Franco-argiloso- } \\
\text { arenoso }\end{array}$ & $\begin{array}{c}\text { Franco-argiloso- } \\
\text { arenoso }\end{array}$ & $\begin{array}{c}\text { Franco-argiloso- } \\
\text { arenoso }\end{array}$ \\
pH em água & 4,7 & 4,5 & 4,8 \\
Matéria Orgânica (dag/Kg) & 2,4 & 3,2 & 2,5 \\
P (mg/dm & 0,5 & 0,5 & 0,6
\end{tabular}




\begin{tabular}{lccc}
\hline & Solo nú & Paspalum atratum & Urochloa brizantha \\
\hline $\mathrm{K}\left(\mathrm{mg} / \mathrm{dm}^{3}\right)$ & 22 & 32,6 & 37,2 \\
$\mathrm{~S}\left(\mathrm{mg} / \mathrm{dm}^{3}\right)$ & 7,5 & 2,6 & 6,8 \\
$\mathrm{Ca}\left(\mathrm{cmolc} / \mathrm{dm}^{3}\right)$ & 0,2 & 0,4 & 0,3 \\
$\mathrm{Mg}\left(\mathrm{cmolc} / \mathrm{dm}^{3}\right)$ & 0,1 & 0,1 & 0,1 \\
$\mathrm{Al}\left(\mathrm{cmolc} / \mathrm{dm}^{3}\right)$ & 0,2 & 0,3 & 0,2 \\
$\mathrm{CTC}$ total $\left(\mathrm{cmolc}^{3} \mathrm{dm}^{3}\right)$ & 4,0 & 5,7 & 3,8 \\
$\mathrm{~B}\left(\mathrm{mg} / \mathrm{dm}^{3}\right)$ & 0,1 & 0,1 & 0,1 \\
$\mathrm{Zn}\left(\mathrm{mg} / \mathrm{dm}^{3}\right)$ & 1,5 & 0,9 & 1,6 \\
$\mathrm{Fe}\left(\mathrm{mg} / \mathrm{dm}^{3}\right)$ & 55,5 & 83 & 93,2 \\
$\mathrm{Mn}\left(\mathrm{mg} / \mathrm{dm}^{3}\right)$ & 41,7 & 16,9 & 65 \\
$\mathrm{Cu}\left(\mathrm{mg} / \mathrm{dm}^{3}\right)$ & 1,1 & 1,1 & 1,3 \\
\hline
\end{tabular}

\section{Análise geral do crescimento das gramíneas}

Durante a estação seca (entre maio e outubro de 2011), não foi possível observar diferenças significativas no incremento de biomassa produzida pelas gramíneas crescendo sob os diversos tratamentos (Figura 1). Embora a diferença estatística não tenha sido observada ao analisar o incremento em biomassa ao longo da estação seca, foi possível verificar que a gramínea exótica sempre apresentou biomassa aérea maior que a nativa, independente da estação (Figura 1). Oliveiras et al. (2013) também observaram maiores taxas de biomassa nas gramíneas crescendo sob diferentes regimes de queima, durante a estação chuvosa em comparação à estação seca, resultante do aumento da disponibilidade de nutrientes do solo.

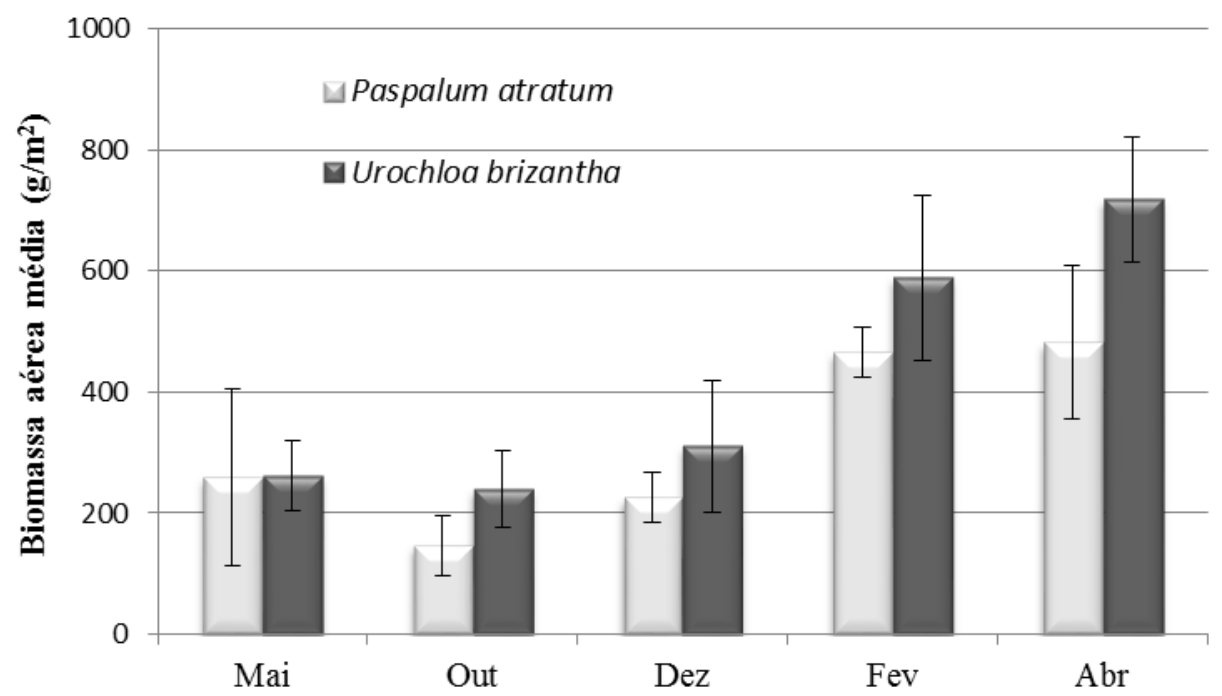

Fig 1 Biomassa média $\left(\mathrm{g} / \mathrm{m}^{2}\right)$ das gramíneas Paspalum atratum e Urochloa brizantha produzida durante as estações seca (maio a outubro) e chuvosa (outubro a abril). Experimento conduzido na Universidade de Brasília, entre maio de 2011 e abril de 2012. Barras de erros indicam o intervalo de confiançada amostra. ( $\square=$ Paspalum atratum; $\square=$ Urochloa brizantha) 
Diversos estudos sugerem que gramíneas exóticas apresentam maiores taxas de crescimento quando comparadas às gramíneas nativas (D’Antonio e Vitousek 1992; Pivello et al. 1999a; Rossiter et al. 2003; Foxcroft et al. 2010; Han et al. 2012). As gramíneas invasoras demostraram ter uma maior eficiência fotossintética e um uso mais eficiente da água e nutrientes que as gramíneas nativas (D'Antonio e Vitousek 1992; Foxcroft et al. 2010; Firn et al. 2012). Nernberg e Dale (1997) mostraram que, mesmo sob stress hídrico, a gramínea exótica Bromus inermis teve maior habilidade competitiva que cinco espécies de gramíneas nativas.

Ao analisar o crescimento das gramíneas ao longo da estação de crescimento, foi possível observar que o fator tempo influenciou a produção de biomassa $\left(\mathrm{p}<0.0001, \mathrm{~F}_{162.959}=8.850\right)$, ou seja, ao dividir a estação de crescimento, que durou 6 meses, em períodos de dois meses cada (início, meio e fim), foi possível verificar que ambas as gramíneas não tem um crescimento uniforme ao longo da estação (Figura 2).

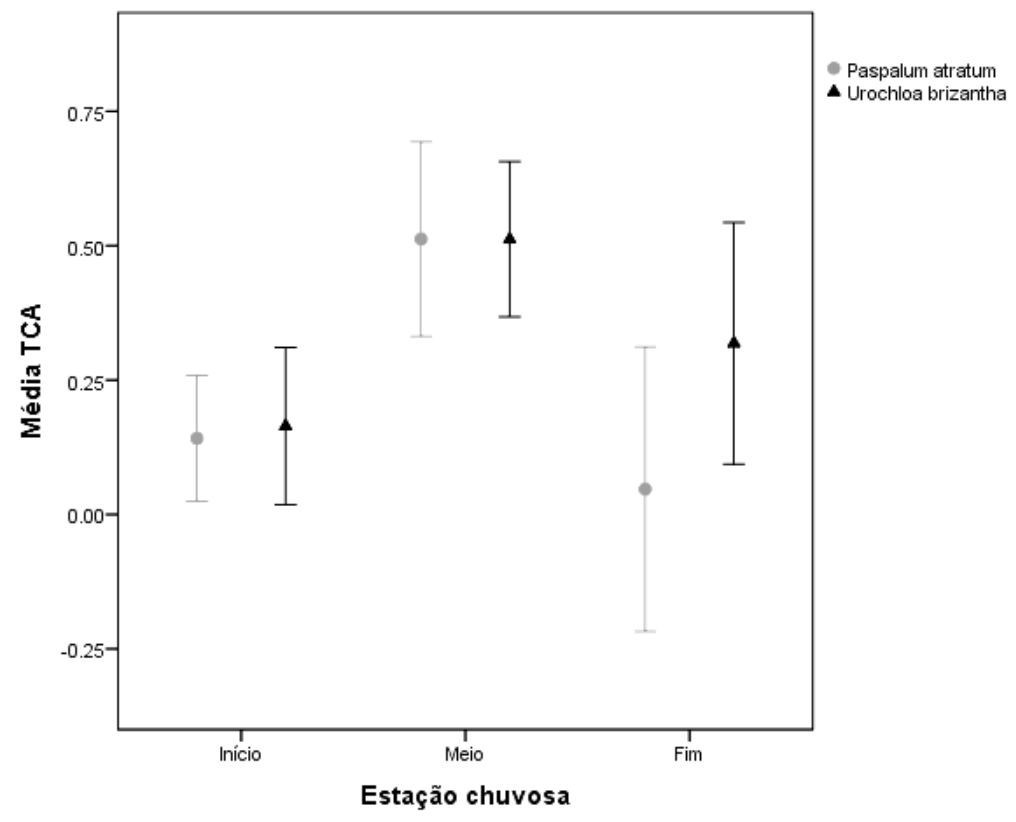

Fig 2 Média das taxas de crescimento absoluto (TCA) das gramíneas Paspalum atratum e Urochloa brizantha, ao longo da estação de crescimento (início - entre os meses de outubro e dezembro de 2011; meio - entre os meses dezembro de 2011 e fevereiro de 2012; fim - entre os meses de fevereiro e abril de 2012). Barras de erros indicam intervalo de confiança de $95 \%$. (apenas tratamentos sem sombreamento foram considerados nesta análise). $\left({ }^{\circ}=\right.$ Paspalum atratum; $\mathbf{\Delta}=$ Urochloa brizantha)

Tanto a gramínea nativa como a gramínea exótica tiveram um leve aumento na produção de biomassa com o início das chuvas seguida por um pico de produção de biomassa concentrada no meio da estação chuvosa (Figura 2). No final da estação chuvosa, houve um decréscimo na produção de biomassa (Figura 2). A menor produção de biomassa no final do período de crescimento foi mais pronunciado na gramínea nativa (Paspalum atratum) do que na gramínea exótica (Urochloa brizantha) (Figura 2).

Desta forma, além da gramínea já apresentar uma biomassa inicial superior à gramínea nativa (Figura 1), ela inicia a rebrota, após a poda, com um crescimento semelhante ao da gramínea nativa mas, ao final da estação de crescimento, apresenta taxa de crescimento muito superior em relação ao Paspalum (Figura 2).

De acordo com Foster e Gross (1997) e Mangla et al. (2011), pequenas diferenças nos tamanhos iniciais e no crescimento, resultantes da competição por recursos, podem promover enormes efeitos nas interações competitivas futuras. De fato, estudos indicam que a competição durante as fases iniciais do crescimento serão determinantes na biomassa final da planta adulta (Goldberg et al. 2001). Estudos mostram, inclusive, que existem evidências de que as 
vantagens competitivas das gramíneas exóticas frente às nativas são principalmente importantes nas fases iniciais do processo de invasão (Claassen e Marler 1998; Corbin e D’Antonio 2004; Sala et al. 2007; Goldstein e Suding 2014).

O aumento da disponibilidade de recursos (água) não tem efeito imediato na taxa de crescimento das gramíneas. As gramíneas só respondem com incremento em biomassa, após os primeiros meses de adição de água ao solo (Figura 2).

Desta forma, inicialmente, com o aumento da disponibilidade de recursos, as gramíneas do presente estudo devem ter priorizado o desenvolvimento de raízes para somente depois investirem em parte aérea, o que poderia explicar a demora na resposta positiva de crescimento na estação chuvosa. Segundo Sarmiento (1992), uma das mais frequentes estratégias de gramíneas de savanas é a que ocorre em plantas com ausência de colmos. Elas apresentam maiores razões biomassa raiz/parte aérea e alocam seus recursos principalmente em órgãos subterrâneos, como rizomas, bases de folhas e raízes, o que lhes permite rápida rebrota e crescimento quando da disponibilidade de água.

Stenaiker et al. (2010) e Aires (2013), ao estudarem a alocação de biomassa em gramíneas, também observaram que existe uma diferença temporal na alocação dos recursos, na qual as plantas priorizam áreas diferentes ao investir em crescimento e otimizar a captação de recursos. Durante seu desenvolvimento, além das capacidades fotossintéticas e de adquirir recursos individuais, cada espécie pode priorizar a energia adquirida na construção de estruturas diferentes ao longo do tempo (Stenaiker et al. 2010).

Estudos mostram que espécies de lenhosas invasoras investem mais na biomassa de raízes que as espécies nativas, o que as auxilia a tolerar períodos de seca (Grotkopp e Rejmanek 2007). Han et al. (2012) também encontraram que as gramíneas exóticas apresentavam maior razão raiz/parte aérea que as nativas em diferentes situações de disponibilidade de água. De acordo com uma revisão realizada por Funk (2013), diversos estudos mostram que o aumento da razão biomassa de raiz/parte aérea resulta em uma maior capacidade em captar água por espécies invadindo ambientes áridos e semi-áridos.

Segundo DeFalco et al. (2003), a gramínea exótica Bromus madritensis, por apresentar maior biomassa radicular e maior área superficial de raízes, foi capaz de captar mais água e com maior rapidez que as gramíneas nativas. Isto também representaria uma vantagem na captação de nutrientes, como o nitrogênio (DeFalco et al. 2003).

Pivello et al. (2010), em solos de cerrado, encontraram que durante a estação chuvosa, os macro e os micronutrientes tornavam-se mais disponíveis que durante a seca, o que foi associado ao aumento da atividade da microbiota do solo durante a estação quente e chuvosa ou simplesmente ao aumento da humidade do solo. Desta forma, é possível também que, com início das chuvas, os nutrientes do solo tornaram-se disponíveis, foram absorvidos pelas gramíneas, tornaram-se componentes estruturais das plantas (constituintes de biomassa) e depois já não estavam mais disponíveis no solo. Desta forma, espécies com maior exigência nutricional poderiam ter seu crescimento limitado pela escassez de nutrientes.

Ao comparar a análise foliar de Urochloa brizantha e Paspalum atratum é fácil constatar uma menor exigência nutricional da gramínea exótica frente à nativa. Foi possível encontrar valores muito inferiores nos níveis de magnésio e dos micronutrientes, ferro e cobre nas folhas de Urochloa brizantha em comparação ao Paspalum atratum (Tabela 2). O solo característico do Cerrado, encontrado em nosso estudo, o latossolo (Tabela 1), apresenta teores baixos de micronutrientes (Reatto et al. 2008) e estes não foram adicionados, durante a fertilização. É possível que a gramínea nativa Paspalum atratum seja mais exigente por nutrientes e a falta destes também esteja limitando o crescimento desta gramínea.

Também foi possível verificar que a gramínea exótica Urochloa brizantha apresentou concentração foliar de nitrogênio levemente superior à encontrada na gramínea nativa (Tabela 2). Em função de Funk e Vitousek (2007) terem encontrado uma correlação positiva entre taxa fotossintética e nitrogênio foliar em espécies de gramíneas, é possível 
associar o crescimento superior da gramínea exótica à maior concentração de nitrogênio, bem como aos altos valores de PNUE associados às plantas invasoras (Sage e Pearcy 1987; Godoy et al. 2011; Firn et al. 2012).

Tabela 2. Análise foliar de Paspalum atratum e Urochloa brizantha, após a conclusão do experimento. Experimento conduzido em área experimental da Universidade de Brasília, entre maio de 2011 e abril de 2012.

\begin{tabular}{lcc}
\hline & Paspalum atratum & Urochloa brizantha \\
\hline $\mathrm{N}(\mathrm{g} / \mathrm{Kg})$ & 0,7 & 0,9 \\
$\mathrm{P}(\mathrm{g} / \mathrm{Kg})$ & 0,6 & 0,5 \\
$\mathrm{~K}(\mathrm{~g} / \mathrm{Kg})$ & 7,1 & 4,7 \\
$\mathrm{Ca}(\mathrm{g} / \mathrm{Kg})$ & 7,9 & 10 \\
$\mathrm{Mg}(\mathrm{g} / \mathrm{Kg})$ & 4,7 & 1,8 \\
$\mathrm{~S}(\mathrm{~g} / \mathrm{Kg})$ & 0,6 & 0,8 \\
$\mathrm{~B}(\mathrm{~g} / \mathrm{Kg})$ & 6 & 5 \\
$\mathrm{Zn}(\mathrm{g} / \mathrm{Kg})$ & 23 & 27 \\
$\mathrm{Fe}(\mathrm{g} / \mathrm{Kg})$ & 647 & 119 \\
$\mathrm{Mn}(\mathrm{g} / \mathrm{Kg})$ & 166 & 164 \\
$\mathrm{Cu}(\mathrm{g} / \mathrm{Kg})$ & 12 & 6 \\
\hline
\end{tabular}

O limiar de nutrientes no solo necessário para promover produção de biomassa mostrou-se diferente entre as espécies: sob condições naturais de nutrientes no solo, a espécie exótica continua a apresentar maior produção de biomassa, enquanto a espécie nativa praticamente reduz a zero sua produção de biomassa no final da estação de crescimento (Figura 2). Este fato representa uma vantagem competitiva da espécie exótica frente à espécie nativa, visto que ela continua a crescer enquanto a outra sofre uma parada no seu crescimento. A habilidade competitiva superior das espécies exóticas frente às nativas tem sido frequentemente associada à grande capacidade em adquirir e armazenar eficientemente os recursos (Tecco et al. 2010).

A longo prazo, este incremento em biomassa no final da estação de crescimento pode representar o aumento da taxa fotossintética e a possibilidade de um maior investimento em novos órgãos para captação de recursos, aumentando seu potencial competitivo. Mangla et al. (2011) sugerem a existência de um mecanismo de feedback positivo entre crescimento e captação de recursos, no qual as espécies de gramíneas invasoras, de crescimento rápido, conseguiriam capturar cada vez mais recursos à medida que fossem crescendo mais (Blank 2010). Isso representaria uma vantagem na ocupação de novas áreas, seja através da multiplicação vegetativa, da produção de sementes, ou mesmo, a partir da produção de órgãos subterrâneos de reserva que irão conferir a elas maior resistência ao fogo e um maior sucesso e rapidez na rebrota.

Efeito do sistema de irrigação e da adição de nutrientes no crescimento das gramíneas, durante a estação de crescimento:

Ao analisar apenas as plantas não sombreadas, o sistema de irrigação e a adição de nutrientes, isoladamente, não exerceram influência na biomassa das gramíneas ( $\mathrm{p}=0.230$ e $\mathrm{p}=0.866$, respectivamente). No entanto, mais uma vez, 
os intervalos de tempo dentro da estação de crescimento apresentaram um resultado significativo no crescimento das gramíneas $\left(\mathrm{p}<0.0001, \mathrm{~F}_{162.959}=8.850\right)($ Tabela 3$)$.

Em função dos baixos valores encontrados para "p", também foi possível identificar uma tendência das gramíneas apresentarem diferenças significativas entre as espécies nativa e exótica $(p=0,086)$, bem como uma interação entre os fatores água e tempo $(\mathrm{p}=0,058)$, espécies e tempo $(\mathrm{p}=0,082)$ e entre os fatores água, nutriente e tempo $(\mathrm{p}=0,095)$ (Tabela 3).

Tabela 3. Resultados estatísticos (modelo linear misto) (graus de liberdade, F, p) testando os efeitos de água, nutrientes, espécies e tempo na taxa de crescimento absoluta de Paspalum atratum e Urochloa brizantha

\begin{tabular}{|c|c|c|c|}
\hline & Graus de liberdade & Estatística F & $\mathrm{P}$ \\
\hline Intercepto & 5.321 & 30.423 & 0.002 \\
\hline Água (W) & 163.374 & 1.451 & 0.230 \\
\hline Nutrientes (N) & 163.252 & 0.028 & 0.866 \\
\hline Espécie (S) & 163.374 & 2.980 & 0.086 \\
\hline Tempo (T) & 162.959 & 8.580 & 0.000 \\
\hline $\mathrm{W} * \mathrm{~N}$ & 163.252 & 0.898 & 0.345 \\
\hline $\mathrm{W} * \mathrm{~S}$ & 163.374 & 1.081 & 0.300 \\
\hline $\mathrm{W} * \mathrm{~T}$ & 162.959 & 2.895 & 0.058 \\
\hline $\mathrm{N} * \mathrm{~S}$ & 163.252 & 1.073 & 0.302 \\
\hline $\mathrm{N} * \mathrm{~T}$ & 162.959 & 2.059 & 0.131 \\
\hline $\mathrm{S} * \mathrm{~T}$ & 162.959 & 2.545 & 0.082 \\
\hline $\mathrm{W} * \mathrm{~N} * \mathrm{~S}$ & 163.252 & 0.227 & 0.634 \\
\hline $\mathrm{W} * \mathrm{~N} * \mathrm{~T}$ & 162.959 & 2.385 & 0.095 \\
\hline $\mathrm{W} * \mathrm{~S} * \mathrm{~T}$ & 162.959 & 0.941 & 0.392 \\
\hline $\mathrm{N} * \mathrm{~S} * \mathrm{~T}$ & 162.959 & 0.189 & 0.828 \\
\hline $\mathrm{W} * \mathrm{~N} * \mathrm{~S} * \mathrm{~T}$ & 162.959 & 0.351 & 0.705 \\
\hline
\end{tabular}

Estas interações são bem representadas na Figura 3, na qual pode-se observar que a taxa de crescimento absoluto das gramíneas foi maior no meio da estação de crescimento e decresce bruscamente, ao final da estação de crescimento. Inclusive, na gramínea nativa, ao final da estação de crescimento, pôde-se verificar valores de taxa de crescimento absoluta abaixo de zero (Figura 3), indicando uma perda de biomassa, o que mais uma vez representaria uma desvantagem competitiva frente à gramínea exótica nos tratamentos com a adição de nutrientes.

Nem mesmo nos tratamentos sem adição de nutrientes, esse decréscimo na produção de biomassa foi observado na gramínea Urochloa brizantha, que mantém seu crescimento durante o final da estação de crescimento (Figura 3), demonstrando sua habilidade de manter sua taxa de crescimento mesmo com baixa disponibilidade de nutrientes no solo. Nas mesmas condições, a gramínea nativa Paspalum atratum reduz sua taxa de crescimento a quase zero (Figura 3).

As espécies de braquiária são reconhecidas por sua habilidade de sobreviver em variadas condições de solos, em particular solos ácidos e pobres em nutrientes (Miles et al. 1996; Andrade et al. 2004; Manzano et al. 2010). 


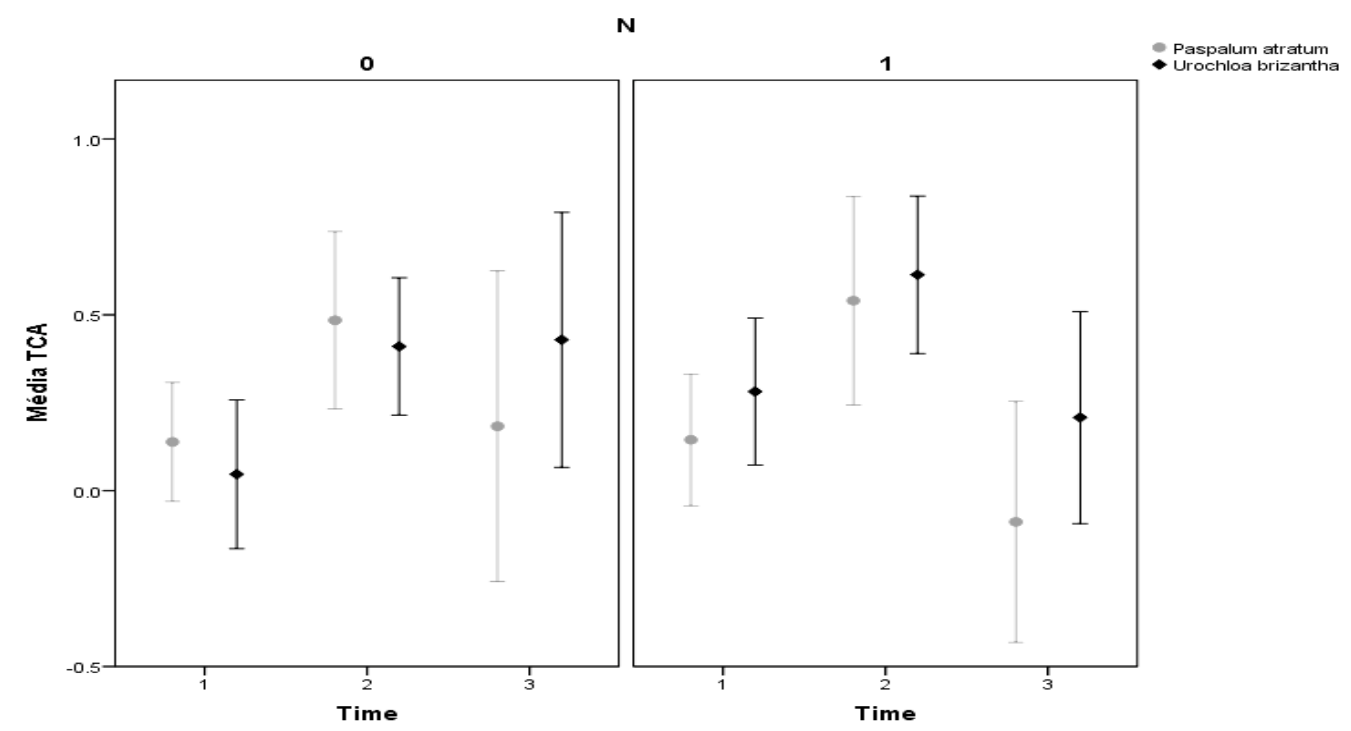

Fig 3 Média das taxas de crescimento absoluto (TCA) de Paspalum atratum e Urochloa brizantha, ao longo da estação chuvosa $($ Tempo $=1$ (início - out a dez/2011); 2 (meio - dez/2011 a fev/2012); 3 (fim - fev a abr/2012)), nos tratamentos com (N1) e sem (N0) adição de nutrientes (NPK). Barras de erros indicam intervalo de confiança de $95 \%$. (Obs.: apenas tratamentos sem sombreamento foram considerados nesta análise). $\left({ }^{\circ}=\right.$ Paspalum atratum; $=$ Urochloa brizantha)

A capacidade de espécies invasoras de crescer rápido durante a rebrota e as fases iniciais do crescimento tem sido associadas a sua maior capacidade em captar recursos, em especial o nitrogênio, que espécies nativas de crescimento mais lento, o que representaria uma vantagem competitiva para as exóticas (Lambers e Poorter 1992; Radosevich et al. 2007).

De acordo com Alpert et al. (2000), a competição por recursos é dependente da distribuição espacial e temporal dos recursos e qualquer alteração no limite de recursos diponível irá alterar o balanço entre espécies nativas e exóticas.

Em ambientes caracterizados por baixa disponibilidade de recursos, como é o caso do Cerrado, qualquer aumento temporário na quantidade de nutrientes deverá ser mais benéfico à espécie exótica que à nativa, em especial com relação às gramíneas (Huenneke et al. 1990; Hoobs e Mooney 1991; Kolb et al. 2002; Abraham et al. 2009). De acordo com Vallano et al. (2012), o aumento temporário da concentração de nitrogênio no solo, resultado da ação antropogênica, favorece o crescimento de gramíneas exóticas, aumentando sua habilidade competitiva em relação à gramínea nativa.

Estudos mostram que gramíneas $\mathrm{C}_{4}$ podem sobreviver em condições de baixa concentração de nitrogênio, em função de sua alta eficiência fotossintética em razão do uso do nitrogênio (PNUE - assimilação de carbono por unidade de N) (Sage e Pearcy 1997). Este alto valor de PNUE é frequentemente associado à espécies invasoras e a fatores como: alocação prioritária do $\mathrm{N}$ em compostos de rotas fotossintéticas, longevidade foliar e reabsorção de $\mathrm{N}$ das folhas senescentes (Funk e Vitousek 2007; Drenovsky et al. 2012; Funk et al. 2013; Funk 2013) .

Daehler (2003) e Vasquez et al. (2008) mostraram que, depois da água, o nitrogênio é frequentemente o recurso mais limitante do crescimento vegetal, em campos graminosos semi-áridos e áridos. Em geral, o aumento na concentração de nitrogênio no solo favorece as espécies invasoras frente às nativas (Chambers et al. 2007; James et al. 2008). Inclusive, diversos estudos mostram que distúrbios no solo que causam aumento na disponibilidade de nutrientes no solo também favorecem mais as espécies invasoras que as espécies nativas (O’Dell e Claassen 2006; Abraham et al. 2009; Sharma et al. 2010). Em espécies de Urochloa o aumento de nutrientes no solo permitem o sucesso da invasão e sua persistência no ambiente (Zupo 2010). 
Da mesma forma, gramínea exótica Eragrostis curvula apresentou maior eficiência fotossintética que gramíneas nativas, em ambientes com baixa concentração de nutrientes (Firn et al. 2012).

Por outro lado, outra gramínea exótica, a Melinis minutiflora, não apresentou apresentou diferença significativa na capacidade de acumular biomassa aérea ao ser comparada com gramíneas nativas do cerrado (Silva e Haridassan 2007). De acordo com Villela e Haridasan (1994), as gramíneas e outras espécies herbáceas do cerrado são adaptadas à baixa fertilidade dos solos, mas mesmo assim elas ainda são capazes de responder a uma maior disponibilidade de nutrientes.

O fato da gramínea exótica apresentar uma melhor resposta à adição de nutrientes, ao longo do tempo, representa uma grande ameaça ao Cerrado, tendo em vista a frequência de queimadas as quais o bioma está submetido. De acordo com Pivello et al. (2010), incêndios geram um "input” temporário de nutrientes no solo e isto iria favorecer o crescimento da gramínea invasora em detrimento da gramínea nativa.

\section{Efeito da luz e da adição de nutrientes no crescimento das gramíneas, durante a estação de crescimento:}

Em plantas sombreadas, os fatores luz e nutrientes, isoladamente, não exerceram influência na biomassa das gramíneas $(\mathrm{p}=0.125$ e p=0.592, respectivamente) (Tabela 4). Da mesma forma, as duas espécies de gramíneas não mostraram diferenças estatísticas na produção de biomassa nem mesmo durante a estação de crescimento, ao analisar plantas sombreadas e não sombreadas juntas $(\mathrm{p}=0.147)$ (Tabela 4).

Mais uma vez, os intervalos de tempo dentro da estação de crescimento apresentaram um resultado significativo no crescimento das gramíneas ( $\left.\mathrm{p}<0.0001, \mathrm{~F}_{162.898}=15.166\right)$ (Tabela 4).

Tabela 4. Resultados estatísticos (modelo linear misto) (graus de liberdade, F, p) testando os efeitos de luz, nutrientes, espécies e tempo na taxa de crescimento absoluta de Paspalum atratum e Urochloa brizantha.

\begin{tabular}{|c|c|c|c|}
\hline & Graus de liberdade & $\mathrm{F}$ & $\mathrm{P}$ \\
\hline Intercepto & 6.052 & 21.692 & 0.003 \\
\hline Luz (L) & 165.233 & 2.380 & 0.125 \\
\hline Nutrientes (N) & 164.600 & 0.289 & 0.592 \\
\hline Espécies (S) & 165.233 & 2.125 & 0.147 \\
\hline Tempo (T) & 162.898 & 15.166 & 0.000 \\
\hline $\mathrm{L} * \mathrm{~N}$ & 164.600 & 1.397 & 0.239 \\
\hline $\mathrm{L} * \mathrm{~S}$ & 165.233 & 0.003 & 0.959 \\
\hline $\mathrm{L} * \mathrm{~T}$ & 162.898 & 2.430 & 0.091 \\
\hline $\mathrm{N} * \mathrm{~S}$ & 164.600 & 0.928 & 0.337 \\
\hline $\mathrm{N} * \mathrm{~T}$ & 162.898 & 4.398 & 0.014 \\
\hline $\mathrm{S} * \mathrm{~T}$ & 162.898 & 4.685 & 0.011 \\
\hline $\mathrm{L} * \mathrm{~N} * \mathrm{~S}$ & 164.600 & 0.207 & 0.650 \\
\hline $\mathrm{L} * \mathrm{~N} * \mathrm{~T}$ & 162.898 & 1.542 & 0.217 \\
\hline $\mathrm{L} * \mathrm{~S} * \mathrm{~T}$ & 162.898 & 4.124 & 0.018 \\
\hline $\mathrm{N} * \mathrm{~S} * \mathrm{~T}$ & 162.898 & 0.006 & 0.994 \\
\hline $\mathrm{L} * \mathrm{~N} * \mathrm{~S} * \mathrm{~T}$ & 162.898 & 0.368 & 0.693 \\
\hline
\end{tabular}


Ao comparar as gramíneas crescendo sob condições de 100\% de luminosidade (sem sombreamento), as espécies exótica e nativa não apresentaram diferenças significativas (Figura 4). Apenas foi possível observar uma taxa de crescimento absoluto ligeiramente superior de Urochloa brizantha comparada à Paspalum atratum (Figura 4).

Por outro lado, foi possível verificar uma interação entre nutriente e tempo $\left(\mathrm{p}=0.014, \mathrm{~F}_{162.898}=4.398\right)$, espécie e tempo $\left(p=0.011, F_{162.898}=4.685\right)$ e entre luz e espécie, ao longo do tempo $\left(p=0.018, F_{162.898}=4.124\right)(T a b e l a ~ 4)$. Quando as plantas estão sombreadas, a gramínea nativa Paspalum atratum tende a apresentar maior taxa de crescimento absoluto inicial (no meio da estação de crescimento), indicando uma aparente melhor tolerância ao sombreamento (Figura 4). No entanto, a produção de biomassa cai muito ao final da estação de crescimento, chegando a se tornar negativa, o que representa uma perda de biomassa (Figura 4).

Já na gramínea exótica Urochloa brizantha, a produção de biomassa não apresenta este decréscimo tão vigoroso na produção de biomassa ao final da estação de crescimento (Figura 4), o que mais uma vez representa uma vantagem competitiva da gramínea exótica frente à gramínea nativa.

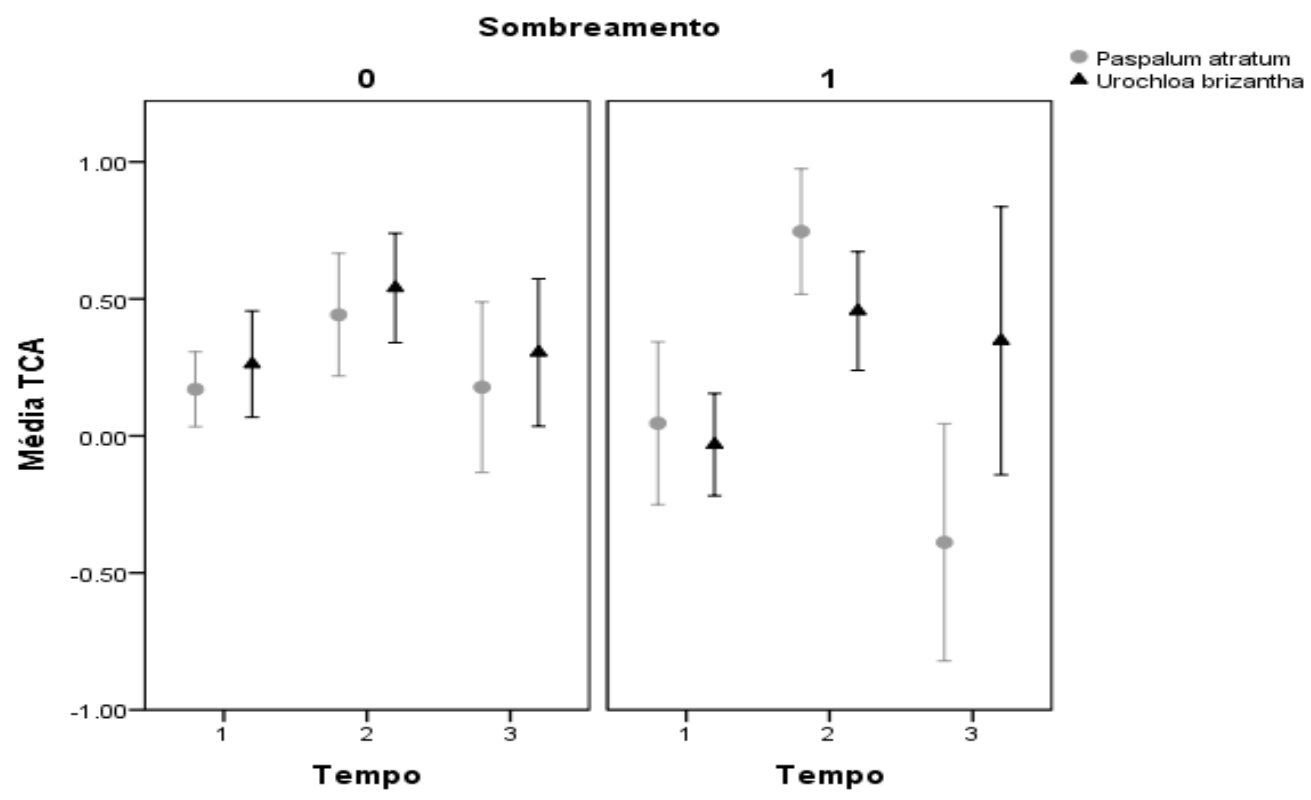

Fig 4 Média das taxas de crescimento absoluto (TCA) de Paspalum atratum e Urochloa brizantha, ao longo da estação chuvosa $($ Tempo $=1$ (início - out a dez/2011); 2 (meio - dez/2011 a fev/2012); 3 (fim - fev a abr/2012)), nos tratamentos luz natural (sombreamento $=0$ ) e sombrite $80 \%$ (sombreamento $=1$ ). Barras de erros indicam intervalo de confiança de 95\%. (Obs.: apenas tratamentos irrigados foram considerados nesta análise) $\left({ }^{\circ}=\right.$ Paspalum atratum; $\boldsymbol{\Delta}=$ Urochloa brizantha)

De acordo com Miles et al. (1996), o gênero Urochloa é caracterizado por apresentar espécies facilmente adaptáveis a diferentes condições climáticas, inclusive ambientes sombreados. Dias-Filho (2000) também observou que duas espécies de braquiária (Urochloa brizantha e $U$. humidicola) foram capazes de se adaptar facilmente às condições de sombreamento, desenvolvendo ajustes fenotípicos que as possibilitaram sobreviver nestes ambientes. Esta aparente tolerância ao sombreamento encontrada em Urochloa brizantha, na qual as plantas conseguem continuar crescendo mesmo sob condições de sombreamento, pode representar mais uma vantagem competitiva da gramínea exótica frente à nativa, além de uma grande ameaça às formações florestais presentes no Cerrado.

Esse aumento na taxa de crescimento absoluto da gramínea nativa Paspalum atratum, no meio da estação de crescimento, quando as plantas estão sombreadas (Figura 4), pode indicar uma intolerância à sombra, já que algumas espécies de Paspalum, como o P. notatum, foram classificadas como espécies adaptadas a ambientes com níveis intermediários de sombreamento (Andrade et al. 2004). Funk (2013) relata que espécies intolerantes ao sombreamento 
tendem a crescer rapidamente para tentar alcançar maiores taxas luminosas, apresentando curto ciclo de vida e reprodução antecipada.

Dias-Filho (2000) observou uma diminuição na taxa de crescimento relativa em espécies de Brachiaria (B. brizantha e $B$. humidicola) em plantas sombreadas em comparação às plantas crescendo a pleno sol. Apesar disso, ele observou um incremento na biomassa aérea em detrimento do crescimento de raízes. D’Antonio et al. (2001) também observaram menor investimento em raízes em duas gramíneas sombreadas, Melinis minutiflora e Schizachyrium condensatum. Como a rebrota está intimamente relacionada à alocação de nutrientes em órgãos subterrâneos e ao desenvolvimento de raízes, plantas sombreadas seriam mais sujeitas ao estresse, como herbivoria ou queimada (DiasFilho 2000).

No presente trabalho, os órgãos subterrâneos não foram analisados, mas uma resposta positiva, ao final da estação de crescimento, como a observada em Urochloa brizantha, deve representar uma vantagem competitiva na rebrota desta espécie após a passagem do fogo, em condições de sombreamento.

Ammondt et al. (2013) encontraram valores semelhantes, superiores às plantas nativas, para o crescimento da gramínea exótica Megathyrsus maximus crescendo sob sol pleno e parcialmente sombreada (23\% de densidade de fótons), indicando que a gramínea invasora pode crescer tanto em ambientes com baixa como com alta intensidade luminosa. Dias-Filho (2000) também observou uma alta plasticidade de Urochloa brizantha em condições de sombreamento.

\section{Conclusões}

Independente da estação, a gramínea exótica Urochloa brizantha sempre apresentou biomassa aérea maior que a nativa Paspalum atratum. No entanto, somente durante a estação chuvosa, foi possível observar diferenças nos crescimentos das gramíneas nativa e exótica, entre os diferentes tratamentos.

Os resultados obtidos permitem inferir que, logo no início da rebrota, a gramínea exótica Urochloa brizantha apresenta uma vantagem competitiva frente à nativa, mesmo sendo uma espécie de estrutura morfológica e funcional semelhante à espécie invasora. Urochloa brizantha foi capaz de se beneficiar mais da adição de água e nutrientes ao solo que Paspalum atratum, sustentando seu crescimento até o fim da estação de crescimento.

Como era esperado para espécies invasoras crescendo em solos pobres em recursos, como é o caso do solo do cerrado, Urochloa brizantha obteve maior incremento de biomassa aérea ao longo da estação de crescimento, enquanto a nativa chegou a apresentar perda de biomassa ao final da estação chuvosa.

A gramínea exótica também se mostrou mais tolerante ao sombreamento, apresentando crescimento mais uniforme ao longo da estação chuvosa, enquanto a gramínea nativa após um excessivo crescimento aéreo no meio da estação chuvosa, apresentou uma expressiva redução na biomassa no final da estação de crescimento, resultando em um crescimento inferior ao da invasora.

Estudos complementares, incluindo gramíneas nativas e exóticas de outras espécies, bem como a análise da biomassa radicular seriam extremamente valiosos no sentido de ampliar esse conhecimento sobre o potencial competitivo de gramíneas crescendo sob mesmas condições.

Compreender mecanismos competitivos entre espécies de gramíneas nativas e invasoras durante os estágios iniciais do desenvolvimento podem fornecer informações importantes e úteis nos estudos de dinâmica da vegetação e nos processos de recuperação de áreas degradadas. 


\section{REFERÊNCIAS BIBLIOGRÁFICAS}

Abraham J, Corbin J, D'Antonio C (2009) California native and exotic perennial grasses differ in their response to soil nitrogen exotic annual grass density and order of emergence. Plant Ecol 201:445-456

Aires SS (2013) Seleção de gramíneas nativas do Cerrado para uso no manejo de Melinis minutiflora: competição entre Melinis minutiflora e Paspalum stellatum. Dissertation, Universidade de Brasília

Almeida-Neto M, Prado PI, Kubota U, Bariani JM, Aguirre GH, Lewinsohn TM (2010) Invasive grasses and native Asteraceae in the Brazilian Cerrado. Plant Ecol 209:109-122

Alpert P, Bone E, Holzapfel C (2000) Invasiveness, invasibility and the role of environmental stress in the spread of non-native plants. Perspect Plant Ecol Evol Syst 3:52-66

Ammondt SA, Litton CM, Ellsworth LM, Leary JK (2013) Restoration of native plant communities in a Hawaiian dry, lowland ecosystem dominated by the invasive grass Megathyrsus maximus. J App Veg Sci 16:29-39

Andrade CMS, Valentim JF, Carneiro JC, Vaz FA (2004) Crescimento de gramíneas e leguminosas forrageiras tropicais sob sombreamento. Pesq Agrop Bras 39(3):263-270

Assad ED, Evangelista BA (1994) Análise frequencial da precipitação pluviométrica In: Assad ED (coord) Chuvas no Cerrado: análise e espacialização. Embrapa/CPAC, Brasília, pp 25-42

Blank RR (2010) Intraspecific and interspecific pair-wise seedling competition between exotic annual grasses and native perennials: plant-soil relationship. Plant Soil 326:331-343

Brooks KJ, Setterfield SA, Douglas MM (2010) Exotic grass invasions: applying a conceptual framework to the dynamics of degradation and restoration in Australia's tropical savannas. Restor Ecol 18(2):188-197

Chambers JC, Meyer SE, Whittaker A, Roundy BA, Blank RR (2007) What makes Great Basin sagebrush ecosystems invasible by Bromus tectorum? Ecol Monogr 77:117-145

Claassen VP, Marler M (1998) Annual and perennial grass growth on nitrogen-depleted decomposed granite. Restor Ecol 6:175-180

Corbin JD, D'Antonio CM (2004) Competition between native perennial and exotic annual grasses: implications for an historical invasion. Ecology 85:1273-1283

Craine JM, Fargione J, Sugita S (2005) Supply pre-emption not concentration reduction is the mechanism of competition for nutrients. New Phytol 166:933-940

D'Antonio CM, Vitousek PM (1992) Biological invasions of alien grasses the grass/fire cycle and global change. Annu Rev Ecol Syst 23:63-87

Daehler CC (2003) Performance comparisons of co-occurring native and alien invasive plants: implications for conservation and restoration. Annu Rev Ecol Syst 34:183-211

D'Antonio CM, Hughes RF, Vitousek PM (2001) Factors influencing dynamics of two invasive $\mathrm{C}_{4}$ grasses in seasonally dry Hawaiian woodlands. Ecology 82:89-104.

Davidson AM, Jennions M, Nicotra AB (2011) Do invasive species show higher phenotypic plasticity than native species and if so is it adaptive? A meta analysis. Ecol Lett 14:419-431

Davis MA, Grime JP, Thompson K (2000) Fluctuating resources in plant communities: a general theory of invisibility. J Ecol 88:528-534

DeFalco LA, Bryla DR, Smith-Longozo V, Nowak RS (2003) Are Mojave Desert annual species equal? resource acquisition and allocation for the invasive grass Bromus madritensis subsp. rubens (Poaceae) and two native species. Am J Bot 90:1045-1053 
Dias BFS (1992) Cerrados: uma caracterização. In: Dias BFS (Ed) Alternativas de desenvolvimento dos Cerrados: manejo e conservação dos recursos naturais renováveis FUNATURA, Brasília, pp 11-25

Dias-Filho MB (2000) Growth and biomass alocation of the $\mathrm{C}_{4}$ grasses Brachiaria brizantha e $B$ humidicola under shade. Pesq Agrop Bras 35(12):2335-2341

Dias-Filho MB (2002) Photosynthetic light response of the $\mathrm{C}_{4}$ grasses Brachiaria brizantha and $B$ humidicola under shade. Sci Agric 59:65-68

Dohn J, Dembélé F, Karembé M, Moustakas A, Amévor KA, Hanan NP (2013) Tree effects on grass growth in savannas: competition, facilitation and the stress-gradient hypothesis. Journal of Ecology, 101:202-209

Drenovsky RE, Grewell BJ, D’Antonio CM, Funk JL, James JJ, Molinari N, et al (2012) A functional trait perspective on plant invasion. Ann Bot 110:141-153

Durigan G, Siqueira MF, Franco GADC (2007) Threats to the Cerrado remnants of the state of São Paulo Brazil. Sci Agric 64:355-363

Eiten G (1972) The cerrado vegetation of Brazil. Bot Rev 38:201-341

Everett RA (2000) Patterns and pathways of biological invasions. Trends Ecol Evol 15:177-178

Firn J, MacDougall A, Schmidt S, Buckley YM (2010) Early emergence and resource availability can competitively favour natives over a functionally similar invader. Oecologia 163:775-784

Firn J, Prober SM, Buckley YM (2012) Plastic traits of an exotic grass contribute to its abundance but are not always favorable. PLOS One 7(4): e35870. http://doi:35810.31371/journal.pone.0035870

Foster B, Gross K (1997) Partitioning the effects of plant biomass and litter on Andropogon gerardi in old field vegetation. Ecology 78:2091-2104

Fowler N (1986) The role of competition in plant communities in arid and semiarid regions. Annu Rev Ecol Syst $17: 89-110$

Foxcroft LC, Richardson DM, Rejmanek M, Pysek P (2010) Alien plant invasions in tropical and sub-tropical savannas: patterns processes and prospects. Biol Invasions 12:3913-3933

Franco AC, Haridasan M, Ferreira CS (2008) Physiological ecology of cerrado plants: new insights and new approaches. Braz J Plant Physiol 20(3):165-166

Funk JL (2013) The physiology of invasive plants in low-resource environments. Conserv Physiol 1:cot026

Funk JL, Vitousek PM (2007) Resource use efficiency and plant invasion in low-resource systems. Nature 446:1079_ 1081

Gioria M, Jarošík V, Pyšek P (2014) Impact of invasive alien plants on the soil seed bank: emerging patterns. Perspect. Plant Ecol. Evol. Syst. 16:132-142

Gioria M, Osborne BA (2014) Resource competition in plant invasions: emerging patterns and research needs. Funct Ecol 5:1-21

Godoy O, Valladares F, Castro-Diez P (2011) Multispecies comparison reveals that invasive and native plants differ in their traits but not in their plasticity. Funct Ecol 25:1248-1259

Goldberg DE (1996) Competitive ability: definitions contingency and correlated traits. Philos Trans R Soc B Biol Sci 351:1377-1385

Goldberg DE, Turkington R, Olsvig-Whittaker L, Dyer AR (2001) Density dependence in an annual plant community: variation among life history stages. Ecol Monogr 71:423-446

Goldstein LJ, Suding KN (2014) Intra-annual rainfall regime shifts competitive interactions between coastal sage scrub and invasive grasses. Ecology 95:425-435 
Gorgone-Barbosa E, Pivello VR, Bautista S, Zupo T, Rissi MN, Fidelis A (2014) How can an invasive grass affect fire behavior in a tropical savanna? A community and individual plant level approach. Ecological Invasions 17 http://link springer com/article/10 1007/s10530-014-0740-z. Accessed 21 July 2014.

Grime JP (1977) Evidence for existence of three primary strategies in plants and its relevance to ecological and evolutionary theory. Am Nat 111:1169-1194

Grotkopp E, Rejmánek M (2007) High seedling relative growth rate and specific leaf area are traits of invasive species: phylogenetically independent contrasts of woody angiosperms. Am J Bot 94:526-532

Han Y, Buckley YM, Firn J (2012) An invasive grass shows colonization advantages over native grasses under conditions of low resource availability. Plant Ecol 213:1117-1130

Hejda M, Pyšek P, Jarošík V (2009) Impact of invasive plants on the species richness diversity and composition of invaded communities. J Ecol 97:393-403

Higgins SI, Bond WJ, Trollope WSW, (2000) Fire resprouting and variability: a recipe for grass-tree coexistence in savanna. J Ecol 88:213-229

Hobbs R, Mooney H (1986) Community changes following shrub invasion of grassland. Oecologia 70:508-513

Hobbs R, Mooney H (1991) Effects of rainfall variability and gopher disturbance on serpentine annual grassland dynamics. Ecology 72:59-68

Hoffmann WA (1996) The effects of fire and cover on seedling establishment in a neotropical savanna. J Ecol 84:383393

Hoffmann WA (1999) Fire and population dynamics of woody plants in a neotropical savanna: matrix model projection. Ecology 80:1354-1369

Hoffmann WA, Jackson RB (2000) Vegetation-climate feedbacks in the conversion of tropical savannah to grassland. J Climate 13:1593-1602

Hoffmann WA, Lucatelli VMPC, Silva FJ, Azeuedo INC, Marinho MS, Albuquerque AMS, Lopes AO, Moreira SP (2004) Impact of the invasive grass Melinis minutiflora at the savanna-forest ecotone in the Brazilian Cerrado. Divers Distrib 10:99-103

Hoffmann WA, Poorter H (2002) Avoiding Bias in calculation of Relative Growth rate. Ann Bot 80:37-42

Hoffmann WA, Schroeder W, Jackson RB (2002) Positive feedbacks of fire climate and vegetation and the conversion of tropical savanna. Geophys Res Lett 29:2052

Horowitz C, Martins CR, Walter BMT (2013) Flora Exótica no Parque Nacional de Brasília: Levantamento e Classificação das Espécies. Biodiversidade Brasileira 3(2):50-73

Huenneke LF, Hamburg SP, Koide R, Mooney HA, Vitousek PM (1990) Effects of soil resources on plant invasion and community structure in Californian serpentine grassland. Ecology 71:478-491

James JJ, Davies KW, Sheley RL, Aanderud ZT (2008) Linking nitrogen partitioning and species abundance to invasion resistance in the great basin. Oecologia 156:637-648

Karia CT, Andrade RP (2001) Cultivo do Capim Pojuca. Recomendação Técnica Embrapa Cerrados 50:1-2

Klink CA, Joly CA (1989) Identification and distribution of $\mathrm{C}_{3}$ and $\mathrm{C}_{4}$ grasses in open and shades habitats in São Paulo State Brazil. Biotropica 21(1):30-34

Klink CA, Machado RB (2005) Conservation of the Brazilian Cerrado. Conservation Biology 19:707-713

Kolb A, Alpert P, Enters D, Holzhapfel C (2002) Patterns of invasion within a grassland community. J Ecol 90:871-881

Kraaij J, Ward D (2006) Effects of rain nitrogen fire and grazing on tree recruitment and early survival in bushencroached savanna South Africa. Plant Ecol 186:235-246 
Lambers H, Poorter H (1992) Inherent variation in plant growth: physiological mechanisms and ecological consequences. Adv Ecol Res 23:18 7-261

Lannes LS, Bustamante MMC, Edwards PJ, Venterink HO (2012). Alien and endangered plants in the Brazilian Cerrado exhibit contrasting relationships with vegetation biomass and N: P stoichiometry. New Phyt 196:816-823

Laris P (2011) Humanizing savanna biogeography: linking human practices with ecological patterns in a frequently burned savanna of southern Mali. Ann Assoc Am Geogr 101(5):1067-1088

Leishman MR, Thomson VP (2005) Experimental evidence for the effects of additional water nutrients and physical disturbance on invasive plants in low fertility Hawkesbury Sandstone soils Sydney. Australia J Ecol 93:38-49

Leite GG, Silveira LF, Fernandes FD, Gomes AC (2001) Crescimento e composição química do capim Paspalum atratum cv Pojuca. Boletim pesquisa e desenvolvimento (Embrapa cerrados) 19:1-22

Levine JM, Vila M, D’Antonio CM, Dukes JS, Grigulis K, Lavorel S (2003) Mechanisms underlying the impacts of exotic plant invasions. Proc R Soc Lond B270:775-781

Lockwood JL, Hoopes MF, Marchetti MP (2007) Invasion Ecology. Blackwell Publishing, Malden. http://www planta cn/forum/files_planta/invasion_ecology_185 pdf. Accessed 17 May 2014.

Lowe P, Lauenroth W, Burke IC (2003) Effects of nitrogen availability on competition between Bromus tectorum and Bouteloua gracilis. Plant Ecol 167:247-254

Macedo MCM (2005) Pastagens no ecossistema cerrados: evolução das pesquisas para o desenvolvimento sustentável. In: Anais da 42 ${ }^{\mathrm{a}}$ Reunião Anual da Sociedade Brasileira de Zootecnia Goiânia Sociedade Brasileira de Zootecnia, pp 56-84

Maciel JR, Oliveira RC, Alves M (2009) Paspalum L (Poaceae: Panicoideae: Paniceae) no estado de Pernambuco Brasil. Acta Bot Bras 23(4):1145-1161

Mangla S, Sheley RL, James JJ, Radosevich SR (2011) Intra and interspecific competition among invasive and native species during early stages of plant growth. Plant Ecol 212(4):531-542

Manzano SJL, Araújo ACG, Valle CB, Santana EF, Carneiro VTC (2010) Histologia da embriogênese somática induzida em embriões de sementes maduras de Urochloa brizantha apomítica. Pesq Agrop Bras 45(5):435-441

Masocha MA, Skidmore K, Poshiwa X, Prins HHT (2010) Frequent burning promotes invasions of alien plants into a mesic African savanna. Biological Invasions 13:1641-1648

Matos DMS, Pivello VR 2009 O impacto das plantas invasoras nos recursos naturais de ambientes terrestres - alguns casos brasileiros. Ciência e Cultura 61(1):27-30

Miles JW, Maass BL, Valle CB, Kumble V (1996) Brachiaria: biology agronomy and improvement EMBRAPA/CNPGC http://books google com br/books/ about/Brachiaria html?id=dMF6QpfVdjMC redir_esc=y. Acessed 02 June 2014.

Miranda HS, Bustamante MMC, Miranda AC (2002) The Fire factor. In: Oliveira PS, Marquis RJ (Eds) The Cerrados of Brazil: ecology and natural history of a neotropical savanna. Columbia University Press, NewYork, pp 51-68

Moles AT, Flores-Moreno H, Bonser SP, Warton DI, Helm A, Warman L et al (2012) Invasions: the trail behind the path ahead and a test of a disturbing idea. J Ecol 100:116-127

Motta PEF, Curi N, Franzmeier DP (2002) Relation of soil and geomorphic surfaces in the Brazilian Cerrado In: Oliveira PS, Marquis RJ (Eds) The Cerrados of Brazil: ecology and natural history of a neotropical savanna. Columbia University Press, NewYork, pp 13-32

Myers JH, Bazely DR (2003) Ecology and Control of Introduced Plants Cambridge. http://assets cambridge org/97805213/55162/ frontmatter/9780521355162_frontmatter pdf. Acessed 05June 2014. 
Nernberg D, Dale MRT (1997) Competition of five native prairie grasses with Bromus inermis under three moisture regimes. Can J Bot 75:2140-2145

O’Dell RE, Claassen VP (2006) Relative performance of native and exotic grass species in response to amendment of drastically disturbed serpentine substrates. J Appl Ecol 43:898-908

Oliveiras I, Meirelles ST, Hirakuri VL, Freitas CR, Miranda HS, Pivello VP (2013) Effects of fire regimes on herbaceous biomass and nutrient dynamics in the Brazilian savanna. Int J Wildland Fire 22:368-380

Pivello VR, Carvalho VMC, Lopes PF, Peccinini AA, Rosso S (1999b) Abundance and distribution of native and alien grasses in a "Cerrado" (Brazilian savanna) biological reserve. Biotropica 31:71- 82

Pivello VR, Shida CN, Meirelles ST (1999a) Alien grasses in Brazilian savannas: a threat to the biodiversity. Biodivers Conserv 8:1281- 1294

Pivello, VR (2011) The use of fire in the Cerrado and Amazonian rainforests of Brazil: past and present. Fire Ecology 7(1):24-39

Pyšek P, Jarošík V, Hulme P, Pergl J, Hejda M, Schaffner U et al (2012) A global assessment of invasive plant impacts on resident species communities and ecosystems: the interaction of impact measures invading species' traits and environment. Global Change Biol 18:1725-1737

Radosevich SR, Holt JS, Ghersa CM (2007) Weed ecology: implications for management, 3rd edn. Wiley, New York, pp 206-207

Reatto A, Correia JR, Spera ST, Martins ES (2008) Solo do Bioma Cerrado: aspectos pedológicos. In: Sano SM, Almeida SP, Ribeiro JF Cerrado: ecologia e flora. Embrapa Cerrados, Brasília, pp 107-149

Rejmánek M (1996) A theory of seed plant invasiveness: the first sketch. Biol Conserv 78:171-181

Rejmánek M (2000) Invasive plants: approaches and predictions. Austral Ecol 25:497-506

Rejmánek M, Richardson DM (1996) What attributes make some plant species more invasive? Ecology 77:1655- 1661

Rejmánek M, Richardson DM, Pysek P (2005) Plant invasions and invasibility of plant communities. In: Van Der Maarel E (Ed) Vegetation ecology. Blackwell, Oxford, pp 332-355

Riginos C (2009) Grass competition suppresses savanna tree growth across multiple demographic stages. Ecology, $90: 335-340$

Rossiter NA, Setterfield SA, Douglas MM, Hutley LB (2003) Testing the grass-fire cycle: alien grass invasion in the tropical savannas of northern Australia. Divers Distrib 9:169-176

Sage RG, Pearcy RW (1987) The nitrogen use efficiency of $\mathrm{C}_{3}$ and $\mathrm{C}_{4}$ plants II. Leaf nitrogen effects on the gas exchange characteristics of Chenopodium album (L.) and Amaranthus retroflexus (L.). Plant Physiol 84:959-963

Saha S, Howe HF (2006) Stature of juvenile trees in response to anthropogenic fires in a tropical deciduous forest of Central India. Conservat Soc 4(4):619-627

Sala A, Verdaguer D, Vilà M (2007) Sensitivity of the invasive geophytes Oxalis pescaprae to nutrient availability and competition. Ann Bot 99:637-645

Sankaran M, Ratnam J, Hanan NP (2004) Tree-grass coexistence in savannas revisited - insights from an examination of assumptions and mechanisms invoked in existing models. Ecol Lett 7:480-490

Sano SM, Almeida SP, Ribeiro JF (Eds) (1998) Cerrado: ecologia e flora. Embrapa Cerrados, Brasília

Sarmiento G (1992) Adaptive strategies of perennial grasses in South American savannas. J Veg Sci 3:325-336

Scholes RJ, Archer SR (1997) Tree-Grass interactions in savannas. Annu Rev Ecol Syst 28:517-544

Seabloom EW, Borer ET, Boucher VL et al (2003) Competition seed limitation disturbance and reestablishment of California native annual forbs. Ecol Appl 13:573-592 
Sharma GP, Muhl SA, Esler KJ, Milton SJ (2010) Competitive interactions between the alien invasive annual grass Avena fatua and indigenous herbaceous plants in South African Renosterveld: the role of nitrogen enrichment. Biol Invasions 12:3371-3378

Silva JS, Haridasan M (2007) Acúmulo de biomassa aérea e concentração de nutrientes em Melinis minutiflora P Beauv e gramíneas nativas do cerrado. Rev Bras Bot 30:321-350

Solbrig OT, Medina E, Silva JF (1996) Biodiversity and savanna ecosystem processes - a global perspective ecological studies. Springer Verlag, Berlin

Steinaker DF, Wilson SD, Peltzer DA (2010) Asynchronicity in root and shoot phenology in grasses and woody plants. Global Change Biology 16:2241-2251.

Stohlgren TJ, Barnett DT, Jarnevich CS, Flather C, Kartesz J (2008) The myth of plant species saturation. Ecol Lett $11: 313-322$

Tecco PA, Diaz S, Cabido M, Urcelay C (2010) Functional traits of alien plants cross contrasting climatic and land-use regimes: do aliens join the locals or try harder than them? J Ecol 98:17-27

Tilman D (1982) Resource competition and community structure. Princeton University Press, New York

Tilman D (1987) Secondary sucession and the pattern of plant dominance along experimental nitrogen gradients. Ecol Monogr 57(3):189-214

Tomlinson KW, Sterck FJ, Bongers F, Silva DA, Barbosa ERM, Ward D, Bakker FT, Van Kaauwen M, Prins HT, de Bie S, Van Langevelde F (2012) Biomass partitioning and root morphology of savanna trees across a water gradient. J Ecol 100(5):1113-1121

Vadigi S, Ward D (2014) Herbivory effects on saplings are influenced by nutrients and grass competition in a humid South African savanna. Persp Plant Ecol Evol Syst 16:11-20

Vallano DM, Selmants PC, Zavaleta ES (2012) Simulated nitrogen deposition enhances the performance of an exotic grass relative to native serpentine grassland competitors. Plant Ecol 213:1015-1026

Vasquez E, Sheley RL, Svejcar TJ (2008) Creating invasion resistant soils via nitrogen management. Invasive Plant Sci Manag 1:304-314

Vilà M, Espinar JL, Hejda M, Hulme PE, Jarošík V, Maron JL et al (2011) Ecological impacts of invasive alien plants: a meta-analysis of their effects on species communities and ecosystems. Ecol Lett 14:702-708

Vilà M, Gomez A, Maron JL (2003) Are alien plants more competitive than their native conspecifics? A test using Hypericum perforatum L. Oecologia 137:211-215

Vilà M, Weiner J (2004) Are invasive plant species better competitors than native plant species? Evidence from pairwise experiments. Oikos 105:229-238

Villela DMV, Haridasan M (1994) Response of the ground layer community of a cerrado vegetation in central Brazil to liming and irrigation. Plant Soil 163:25-31

Vitousek PM, D’Antonio CM, Loope LL, Rajmanek M, Westbrooks R (1997) Introduced species: a significant component of human-caused global change New Zealand. J Ecol 21:1-16

Vitousek PM, D’Antonio CM, Loope LL, Westbrooks R (1996) Biological invasions as global environmental change. Am Sci 84:179-468

Walker BH, Knoop WT (1987) The response of the herbaceous layer in a dystrophic Burkea africana savanna to increased levels of nitrogen phosphate and potassium. Journal of the Grassland Society of South Africa 4:31-34

Williams DG, Baruch Z (2000) African grass invasion in the Americas: ecosystem consequences and the role of ecophysiology. Biol Invasions 2:123-140

Williamson MH, Fitter A (1996) The characters of successful invaders. Biological conservation 78:163-170 
Zupo TM (2010) Invasão competição e uso de recursos por uma gramínea nativa e uma gramínea invasora do cerrado. Dissertation, Universidade de São Paulo 


\title{
Capítulo III
}

\section{Efeitos das gramíneas Paspalum atratum (Swallen) e Urochloa brizantha (Hochst.}

\author{
ex A. Rich.) Stapf. na rebrota de plantas jovens de lenhosas do Cerrado
}

\section{Resumo}

Vários estudos mostram que gramíneas por si só já estabelecem uma relação competitiva com as espécies de lenhosas e influenciam negativamente no desenvolvimento destas, principalmente nas fases iniciais do estabelecimento. Da mesma forma ocorre com a defoliação, promovida pela herbivoria ou pelo fogo. Gramíneas exóticas são espécies de maior produtividade que as nativas e, consequentemente, exercem uma influência negativa maior no estabelecimento das espécies lenhosas. O objetivo deste trabalho foi avaliar a influência da presença de gramíneas exótica (Urochloa brizantha) e nativa (Paspalum atratum) e da adição de nutrientes na rebrota de plantas de seis espécies de lenhosas do Cerrado submetidas à defoliação. Foram estabelecidas cinco parcelas experimentais (réplicas), subdivididas em 6 partes: 2 sem gramíneas, 2 com gramínea nativa e 2 com gramínea exótica. Em metade delas foi adicionado nutriente inorgânico NPK. Em cada subparcela foram plantadas 4 mudas de 6 espécies de lenhosas do Cerrado. Após três meses do plantio, metade das mudas foi defoliada. Análises biométricas, de biomassa aérea e de sobrevivência foram coletadas antes do plantio no campo, no momento da defoliação e após 11 meses da defoliação. Foi possível verificar a existência de uma relação positiva entre a biomassa aérea das plantas de lenhosa, antes do plantio no campo, e sua sobrevivência após 3 meses de cultivo no campo. Uma correlação negativa entre biomassa inicial e biomassa após três meses no campo também foi observada. A sobrevivência e o crescimento das plantas das espécies lenhosas foram inibidos pela presença das gramíneas, sendo que a gramínea exótica exerceu a maior inibição. A adição de nutrientes não influenciou na sobrevivência das lenhosas, mas afetou positivamente o desenvolvimento daquelas que conseguiram rebrotar, mas apenas na ausência de gramíneas, devido à existência de uma interação entre gramíneas e nutrientes, na qual as gramíneas evitam o uso deste recurso pelas plântulas de lenhosas.

Palavras chave: Cerrado; plântulas; lenhosas; defoliação; rebrota; Paspalum atratum; Urochloa brizantha; biomassa aérea; gramínea; braquiária; fogo; savana 


\begin{abstract}
Several studies show that grasses establish a competitive relationship with the woody species and negatively influence the development of these, especially in the early stages of establishment. Defoliation, promoted by herbivory or fire, produce the same effect. Exotic grasses are species of higher productivity than native and therefore have the most negative effect on the woody species stablishment. The aim of this study was to evaluate the influence of the presence of exotic (Urochloa Brizantha) and native grasses (Paspalum atratum) and the addition of nutrients in the regrowth of plants of six woody Cerrado's species, subjected to defoliation. Five plots (replicates), subdivided into 6 parts were established: 2 without grasses, 2 planted by native grass with 2 by exotic grass. In half of them was added inorganic nutrient NPK. In each subplot, 4 seedlings of six Cerrado's woody species were planted. Three months after planting, half of the plants were defolliated. Biometric analyzes, such as biomass, and survival were collected before planting in the field, at the time of defoliation and after 11 months of defoliation. It was possible to verify the existence of a positive relationship between aboveground biomass of woody plants before planting in the field, and their survival after 3 months of field cultivation. A negative correlation between initial biomass and biomass after three months was also observed in the field. Survival and growth of woody plant species were inhibited by the presence of grasses, and exotic grass had the greatest inhibition. The addition of nutrients did not influence the survival of tree seedlings, but positively affected the development of those who managed to sprout, but only in the absence of grasses due to the existence of an interaction between grasses and nutrients in which grasses avoid the use of this resource by tree seedlings.
\end{abstract}

Key-words: Cerrado; seedlings; defoliation; Paspalum atratum; Urochloa brizantha; grass; braquiária; biological invasion; fire; biomass; regrowth; savanna 


\section{Introdução}

Diversos modelos tem sido apresentados para se explicar a dinâmica entre árvores e gramíneas nas savanas (Higgins et al., 2000; Van Langevelde et al., 2003; Beckage et al., 2011; Laris, 2011; Wakeling et al., 2012). Eles se baseiam primariamente na disponibilidade água e nutrientes no solo (Scholes \& Archer, 1997; Higgins et al., 2000; Van Langevelde et al, 2003; Bond et al., 2005; Kambatuku et al., 2011; Silva \& Batalha, 2011a), fornecendo uma falsa aparência de estabilidade. No entanto, a estrutura da comunidade vegetal das savanas é também determinada por distúrbios, como fogo e herbivoria, que mantém a composição florística e evita a transformação em formações florestais mais densas (Scholes \& Walker, 1993; Jeltsch et al., 1996; Laris, 2011).

A ocorrência de árvores e gramíneas nas savanas está sempre associada às interações competitivas entre estas duas formas de vida, sendo estas relações negativas, neutras ou positivas (Kambatuku et al., 2011; Laris, 2011; Dohn et al., 2013). As interações entre árvores e gramíneas podem ser consideradas como relações de competição por recursos ou como uma relação facilitadora do desenvolvimento da outra espécie (Kambatuku et al., 2011; Dohn et al., 2013).

Além da competição direta por recursos (Scholes \& Archer, 1997; Ludwig et al., 2004; Kambatuku et al., 2011; Dohn et al., 2013), árvores podem promover sombreamento de gramíneas (Scholes \& Archer, 1997; Ludwig et al., 2004) e diminuir a infiltração de água no solo, pela interceptação da água das chuvas nas copas (Kambatuku et al., 2011). Por outro lado, podem beneficiar as gramíneas pela fixação do nitrogênio, pela diminuição da temperatura na superfície do solo ou pelo aumento da serrapilheira (Scholes \& Archer, 1997; Ludwig et al., 2004; Kambatuku et al., 2011; Dohn et al., 2013).

Ludwig et al. (2004), ao pesquisarem a influência de plantas lenhosas adultas no estabelecimento de gramíneas na África, verificaram que os nutrientes do solo são afetados pela presença da espécie lenhosa Acacia sp., em seus diferentes estágios de desenvolvimento. A disponibilidade de nutrientes foi observada como sendo o principal fator promotor de mudança na 
composição das espécies herbáceas, em comparação à luz e disponibilidade de água (Ludwig et al., 2004).

No entanto, as gramíneas também podem interferir no estabelecimento e desenvolvimento das espécies lenhosas.Vários estudos mostram que gramíneas, de maneira geral, por si só já estabelecem uma relação competitiva com as espécies de lenhosas e influenciam negativamente no desenvolvimento destas (Kambatuku et al., 2011; Vadigi \& Ward, 2014), principalmente nas fases iniciais do estabelecimento de plântulas de lenhosas (Walker et al., 1981; Scholes \& Archer 1997; Higgins et al., 2000; Roques et al., 2001; Van Langevelde et al., 2003; Ludwig et al., 2004; Bond, 2008; Hoffmann \& Haridasan, 2008; Riginos, 2009; Kambatuku et al., 2011). Seu ciclo de vida mais curto, sua alta taxa de crescimento e seu grande potencial de rebrota, lhes garante uma vantagem competitiva frente às plântulas e mudas de lenhosas na obtenção de recursos como água e nutrientes.

Por outro lado, gramíneas podem promover um microclima favorável para plântulas de algumas espécies mais sensíveis, reduzindo a transpiração, ou proteger as mudas da herbivoria (Holmgren et al., 1997; Davis et al., 1998; Brown \& Archer, 1999; Riginos \& Young, 2007; Seymour, 2008; Kambatuku et al., 2011; Grellier et al., 2012).

O fogo é reconhecido por promover um papel fundamental na determinação florística de savanas (Bond, 2008; Laris, 2011; Hoffmann et al., 2012). Incêndios causam declínio na cobertura vegetal lenhosa, matando as plântulas diretamente ou reduzindo a altura da população (Scholes \& Archer, 1997; D’Antonio et al., 1998; Miranda et al., 2002; Van Langevelde et al., 2003; Sankaran et al., 2004; Higgins et al., 2007; Laris, 2011).

Da mesma forma, o estabelecimento inicial e desenvolvimento das plântulas no campo também são influenciados pelo fogo, já que estão relacionados ao intervalo entre queimas (D’Antonio et al., 1998; Miranda et al., 2002; Setterfield, 2002; Rossiter et al., 2003; Hoffmann \& Haridasan, 2008). Com pequenos intervalos entre queimadas, as plântulas não se desenvolvem o 
suficiente para atingir o tamanho crítico de escape ao fogo e acabam morrendo (Ramos, 1990; Sato \& Miranda, 1996; Miranda et al., 2002; Rossiter et al., 2003).

O fogo, então, impede o estabelecimento de novos indivíduos e o desenvolvimento das plantas recém-estabelecidas até a idade adulta (Higgins et al., 2000; Hoffmann \& Solbrig, 2003). Os indivíduos jovens podem ser quase ou totalmente queimados durante várias estações de estiagem, antes de se tornarem adultos (Scholes \& Archer, 1997; Wakeling et al., 2012). Ainda assim alguns podem conseguir sobreviver em função da presença de órgãos subterrâneos (Scholes \& Archer, 1997, Wakeling et al., 2012). Uma vez tendo atingido tamanho suficiente de escape ao fogo (aproximadamente 2 a 4 metros) ficam bem menos suceptíveis às queimadas (Scholes \& Archer, 1997; Higgins et al., 2000; Wakeling et al., 2012).

Em função da camada herbácea frequentemente presente, as savanas são altamente inflamáveis e bastante sujeitas a queimadas, reduzindo assim a dominância das espécies lenhosas (Higgins et al., 2000; Hoffmann et al., 2012). Em contraste, em formações florestais mais fechadas, como Matas de Galerias, nas quais as gramíneas possuem um desenvolvimento menor, o fogo é menos freqüente e o desenvolvimento de combustível para o fogo é restrito (Higgins et al., 2000; Hoffmann et al., 2012).

Acredita-se, então, que exista um feedback positivo entre fogo e a cobertura graminosa (Higgins et al., 2000; Hoffmann et al., 2012), já que a biomassa das gramíneas acumulada durante o período chuvoso serve de combustível para o fogo na seca subseqüente (Miranda et al., 1993; D’Antonio et al., 1998). Desta forma, quanto mais biomassa for acumulada na superfície no solo, maior será a intensidade do fogo subseqüente (Miranda et al., 1993; D’Antonio et al., 1998). O aumento na frequiência de queimadas favorece as gramíneas em detrimento das árvores (Sato \& Miranda, 1996; Hoffmann, 1999).

Plantas lenhosas adultas possuem mecanismos de armazenamento e proteção contra o fogo que geram uma taxa muito baixa de mortalidade, permitindo a sobrevivência da população de árvores em baixas densidades, compensando a perda de árvores jovens (Miranda et al., 2002; Hanan 
et al., 2008; Baudena et al., 2010). Apesar de muitas espécies vegetais das savanas, principalmente do Cerrado, apresentarem características morfológicas que conferem resistência ao fogo, os incêndios em intervalos muito curtos, ainda assim, desfavorecem a camada lenhosa (Moreira, 2000; Miranda et al., 2002; Felfili et al., 2005).

Da mesma forma, ocorre com a herbivoria: existe uma influência direta na interação competitiva entre espécies lenhosas e herbáceas. A herbivoria em savanas, em geral, promove a defoliação das ervas, favorecendo o crescimento das lenhosas (Scholes \& Archer, 1997; Van Langevelde et al., 2003). No entanto, alguns herbívoros podem também reduzir a população lenhosa, matando-as ou deixando-as totalmente desfolhadas ou favorecendo o crescimento das populações de gramíneas em determinados locais, em função da deposição de fezes e urina (Van Langevelde et al., 2003; Kraaij \& Ward, 2006).

A proteção contra o fogo, ou mesmo contra a herbivoria, pode determinar mudanças graduais na fitofisionomia de uma savana, desde uma formação mais aberta até uma formação florestal mais fechada, com maior número e densidade de espécies lenhosas (Pivello \& Coutinho, 1996; Moreira, 2000; Van Langevelde et al., 2003; Pivello, 2011).

Uma grande ameaça à dinâmica e cobertura vegetal nativa nas savanas neotropicais é a invasão por gramíneas exóticas (Williams \& Baruch, 2000; Hoffmann \& Haridasan, 2008). Elas podem alterar a composição e abundância das espécies, afetando o funcionamento dos ecossistemas (Pivello et al., 1999b; Williams \& Baruch, 2000), incluindo os regimes de queima (D’Antonio \& Vitousek, 1992; Levine et al., 2003). Além de alterar as freqüências de queimadas, podem também aumentar a intensidade do fogo, em função de produzirem mais biomassa, o combustível para o fogo, que as plantas nativas (D’Antonio et al., 1998; Levine et al., 2003; Hoffmann et al., 2004).

De acordo com Hoffmann et al. (2004), gramíneas exóticas são espécies de maior produtividade que gramíneas nativas e, consequentemente, exercem uma influência negativa maior no estabelecimento das espécies lenhosas (Hoffmann \& Haridasan, 2008). Também possuem 
características que as faz conquistar mais espaços que as gramíneas nativas após as queimadas (D’Antonio \& Vitousek, 1992; Pivello et al., 1999b; Foxcroft et al., 2010).

Hoffmann \& Haridasan (2008) sugerem que a completa remoção das gramíneas invasoras, ou mesmo a sua defoliação, pode aumentar o estabelecimento, a sobrevivência e o crescimento de plântulas de lenhosas. A influência negativa da competição com gramíneas é tão importante quanto o fogo ou a herbivoria na determinação da densidade populacional de lenhosas (Riginos, 2009).

Estas plantas invasoras também apresentam outras características que podem diminuir o recrutamento de espécies lenhosas, como altas taxas de crescimento, altas taxas de germinação, produção de aleloquímicos, uso efetivo dos nutrientes do solo, curtos ciclos de vida e sementes facilmente dispersas (Freitas \& Pivello, 2005; Martins et al., 2006; Barbosa et al., 2008; Hoffmann \& Haridasan, 2008). D’Antonio et al. (1998) também acreditam que a remoção das gramíneas invasoras deve aumentar a densidade de arbustos nativos, em função do impacto negativo que as gramíneas exóticas exerceram no estabelecimento inicial e na sobrevivência das mudas. Pivello et al. (1999b) afirmam também que muitas gramíneas invasoras são mais resistentes ao fogo, competindo e ganhando das gramíneas nativas na ocupação da área após a passagem do fogo.

Gramíneas perenes africanas tem invadido as savanas neotropicais e tem se tornado cada vez mais abundantes, como é o caso do Andropogon sp., Pennisetum sp., Melinis spp. e Urochloa spp. (Klink \& Joly, 1989; Rossiter et al., 2003; Hoffmann et al., 2004; Hoffmann \& Haridasan, 2008; Brooks et al., 2010; Foxcroft et al., 2010).

Nas savanas brasileiras, Pivello et al. (1999b) afirmam que as gramíneas exóticas estão invadindo e, provavelmente, substituindo as gramíneas nativas. No Brasil, as gramíneas especialmente trazidas para o país com o objetivo de formar pastagens representam grande quantidade das espécies que se tornaram invasoras, como Urochloa spp. (braquiárias), Hyparrhenia rufa (capim-jaraguá), Melinis minutiflora (capim-gordura), Panicum maximum (capim-colonião), Paspalum spp. (Pivello et al., 1999b; Matos \& Pivello, 2009). 
Elas são plantadas como forrageiras para aumentar a produtividade do gado e acabam se espalhando ao longo de toda a área, incluindo unidades de conservação (Klink \& Joly, 1989; Pivello et al., 1999a; Martins et al., 2006). Apesar de seu comportamento considerado agressivo, no que diz respeito a estabelecimento e disseminação, o plantio destas gramíneas exóticas continua a ser promovido em pastagens, no sentido de aumentar a produtividade das forragens (Pivello et al., 1999b; Pivello et al., 1999a). São plantas difíceis de serem controladas manualmente e o uso de herbicidas para o controle do crescimento destas gramíneas invasoras pode não ser muito adequado ao ambiente (Pivello et al., 1999b).

De acordo com Fonseca (2008), as gramíneas invasoras representam atualmente a mais séria ameaça vegetal à conservação da biodiversidade na região do Cerrado, pois são extremamente agressivas, resistentes ao fogo, produzem grande quantidade de sementes viáveis e competem, com sucesso, com a flora nativa, eliminando-a muitas vezes.

As espécies de braquiária representam as mais comuns e mais agressivas gramíneas exóticas encontradas nas áreas do Cerrado (Almeida Neto et al., 2010; Lannes et al., 2012), sendo que somente no Brasil, já existem 50 milhões de hectares de pastos constituídos por braquiária (Macedo, 2005). Podem diminuir drasticamente a abundância de gramíneas nativas (Pivello 1999b) e de Asteraceae (Almeida-Neto et al., 2010) e dominar a comunidade herbácea (Almeida-Neto et al., 2010; Gorgone-Barbosa et al., 2014).

O capim pojuca (Paspalum atratum Swallen) é uma gramínea $\mathrm{C}_{4}$ (Klink \& Joly, 1989) nativa do Cerrado, que apresenta crescimento vigoroso e grande velocidade de rebrota (Karia \& Andrade, 2001; Leite et al., 2001). Possui morfologia semelhante à Urochloa brizantha, sendo uma espécie perene, com rizomas longos e profundos e com colmos de até $130 \mathrm{~cm}$ de comprimento e também é utilizada como forrageira (Maciel et al., 2009).

Tendo em vista que, em função de mudanças climáticas e da ação antrópica, as queimadas no Cerrado tem se tornado cada vez mais freqüentes (Pivello, 2011), e que o bioma também tem sido invadido por espécies de gramíneas exóticas, é de extrema importância conhecer como as 
espécies lenhosas se comportam após a simulação da passagem do fogo na presença de uma gramínea exótica.

O complexo mecanismo de estabelecimento e sobrevivência das mudas de lenhosas no campo ainda não foi totalmente elucidado (Sankaran et al., 2005), mesmo tendo sido estudado para várias espécies em diversos habitats diferentes (p.e. Ward \& Esler, 2010; Kambatuku et al., 2011). Desta forma, a análise das plantas durante as fases mais críticas do seu estabelecimento, como no primeiro ano de desenvolvimento, período no qual as plantas estão mais suceptíveis à ação de uma defoliação inesperada é de extrema importância.

Compreender melhor os fatores que influenciam a formação e a composição da estrutura florística das savanas, em especial a rebrota de espécies lenhosas do Cerrado, é essencial para se poder prever mudanças na composição da comunidade e eventualmente poder fazer o manejo e a conservação deste bioma.

O objetivo deste trabalho foi avaliar a influência da presença de gramíneas exótica e nativa e da adição de nutrientes na rebrota de plantas de seis espécies de lenhosas do Cerrado submetidas à defoliação.

Espera-se com este trabalho que as gramíneas influenciem negativamente a rebrota das plantas e que a adição de nutrientes beneficie o crescimento das gramíneas, inibindo o crescimento de plantas lenhosas. Por apresentar um crescimento potencial aparentemente maior, de acordo com o discutido acima, também espera-se que a gramínea exótica exerça uma inibição no crescimento das lenhosas mais acentuada que a gramínea nativa. 


\section{Material e Métodos}

Preparo da área experimental, espécies selecionadas e delineamento experimental.

O experimento foi instalado em uma área adjacente ao laboratório de Termobiologia,

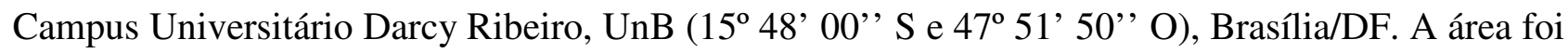
cercada, sua vegetação removida, e o solo limpo e aplainado.

Nesta área, foram estabelecidas cinco parcelas experimentais (9x6 metros), cobertas com plástico transparente para exclusão de chuva. Cada parcela representou uma réplica do desenho experimental.

Estas parcelas foram mantidas sob irrigação artificial, duas vezes ao dia, ao longo de seis meses (durante a estação chuvosa). O volume de água adicionado pela irrigação foi de $37,5 \mathrm{~L} / \mathrm{m}^{2}$ (37,5 mm) a cada semana, equivalente a aproximadamente $150 \mathrm{~mm}$ de chuva por mês, ou $900 \mathrm{~mm}$ ao longo dos seis meses de experimento. O período de irrigação foi de outubro de 2011 a abril de 2012.

Cada uma destas parcelas foi subdividida em 6 subparcelas de $4 \mathrm{~m}^{2}$, sendo que em duas delas o solo permaneceu nú (G0), em duas foi plantada a gramínea nativa (Paspalum atratum Swallen) (G1), e nas outras duas foi plantada a gramínea exótica (Urochloa brizantha (Hochst. ex A. Rich.) Stapf) (G2).

No início da estação chuvosa (novembro de 2009), as gramíneas foram plantadas, semeando-se a lanço aproximadamente 50 gramas de sementes por parcela. Estas parcelas foram irrigadas frequentemente para promover o estabelecimento das gramíneas e, quando necessário, novas semeaduras foram realizadas com o objetivo de formar uma cobertura graminosa consistente e uniforme.

Enquanto as gramíneas eram estabelecidas no campo, mudas de espécies lenhosas do Cerrado foram produzidas. As sementes vinham sendo coletadas desde maio de 2008, em áreas de 
Cerrado do Distrito Federal. Após a coleta, os diásporos foram dispostos em bandejas para secar, e as sementes beneficiadas e armazenadas em sacos de papel, em geladeira $\left(5^{\circ} \mathrm{C}\right)$.

Foram selecionadas seis espécies de lenhosas arbóreas nativas do Cerrado, conforme Tabela 1. Os critérios de escolha dessas espécies foram: 1) representatividade das espécies nas comunidades de Cerrado; 2); disponibilidade e germinabilidade das sementes; 3 ) estabelecimento e sobrevivência das plântulas em casa de vegetação. Por ser considerada como uma das famílias mais representativas em número de espécies em levantamentos florísticos realizados em áreas de Cerrado (Lopes et al., 2011; Silva et al., 2002), a Fabaceae foi representada neste estudo por três espécies (Tabela 1).

Tabela 1. Espécies lenhosas utilizadas no experimento de defoliação e rebrota e suas características.

\begin{tabular}{lccc}
\hline \multicolumn{1}{c}{ Espécies } & Família & Deciduidade & Ocorrência no Cerrado \\
\hline Copaifera langsdorffii & Fabaceae - Caesalpinoideae & Semi-decídua & cerrado, cerradão, mata de galeria (+)* \\
Dalbergia miscolobium & Fabaceae - Papilionoideae & Semi-decídua & cerrado e florestas estacionais \\
Eugenia dysenterica & Myrtaceae & Decídua & cerrado, cerradão \\
Eriotheca pubescens & Bombacaceae & Decídua & cerrado, cerradão, campo cerrado \\
Myracrodruon urundeuva & Anacardiaceae & Decídua & Cerradão, mata de galeria (+) \\
Stryphnodendron adstringens & Fabaceae - Mimosoideae & Cerrado, Cerradão, Campo cerrado &
\end{tabular}

*predominância

Sementes de Copaifera langsdorffii, Eugenia dysenterica e Stryphnodendron adstringens receberam tratamentos apropriados para eliminar a dormência tegumentar ou mesmo para uniformizar a germinação (Ferreira \& Borghetti, 2004). As sementes foram postas para germinar em placas de petri contendo papel filtro e água em câmaras de germinação com fotoperíodo de 12 horas e temperatura de $30^{\circ} \mathrm{C}$.

Após a germinação, as plântulas foram transplantadas para sacos de mudas com latossolo vermelho, adicionado de 1/3 de areia para melhorar a aeração, e mantidas em casa de vegetação. As plântulas foram crescidas por aproximadamente 120 dias, a depender da época da coleta das sementes e plantio em campo. Plântulas com crescimento anormal foram descartadas. 
Antes do transplante, dez plantas de cada espécie foram retiradas ao acaso para a coleta das medidas iniciais. Dados como comprimento do caule, presença ou não de cotilédones, peso fresco de raiz, caule, folhas e cotilédones foram anotados. As plantas foram postas para secar em estufa, a $80^{\circ} \mathrm{C}$, por 72 horas e a massa seca de cada parte vegetal determinada. Estas medidas das plantas antes do seu plantio na área experimental podem ser encontradas na Tabela 2 (comprimento do caule e biomassa da raiz, caule, folha e cotilédones).

Em cada subparcela foram plantadas quatro plântulas de cada espécie, em fevereiro de 2011 (T0). Antes do plantio, contudo, a parte aérea das gramíneas foi cortada a dois centímetros do solo com uma tesoura de jardim, buscando uniformizar o tamanho da parte aérea das gramíneas antes do inicio do experimento. As plantas recém-transplantadas foram irrigadas diariamente até seu completo estabelecimento.

Após três meses do início do plantio no campo (T3), em maio de 2011, foi avaliada a porcentagem de sobrevivência e medidos o comprimento e o diâmetro do caule para cada planta de lenhosa. Após tais medidas, todas as plantas tiveram sua parte aérea removida logo acima do primeiro nó, simulando uma defoliação. Vadigi e Ward (2014), em seu experimento com plântulas e gramíneas também simularam a defoliação após três meses de plantio das mudas no campo. Neste momento, as gramíneas foram novamente cortadas a dois centímetros do solo. As partes aéreas removidas das plantas de lenhosa foram identificadas e levadas à estufa a $80^{\circ} \mathrm{C}$, por 72 horas para secagem e determinação da biomassa aérea.

Para avaliar a influência da adição de nutrientes no crescimento das gramíneas e na rebrota das lenhosas, foi acrescentado em três das seis subparcelas (N1) de cada parcela o fertilizante inorgânico "Osmocote ${ }^{\circledR}$ 15:9:12 (NPK)" do tipo granular de liberação lenta. Este fertilizante foi adicionado mensalmente, totalizando 4 aplicações por ano, durante os meses abril a julho de 2011. A aplicação de fertilizantes em diferentes datas teve a finalidade de reduzir possível lixiviação de nutrientes. A quantidade de fertilizante foi de $26,7 \mathrm{~g}$ por $\mathrm{m}^{2}$ por aplicação (3:1:2 NPK). 
Esta quantidade foi determinada com base na adição de $4 \mathrm{~g}$ de N.m ${ }^{-2}$ por aplicação, vista com uma alta concentração de nitrogênio em diversos estudos (Tilman, 1987; Walker \& Knoop, 1987; Kraaij \& Ward, 2006; Tomlinson et al., 2012; Vadigi \& Ward, 2014). A quantidade de nitrogênio utilizada ( $4 \mathrm{~g} / \mathrm{m}^{2}$ por mês) é quase o dobro da mais alta concentração utilizada por Kraaij e Ward (2006) (2,8 g/mes) e por Tilman (1987) (2,3 g/mes) (Vadigi \& Ward, 2014). Kozovits et al., 1996, em áreas de cerrado sentido restrito, encontraram concentrações de nitrato no solo variando entre 2,7 a 4,4 mg/Kg e de amônia entre 17 e 8,6 mg/kg, antes das queimadas.

Após 11 meses da defoliação (T14), em abril de 2012, foram medidos novamente comprimento e diâmetro do caule, número de folhas vivas e número de ramificações a partir do caule para cada planta sobrevivente. As partes aéreas das plantas restantes foram coletadas e postas para secar em estufa a $80^{\circ} \mathrm{C}$, por 72 horas para determinação da biomassa aérea.

\section{Análise estatística}

Os dados coletados foram submetidos à análise de variância, modelo linear geral, quando detectados padrões de normalidade dos dados. Para se testar os padrões de normalidade, utilizou-se o teste de Kolmogorov Smirnov. Para verificar a homogeneidade das variâncias, que é outra premissa para a utilização da análise de variância, o teste de Levene foi executado.

Em alguns casos, para conseguir a normalidade, os dados foram transformados em logaritmo natural ou ln $(\mathrm{x}+1)$ (para dados contendo zero). Após a realização da análise de variância, quando possível, o teste de Tukey ("post-hoc test") foi realizado para a comparação das amostras diferentes entre si.

Nos casos em que os dados não apresentavam curva normal, mesmo após a transformação logarítmica, testes não paramétricos, como Kruskal Wallis foram utilizados.

O pacote estatístico utilizado para a análise foi o SPSS.

Foram consideradas variáveis independentes, as espécies lenhosas, as gramíneas (G0, G1 e G2) e a adição de nutrientes (N0 e N1). As diferentes respostas no crescimento, como biomassa, 
comprimento do caule, sobrevivência, foram consideradas variáveis dependentes. As parcelas foram incluídas inicialmente como fator dependente e, quando não influenciadoras na resposta, removidas para uma repetição na análise.

\section{Resultados e Discussão}

1. Biometria e biomassa das plantas que foram levadas ao campo - dados iniciais:

De maneira geral, as espécies que apresentaram maior desenvolvimento de biomassa aérea, nos 120 dias que antecederam o plantio no campo, foram Eriotheca pubescens e Eugenia dysenterica (Figura 1). Elas apresentaram os maiores valores de biomassa seca das folhas, do caule e dos cotilédones, resultando em um alto valor de biomassa aérea, em comparação às outras espécies (Tabela 2).

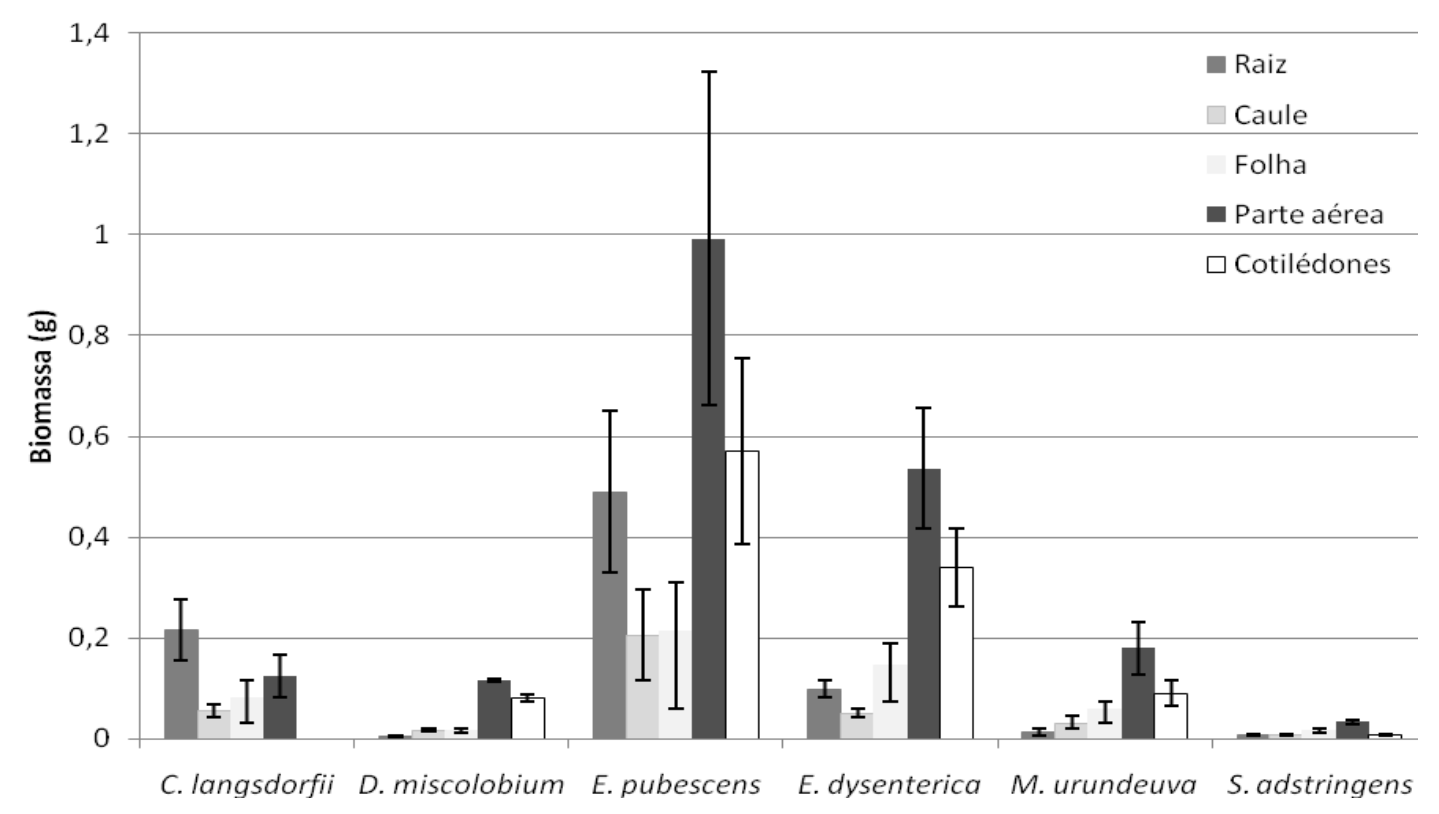

Figura 1. Biomassa seca média (g) de dez amostras retiradas ao acaso das amostras de plantas utilizadas no experimento (antes do plantio das mudas na área experimental). Plantas das espécies: Copaifera langsdorffii, Dalbergia miscolobium, Eriotheca pubescens, Eugenia dysenterica, Myracrodruon urundeuva e Stryphnodendron adstringens. Plantas, com aproximadamente 120 dias de vida, produzidas a partir de sementes, entre os meses de out/2010 a jan/2012, em condições relativamente controladas. Barras de erros indicam o intervalo de confiança de $95 \%$. 
Apesar de Copaifera langsdorffii também ter apresentado altos valores para biomassa de folhas e caule, em função da ausência dos cotilédones, a biomassa aérea total acabou ficando com um valor relativamente baixo, em comparação às outras espécies (Tabela 2, Figura 1).

Kitajima e Fernner (2000) descreveram alguns grupos funcionais com base nas características dos cotilédones, nos quais eles seriam divididos basicamente de acordo com sua posição e função (armazenamento, foliáceo/fotossintético). De acordo com Kitajima (1992), os cotilédones e suas funções teriam implicações ecológicas na vida das plântulas, já que plantas com cotilédones foliáceos precisariam começar a utilizar energia luminosa antes das espécies com cotilédones de reserva.

Tabela 2. Biometria média (média $(\mathrm{g}) \pm$ desvio padrão) de dez indivíduos retirados ao acaso das amostras de plantas utilizadas no experimento (antes do plantio das mudas na área experimental). Plantas das espécies: Copaifera langsdorffii, Dalbergia miscolobium, Eriotheca pubescens, Eugenia dysenterica, Myracrodruon urundeuva e Stryphnodendron adstringens. Plantas, com aproximadamente 120 dias de vida, produzidas a partir de sementes, em condições relativamente controladas.

\begin{tabular}{|c|c|c|c|c|c|c|}
\hline & $\begin{array}{c}\begin{array}{c}\text { Biomassa } \\
\text { raiz }\end{array} \\
\end{array}$ & $\begin{array}{c}\text { Biomassa } \\
\text { caule }\end{array}$ & $\begin{array}{c}\begin{array}{c}\text { Biomassa } \\
\text { folha }\end{array} \\
\end{array}$ & $\begin{array}{c}\text { Biomassa } \\
\text { cotilédones }\end{array}$ & $\begin{array}{c}\begin{array}{c}\text { Biomassa } \\
\text { aérea }\end{array} \\
\end{array}$ & $\begin{array}{c}\text { Comprimento } \\
\text { caule }(\mathbf{m m})\end{array}$ \\
\hline $\begin{array}{l}\text { Copaifera } \\
\text { langsdorfii }\end{array}$ & $\begin{array}{c}0,217 \pm \\
0,098(\mathbf{a b})^{*}\end{array}$ & $\begin{array}{c}0,055 \pm \\
0,022 \text { (b) }\end{array}$ & $\begin{array}{c}0,083 \pm \\
0,051(\mathbf{b c})\end{array}$ & $0,000(\mathbf{c})$ & $\begin{array}{c}0,124 \pm \\
0,067 \text { (bc) }\end{array}$ & $\begin{array}{c}39,537 \pm \\
13,518(\mathbf{b c})\end{array}$ \\
\hline $\begin{array}{c}\text { Dalbergia } \\
\text { miscolobium }\end{array}$ & $\begin{array}{c}0,005 \pm \\
0,003(\mathbf{c})\end{array}$ & $\begin{array}{c}0,017 \pm \\
0,003(\mathbf{d})\end{array}$ & $\begin{array}{c}0,018 \pm \\
0,006(\mathbf{d})\end{array}$ & $\begin{array}{c}0,081 \pm \\
0,011(\mathbf{b})\end{array}$ & $\begin{array}{c}0,116 \pm \\
0,018(\mathbf{c})\end{array}$ & $\begin{array}{c}56,802 \pm \\
7,702(\mathbf{a b})\end{array}$ \\
\hline $\begin{array}{l}\text { Eriotheca } \\
\text { pubescens }\end{array}$ & $\begin{array}{c}0,490 \pm \\
0,258 \text { (a) }\end{array}$ & $\begin{array}{c}0,206 \pm \\
0,147 \text { (a) }\end{array}$ & $\begin{array}{c}0,214 \pm \\
0,154 \text { (a) }\end{array}$ & $\begin{array}{c}0,571 \pm \\
0,297 \text { (a) }\end{array}$ & $\begin{array}{c}0,992 \pm \\
0,534 \text { (a) }\end{array}$ & $\begin{array}{c}3,368 \pm \\
1,333(\mathbf{d})\end{array}$ \\
\hline $\begin{array}{c}\text { Eugenia } \\
\text { dysenterica }\end{array}$ & $\begin{array}{c}0,100 \pm \\
0,026 \text { (b) }\end{array}$ & $\begin{array}{c}0,051 \pm \\
0,015(\mathbf{b c})\end{array}$ & $\begin{array}{c}0,145 \pm \\
0,071(\mathbf{a b})\end{array}$ & $\begin{array}{c}0,340 \pm \\
0,124 \text { (a) }\end{array}$ & $\begin{array}{c}0,536 \pm \\
0,193 \text { (a) }\end{array}$ & $\begin{array}{c}82,141 \pm \\
31,577 \text { (a) }\end{array}$ \\
\hline $\begin{array}{l}\text { Myracrodruon } \\
\text { urundeuva }\end{array}$ & $\begin{array}{c}0,014 \pm \\
0,013 \text { (c) }\end{array}$ & $\begin{array}{c}0,032 \pm \\
0,021(\mathbf{c d})\end{array}$ & $\begin{array}{c}0,058 \pm \\
0,026 \text { (c) }\end{array}$ & $\begin{array}{c}0,090 \pm \\
0,042 \text { (b) }\end{array}$ & $\begin{array}{c}0,180 \pm \\
0,084 \text { (b) }\end{array}$ & $\begin{array}{c}66,945 \pm \\
25,195 \text { (a) }\end{array}$ \\
\hline $\begin{array}{l}\text { Stryphnodendron } \\
\text { adstringens }\end{array}$ & $\begin{array}{c}0,008 \pm \\
0,003(\mathbf{c})\end{array}$ & $\begin{array}{c}0,008 \pm \\
0,002(\mathbf{e})\end{array}$ & $\begin{array}{c}0,017 \pm \\
0,006(\mathbf{d})\end{array}$ & $\begin{array}{c}0,007 \pm \\
0,002(\mathbf{c})\end{array}$ & $\begin{array}{c}0,033 \pm \\
0,008(\mathbf{c})\end{array}$ & $\begin{array}{l}33,045 \pm \\
6,072(\mathbf{c})\end{array}$ \\
\hline Estatística & $\begin{array}{c}\text { Kruskal-Wallis, } \\
\mathrm{F}_{5}=49,530 \\
\mathrm{p}<0,001\end{array}$ & $\begin{array}{c}\text { ANOVA, } \\
\mathrm{F}_{5}=10,631, \\
\mathrm{p}<0,001\end{array}$ & $\begin{array}{c}\text { Kruskal-Wallis, } \\
\mathrm{F}_{5}=41,036 \\
\mathrm{p}<0,001\end{array}$ & $\begin{array}{c}\text { Kruskal-Wallis, } \\
\mathrm{F}_{5}=54,380 \\
\mathrm{p}<0,001\end{array}$ & $\begin{array}{c}\text { Kruskal-Wallis, } \\
\mathrm{F}_{5}=51,272 \\
\mathrm{p}<0,001\end{array}$ & $\begin{array}{c}\text { ANOVA, } \\
\mathrm{F}_{5}=127,155, \\
\mathrm{p}<0,001\end{array}$ \\
\hline
\end{tabular}

* letras diferentes na mesma coluna representam diferenças significativas entre as espécies, de acordo com o teste de Tukey (p $\leq 0,05)$.

Estas mesmas espécies (Eugenia dysenterica, Copaifera langsdorffii e Eriotheca pubescens) foram as que apresentaram maior desenvolvimento do sistema radicular (Kruskal-Wallis, $\left.\mathrm{F}_{5}=49,530, \mathrm{p}<0,001\right)($ Figura 1, Tabela 2).

Por outro lado, aquelas que apresentaram maior crescimento em altura do caule foram Eugenia dysenterica, Myracrodruon urundeuva e Dalbergia miscolobium (ANOVA, $\mathrm{F}_{5}=127,155$, $\mathrm{p}<0,001$ ) (Figura 2). 


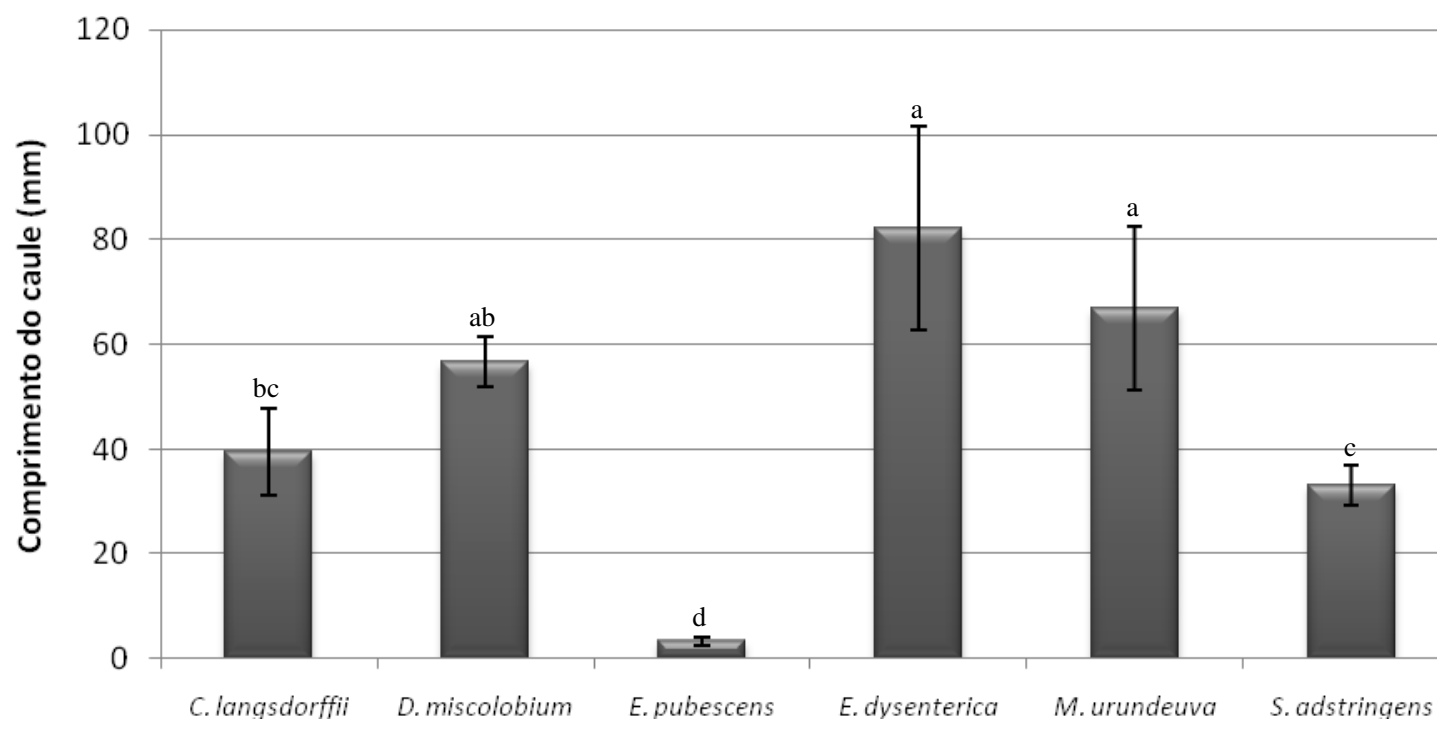

Figura 2. Comprimento médio do caule $(\mathrm{mm})$ de dez indivíduos retirados ao acaso das amostras de plantas utilizadas no experimento (antes do plantio das mudas na área experimental). Plantas das espécies: Copaifera langsdorffii, Dalbergia miscolobium, Eriotheca pubescens, Eugenia dysenterica, Myracrodruon urundeuva e Stryphnodendron adstringens. Plantas, com aproximadamente 120 dias de vida. Barras de erros indicam o intervalo de confiança de 95\%. (Obs.: letras diferentes sobre as colunas indicam diferenças estatísticas significativas entre os tratamentos, de acordo com o teste de Tukey, $\mathrm{p} \leq 0,05$ ).

Duas espécies apresentaram crescimento inicial bem mais expressivo que as outras, Eriotheca pubescens e Eugenia dysenterica e, nestes primeiros meses de desenvolvimento, já foi possível inferir algumas estratégias ecológicas. Eriotheca pubescens, que foi a que apresentou os maiores valores de biomassa, foi a que obteve o menor crescimento do caule (Tabela 2). Esta pode ser uma estratégia da espécie, na qual a planta investe em reserva, evitando um grande incremento em altura e suas conseqüências, como aumento da perda de água e aumento da susceptibilidade ao ataque de patógenos. Segundo Silva e Batalha (2011b), valores baixos de área foliar específica, bem como folhas mais rígidas e fibrosas podem deixar a planta menos suscetível à herbivoria. Em um estudo realizado com 30 espécies lenhosas do Cerrado, Eriotheca pubescens foi uma das sete que conseguiu não sofrer alteração no número de indivíduos da população após a passagem de quatro incêncios induzidos durante dois anos (Rocha \& Silva, 1999).

Já Eugenia dysenterica possui as maiores sementes dentre as espécies utilizadas (Tabela 3), com cotilédones de reserva, o que poderia promover um bom desenvolvimento do embrião até plântula e, consequentemente, as plantas formadas seriam mais vigorosas e robustas. Duarte et al. 
(2006) observaram que sementes maiores de Eugenia dysenterica Mart. ex. DC. provenientes de frutos maduros coletados do solo apresentavam maiores taxas de germinação e maior vigor das plântulas.

Tabela 3. Peso médio das sementes de espécies de lenhosas do Cerrado (Copaifera langsdorffii, Dalbergia miscolobium, Eriotheca pubescens, Eugenia dysenterica, Myracrodruon urundeuva e Stryphnodendron adstringens). Adaptado de Almeida et al. (1998).

\begin{tabular}{ccc}
\hline & Sementes por Kg & Peso por semente (mg) \\
\hline Copaifera langsdorfii & 1720 & 581 \\
Dalbergia miscolobium & 3100 & 322 \\
Eriotheca pubescens & 6700 & 149 \\
Eugenia dysenterica & 700 & 1428 \\
Myracrodruon urundeuva & 6711 & 149 \\
Stryphnodendron adstringens & 940 & 1063 \\
\hline
\end{tabular}

2. Dados coletados antes da defoliação, aos 3 meses após o plantio:

Após três meses do plantio no campo, a porcentagem geral de sobrevivência entre todas as espécies foi de $76 \%$. As espécies que apresentaram maiores taxas de sobrevivência, acima de $80 \%$, foram Eriotheca pubescens, Eugenia dysenterica, Myracrodruon urundeuva e Copaifera langsdorffii (Kruskal-Wallis, $\mathrm{F}_{5}=23,642, \mathrm{p} \leq 0,001$ ) (Figura 3). Dalbergia miscolobium e Eriotheca pubescens obtiveram sobrevivências em torno de 50\% (Figura 3).
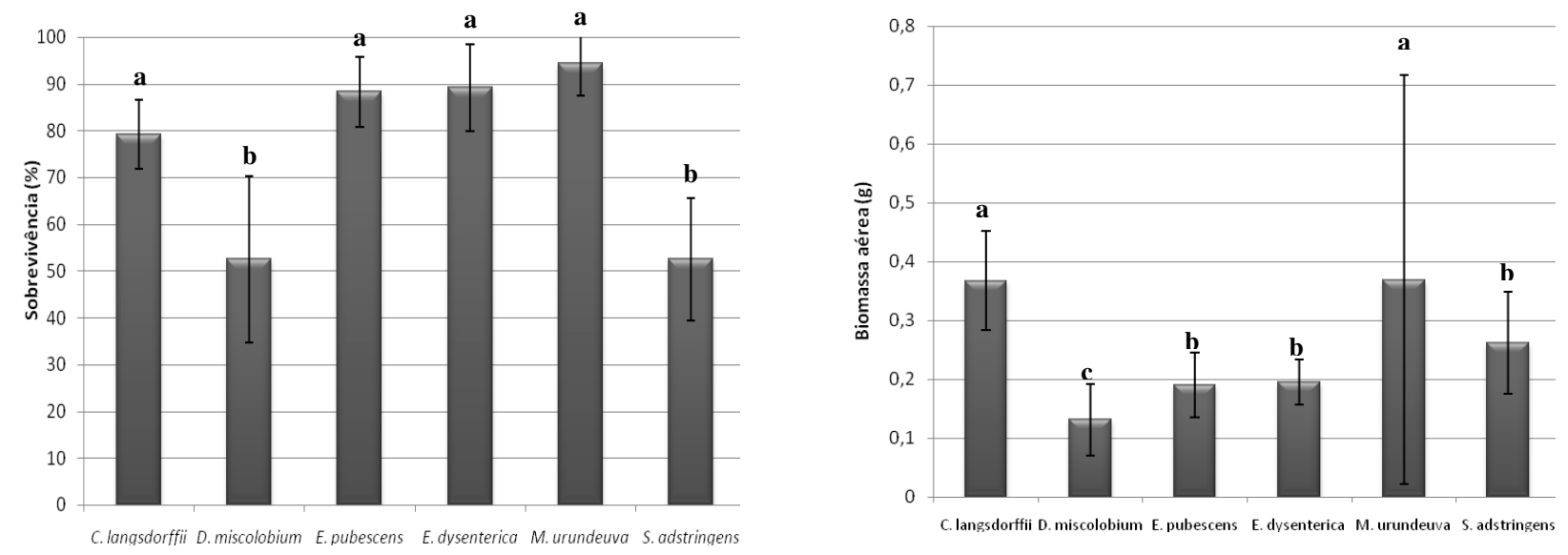

Figura 3. Porcentagem de plantas de lenhosas sobreviventes e biomassa aérea média para cada uma das espécies plantadas na área experimental, após 3 meses de crescimento em condições de campo. Plantas das espécies: Copaifera langsdorffii, Dalbergia miscolobium, Eriotheca pubescens, Eugenia dysenterica, Myracrodruon urundeuva e Stryphnodendron adstringens. Barras de erros indicam intervalo de confiança de $95 \%$. Obs. Plantas com aproximadamente 210 dias de vida. (Obs.: letras diferentes sobre as colunas indicam diferenças estatísticas significativas entre as espécies). 
A fase de plântula, juntamente com a germinação, é considerada uma das mais delicadas fases da vida da planta, já que os indivíduos estão mais sujeitos à competição, ataque por patógenos, pisoteio, herbivoria e predação (Sousa-Silva \& Fagg, 2011; Fagg \& Felfili, 2008). Essa fase, de extrema sensibilidade para o vegetal, é considerada decisiva para o estabelecimento da planta e de sua população (Larcher, 2000).

As espécies que apresentaram maior biomassa aérea, após três meses de cultivo no campo, foram Copaifera langsdorffii, Myracrodruon urundeuva e Stryphnodendron adstringens, enquanto Dalbergia miscolobium, Eriotheca pubescens e Eugenia dysenterica apresentaram o menor crescimento (Figura 3). Foi observada uma relação positiva entre a biomassa aérea, antes do plantio no campo, e a sobrevivência após 3 meses de cultivo no campo (Pearson=0,381, p=0,001), sendo que as espécies que apresentaram menor sobrevivência foram aquelas com os valores mais baixos de biomassa aérea (Figura 4). LLoret et al. (1999) também encontraram correlação positiva entre o tamanho da semente, tamanho inicial e a sobrevivência das plântulas. De acordo com Mangla et al. (2011), pequenas diferenças no tamanho inicial entre indivíduos e espécies podem potencialmente influenciar o desenvolvimento a longo prazo.
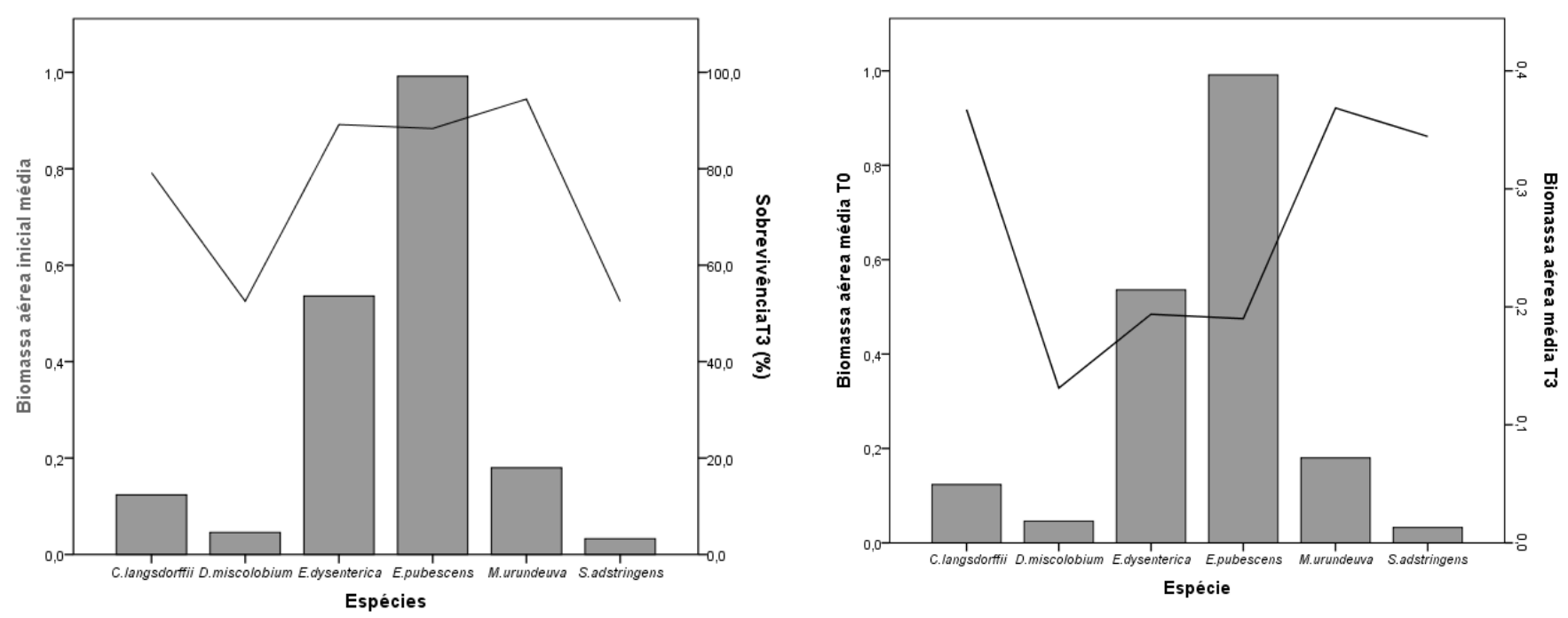

Figura 4. Gráficos de correlação entre biomassa aérea média antes do plantio (y) e porcentagem de plantas de lenhosas sobreviventes, após 3 meses de crescimento em condições de campo (z), Biomassa aérea média antes do plantio (y) e após 3 meses de crescimento em condições de campo (z), entre as plantas das espécies: Copaifera langsdorffii, Dalbergia miscolobium, Eriotheca pubescens, Eugenia dysenterica, Myracrodruon urundeuva e Stryphnodendron adstringens. 
Também foi possível verificar a existência de correlação negativa entre biomassa inicial e biomassa após três meses no campo (Pearson= -0,259, p=0,028) (Figura 4). Desta forma, ao contrário do esperado, um maior investimento em biomassa antes do plantio no campo acabou resultando em um menor investimento em biomassa durante os meses iniciais de crescimento no campo (Figura 4).

Esta pode também ser uma estratégia de algumas espécies, na qual, mesmo plantas que caracteristicamente possuem um crescimento mais acelerado que outras, no momento de algum distúrbio, como o transplantio neste caso, desaceleram seu crescimento até a sua estabilização e o retorno do crescimento, evitando assim uma morte precipitada.

Após três meses de crescimento em condições de campo, antes da defoliação, já foi possível observar um efeito negativo das gramíneas nativa e exótica na sobrevivência (ANOVA, $\mathrm{F}_{2}=44,666$, $\mathrm{p} \leq 0,001)$ e no crescimento aéreo das plantas de lenhosas, principalmente nos parâmetros biomassa aérea $(\mathrm{p} \leq 0,001)$ e diâmetro do caule $(\mathrm{p} \leq 0,001)$ (Tabela 4, Figura 5). Também existe uma tendência em observar esta mesma influência negativa das gramíneas no crescimento em altura do caule, já que o resultado estatístico encontrado deu muito próximo ao significativo ( $\mathrm{p}=0,060)$ (Tabela 4). Possivelmente uma amostra maior poderia elucidar a resposta.

Tabela 4. Análise estatística (ANOVA - Modelo linear geral) dos dados coletados a partir das plantas que rebrotaram, após 3 meses do plantio no campo. Experimento conduzido em área experimental do Laboratório de Termobiologia, UnB/Brasília, entre fevereiro de 2011 e abril de 2012.

\begin{tabular}{lccccc}
\hline & $\begin{array}{c}\text { Graus de } \\
\text { liberdade }\end{array}$ & Sobrevivência & Biomassa aérea & $\begin{array}{c}\text { Comprimento } \\
\text { do caule }\end{array}$ & $\begin{array}{c}\text { Diâmetro do } \\
\text { caule }\end{array}$ \\
\hline Gramínea (G) & 2 & $\mathrm{~F}=4,846$, & $\mathrm{F}=44,666$, & $\mathrm{F}=5,616$, & $\mathrm{F}=30,567$, \\
& & $\mathrm{p}=0,021$ & $\mathrm{p} \leq 0,001$ & $\mathrm{p}=0,060$ & $\mathrm{p} \leq 0,001$ \\
Espécie (Spp) & 5 & $\mathrm{~F}=11,913$, & $\mathrm{F}=20,136$, & $\mathrm{F}=44,666$, & $\mathrm{F}=38,806$, \\
& & $\mathrm{p} \leq 0,001$ & $\mathrm{p} \leq 0,001$ & $\mathrm{p} \leq 0,001$ & $\mathrm{p} \leq 0,001$ \\
G*Spp & \multirow{2}{*}{10} & $\mathrm{~F}=0,421$, & $\mathrm{F}=5,035$, & $\mathrm{F}=6,096$, & $\mathrm{F}=5,748$, \\
& $\mathrm{p}=0,918$ & $\mathrm{p} \leq 0,001$ & $\mathrm{p} \leq 0,001$ & $\mathrm{p} \leq 0,001$ \\
\hline
\end{tabular}

Não foi possível verificar diferenças significativas entre as respostas produzidas gramíneas nativa e exótica (Figura 5, Tabela 5). Ambas exerceram influência negativa na sobrevivência e no 
crescimento das lenhosas, mas nenhuma se sobressaiu frente à outra. Como as gramíneas foram defoliadas no momento do plantio das lenhosas no campo, é possível que o tempo ainda não tenha sido suficiente para que as gramíneas demonstrem seu potencial competitivo.
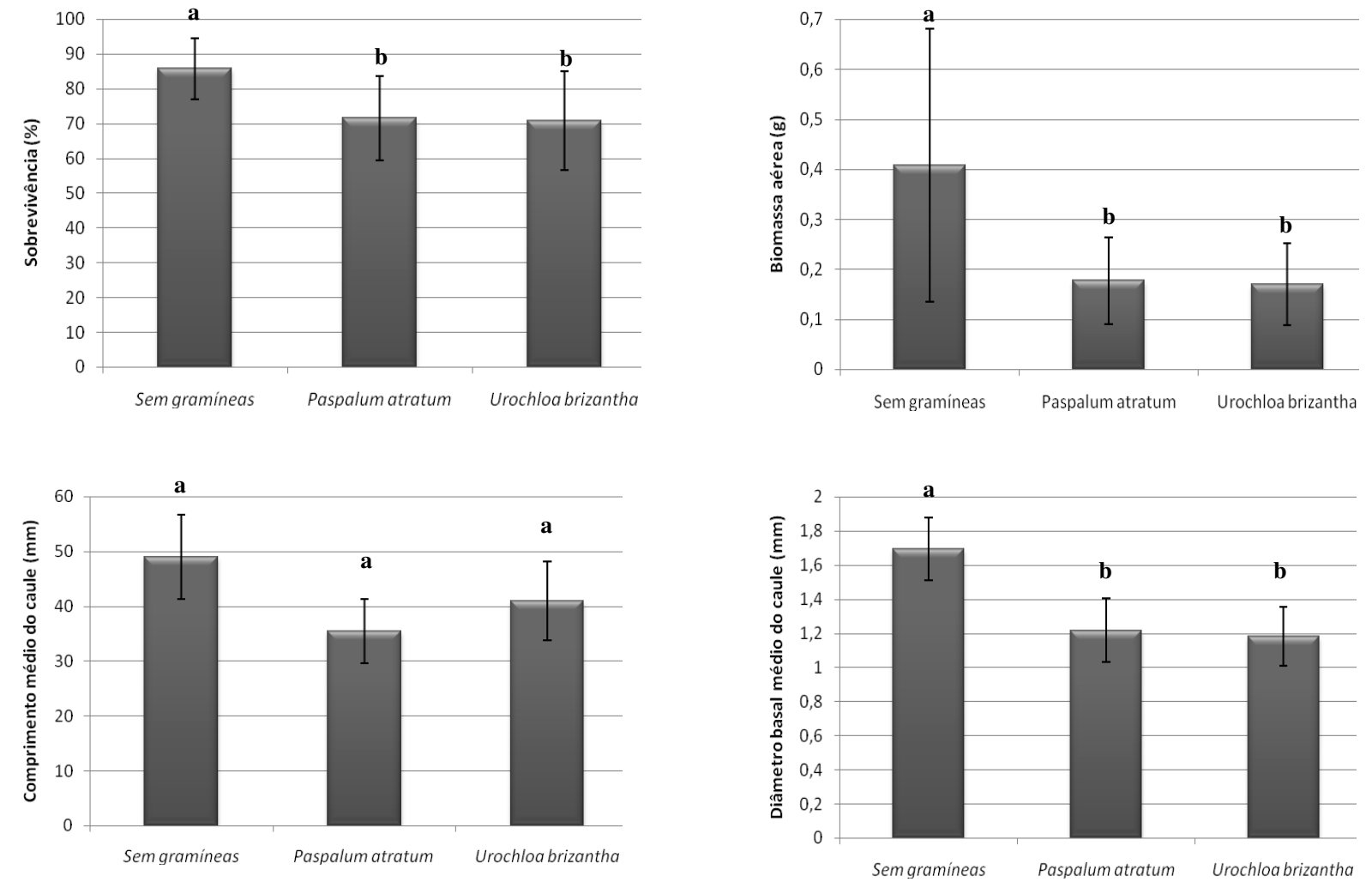

Figura 5. Sobrevivência e biometria média dos indivíduos de espécies de lenhosas plantados nos diferentes tratamentos com e sem gramíneas nativa (Paspalum atratum) e exótica (Urochloa brizantha), após 3 meses de crescimento em condições de campo. Barras de erros indicam o intervalo de confiança de $95 \%$. Obs. Plantas com aproximadamente 210 dias de vida. 
Tabela 5. Sobrevivência (\%) e biometria (média \pm desvio padrão) de mudas de lenhosas plantadas na área experimental, nos diferentes tratamentos, após 3 meses de crescimento em condições de campo. Plantas das espécies: Copaifera langsdorffii, Dalbergia miscolobium, Eriotheca pubescens, Eugenia dysenterica, Myracrodruon urundeuva e Stryphnodendron adstringens. Obs. Plantas com aproximadamente 210 dias de vida.

\begin{tabular}{|c|c|c|c|c|c|c|c|}
\hline Espécie & Tratamento* & $\mathbf{N}$ & Sobreviventes & $\begin{array}{c}\text { Sobrevi- } \\
\text { vência }(\%)\end{array}$ & $\begin{array}{l}\text { Comprimento } \\
\text { caule }(\mathbf{m m})\end{array}$ & $\begin{array}{c}\text { Diâmetro caule } \\
(\mathbf{m m})\end{array}$ & $\begin{array}{c}\text { Biomassa aérea } \\
(\mathrm{g})\end{array}$ \\
\hline \multirow{4}{*}{$\begin{array}{l}\text { Copaifera } \\
\text { langsdorffii }\end{array}$} & G0 & 40 & $35,00 \pm 0,317$ & 87,5 & $48,744 \pm 20,749$ & $1,706 \pm 0,524$ & $0,487 \pm 0,302$ \\
\hline & G1 & 40 & $30,00 \pm 0,440$ & 75,0 & $48,492 \pm 18,471$ & $1,668 \pm 0,519$ & $0,333 \pm 0,193$ \\
\hline & $\mathrm{G} 2$ & 40 & $30,00 \pm 0,440$ & 75,0 & $45,305 \pm 21,416$ & $1,609 \pm 0,382$ & $0,281 \pm 0,128$ \\
\hline & Todos Trats & 200 & $160,00 \pm 0,394$ & 80,0 & $47,790 \pm 20,061$ & $1,668 \pm 0,487$ & $0,378 \pm 0,218$ \\
\hline \multirow{4}{*}{$\begin{array}{l}\text { Dalbergia } \\
\text { miscolobium }\end{array}$} & G0 & 40 & $30,00 \pm 0,440$ & 75,0 & $71,439 \pm 33,592$ & $1,859 \pm 0,628$ & $0,195 \pm 0,163$ \\
\hline & G1 & 40 & $17,00 \pm 0,501$ & 42,5 & $39,615 \pm 22,980$ & $1,329 \pm 0,626$ & $0,081 \pm 0,065$ \\
\hline & $\mathrm{G} 2$ & 40 & $16,00 \pm 0,457$ & 40,0 & $66,735 \pm 45,914$ & $1,520 \pm 0,576$ & $0,118 \pm 0,110$ \\
\hline & Todos Trats & 200 & $110,00 \pm 0,467$ & 55,0 & $58,329 \pm 32,693$ & $1,575 \pm 0,614$ & $0,133 \pm 0,113$ \\
\hline \multirow{4}{*}{$\begin{array}{l}\begin{array}{l}\text { Eriotheca } \\
\text { pubescens }\end{array} \\
\end{array}$} & G0 & 40 & $38,00 \pm 0,154$ & 95,0 & $24,560 \pm 21,880$ & $2,029 \pm 0,586$ & $0,274 \pm 0,323$ \\
\hline & G1 & 40 & $33,00 \pm 0,376$ & 82,5 & $12,329 \pm 10,078$ & $1,321 \pm 0,961$ & $0,136 \pm 0,117$ \\
\hline & $\mathrm{G} 2$ & 40 & $35,00 \pm 0,317$ & 87,5 & $16,900 \pm 19,196$ & $1,369 \pm 1,026$ & $0,160 \pm 0,163$ \\
\hline & Todos Trats & 200 & $177,00 \pm 0,278$ & 88,5 & $18,059 \pm 16,783$ & $1,599 \pm 0,837$ & $0,194 \pm 0,206$ \\
\hline \multirow{4}{*}{$\begin{array}{l}\text { Eugenia } \\
\text { dysenterica }\end{array}$} & G0 & 40 & $38,00 \pm 0,154$ & 95,0 & $30,489 \pm 20,214$ & $1,021 \pm 0,407$ & $0,234 \pm 0,263$ \\
\hline & G1 & 40 & $34,00 \pm 0,334$ & 85,0 & $38,835 \pm 23,530$ & $0,949 \pm 0,319$ & $0,156 \pm 0,103$ \\
\hline & $\mathrm{G} 2$ & 40 & $35,00 \pm 0,222$ & 87,5 & $53,827 \pm 28,330$ & $1,028 \pm 0,362$ & $0,191 \pm 0,126$ \\
\hline & Todos Trats & 200 & $179,00 \pm 0,238$ & 89,5 & $39,453 \pm 23,487$ & $0,996 \pm 0,363$ & $0,194 \pm 0,169$ \\
\hline \multirow{4}{*}{$\begin{array}{l}\text { Myracrodruon } \\
\text { urundeuva }\end{array}$} & G0 & 24 & $24,00 \pm 0,503$ & 100,0 & $89,909 \pm 37,233$ & $2,220 \pm 0,671$ & $0,875 \pm 0,641$ \\
\hline & G1 & 24 & $22,00 \pm 0,508$ & 91,7 & $52,268 \pm 24,818$ & $1,188 \pm 0,676$ & $0,143 \pm 0,124$ \\
\hline & $\mathrm{G} 2$ & 24 & $22,00 \pm 0,508$ & 91,7 & $47,908 \pm 10,711$ & $0,947 \pm 0,534$ & $0,088 \pm 0,077$ \\
\hline & Todos Trats & 120 & $114,00 \pm 0,506$ & 95,0 & $65,294 \pm 25,947$ & $1,515 \pm 0,638$ & $0,404 \pm 0,306$ \\
\hline \multirow{4}{*}{$\begin{array}{l}\text { Stryphnodendron } \\
\text { adstringens }\end{array}$} & G0 & 40 & $25,00 \pm 0,479$ & 62,5 & $28,609 \pm 15,560$ & $1,334 \pm 0,703$ & $0,385 \pm 0,316$ \\
\hline & G1 & 40 & $21,00 \pm 0,480$ & 52,5 & $21,598 \pm 13,708$ & $0,853 \pm 0,504$ & $0,215 \pm 0,236$ \\
\hline & G2 & 40 & $17,00 \pm 0,507$ & 42,5 & $15,332 \pm 12,851$ & $0,612 \pm 0,471$ & $0,185 \pm 0,201$ \\
\hline & Todos Trats & 200 & $109,00 \pm 0,486$ & 54,5 & $22,661 \pm 14,188$ & $0,973 \pm 0,570$ & $0,271 \pm 0,257$ \\
\hline
\end{tabular}

* G0=sem gramíneas; G1=com Paspalum atratum; G2=com Urochloa brizantha

3. Dados coletados, após a defoliação, aos 14 meses após o plantio no campo:

A sobrevivência geral entre todos os indivíduos das espécies lenhosas, após 11 meses da defoliação foi de 27,6\%, sendo que as espécies que apresentaram maior sobrevivência nos diferentes tratamentos, foram Eriotheca pubescens, Eugenia dysenterica e Myracrodruon urundeuva (Figura 6). As espécies Copaifera langsdorffii, Dalbergia miscolobium e 
Stryphnodendron adstringens tiveram cada uma ao final do experimento um total de menos $20 \%$ de plantas sobreviventes distribuídas ao longo dos tratamentos (Figura 6).
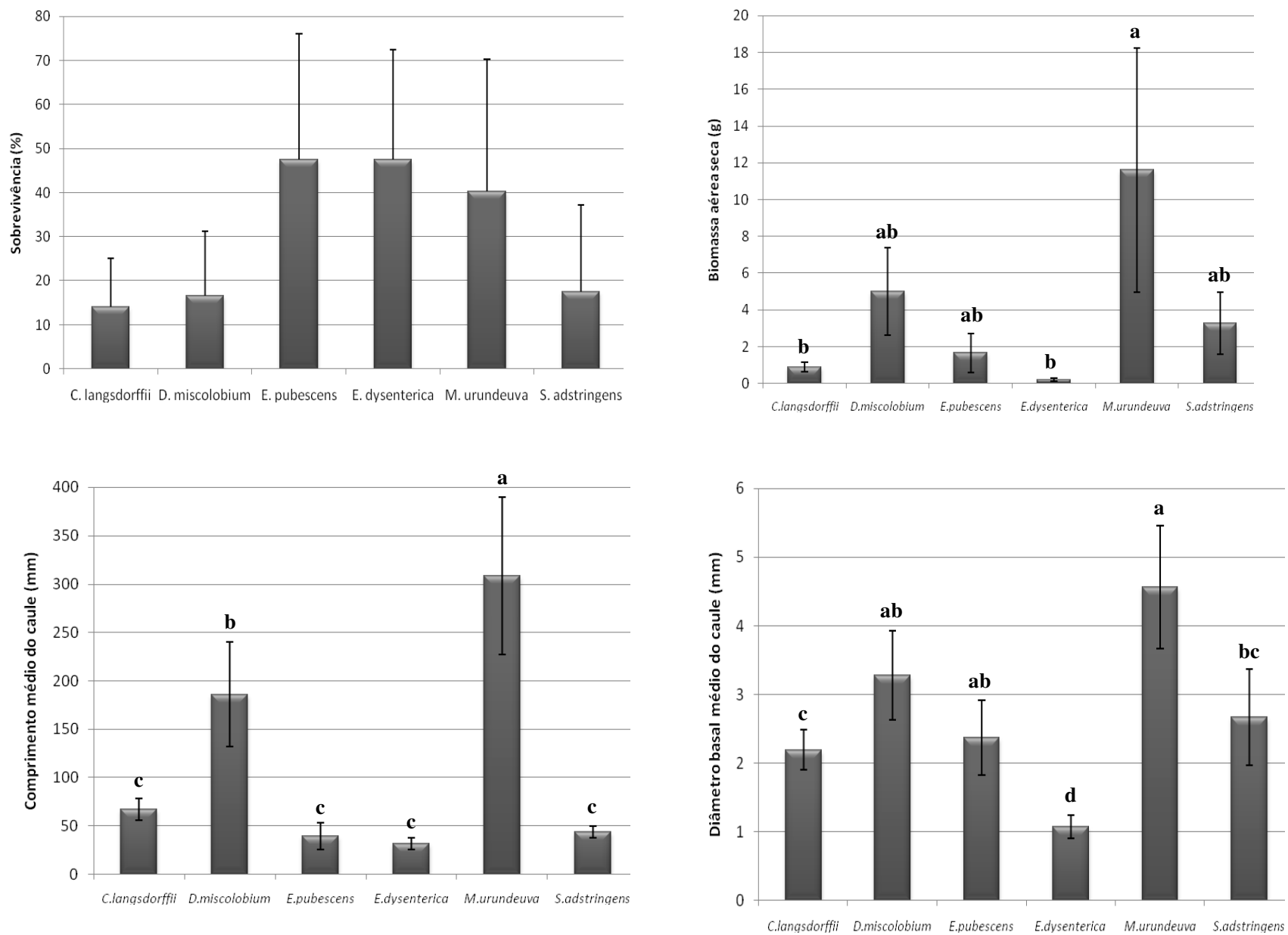

Figura 6. Sobrevivência e biometria média dos indivíduos de espécies de lenhosas plantados nos diferentes tratamentos com e sem gramíneas nativa (Paspalum atratum) e exótica (Urochloa brizantha), após 11 meses da defoliação. Barras de erros indicam o intervalo de confiança de 95\%. Obs. Plantas com aproximadamente 540 dias de vida.

Algumas espécies se destacaram por apresentar maiores taxas de crescimento nos diferentes parâmetros observados. Myracroduron urundeuva foi a espécies que apresentou maior desenvolvimento de parte aérea, tanto biomassa, como diâmetro e comprimento do caule (Figura 6, Tabela 6). Myracroduron urundeuva é uma espécie que, apesar de ocorrer no cerrado, é mais comum em Caatinga (Almeida et al., 1998; Silva Junior et al., 2005; Lorenzi, 2008). 
Caracteristicamente possui um crescimento mais rápido que as outras espécies, como estratégia adaptativa ao seu ambiente.

De acordo com Vadigi e Ward (2014), espécies de savanas úmidas, como o Cerrado, tem seu crescimento reduzido em relação às outras espécies e consequentemente são mais vulneráveis à defoliação que espécies de savanas mais secas. Após defoliação, as plantas de savanas úmidas apresentaram menores valores de biomassa seca total, diâmetro basal do caule e razão folha/parte aérea, do que as espécies características de savanas mais secas (Vadigi \& Ward, 2014).

Dalbergia miscolobium também apresentou um bom desenvolvimento da parte aérea, resultado este inesperado, já que esta espécie é bem característica de fitofisionomias mais aberta (Almeida et al., 1998).

Espécies características de fitofisionomias mais abertas, como Eugenia dysenterica, Eriotheca pubescens e Stryphnodendron adstringens, que reconhecidamente priorizam o investimento em sistema radicular (Tomlinson et al., 2011), mantiveram pequenos incrementos em biomassa aérea e desenvolvimento do caule (Figura 6). Certamente, esta é uma adaptação evolutiva que permitiu com que estas espécies sobrevivessem em ambientes como o cerrado, com grande frequência de queimadas (Tomlinson et al., 2011).

Tabela 6. Análises estatísticas dos dados coletados a partir das plantas que rebrotaram, após 11 meses da defoliação. Experimento conduzido em área experimental do Laboratório de Termobiologia, UnB/Brasília, entre fevereiro de 2011 e abril de 2012.

\begin{tabular}{lcccc}
\hline & $\begin{array}{c}\text { Graus de } \\
\text { liberdade }\end{array}$ & Biomassa aérea & $\begin{array}{c}\text { Comprimento } \\
\text { do caule }\end{array}$ & $\begin{array}{c}\text { Diâmetro do } \\
\text { caule }\end{array}$ \\
\cline { 3 - 5 } Gramínea (G) & 2 & 0,013 & 0,000 & 0,000 \\
Nutriente (N) & 1 & 0,001 & 0,008 & 0,049 \\
Espécie (Spp) & 5 & 0,050 & 0,000 & 0,000 \\
$\mathbf{G * N}$ & 2 & 0,085 & 0,020 & 0,000 \\
$\mathbf{G * S p p}$ & 7 & 0,049 & 0,000 & 0,000 \\
$\mathbf{N} * \mathbf{S p p}$ & 5 & 0,019 & 0,000 & 0,000 \\
$\mathbf{G * N * S p p}$ & 6 & 0,032 & 0,000 & 0,000 \\
\hline
\end{tabular}


As variações interespecíficas observadas nas espécies de lenhosas podem ser função do seu habitat, de sua estrutura morfológica e fisiológica e de sua capacidade e velocidade de resposta às variações ambientais. O desenvolvimento das plantas em condições de competição e de estresse envolvem alocação de recursos em determinados órgãos, em detrimento de outros (trade-offs) (Tomlinson et al., 2011; Higgins et al., 2000; Tilman, 1988).

Em um estudo com 51 espécies de lenhosas de savanas, Tomlinson et al. (2011) dividiram as espécies de savanas em grupos funcionais, de acordo com suas características de desenvolvimento, após a defoliação. A maior parte das espécies de lenhosas da América do Sul estudadas eram decíduas, assim como no presente trabalho, e alocavam recursos principalmente em órgãos subterrâneos em detrimento do desenvolvimento da parte aérea. Este tipo de resposta pode ser uma adaptação evolutiva às freqüentes queimadas que ocorrem no Cerrado (Tomlinson et al., 2011).

Diferenças significativas foram observadas na sobrevivência entre os diferentes tratamentos graminosos. Independentemente da espécie, a sobrevivência das plantas de lenhosas foi inibida pela presença das gramíneas (ANOVA, $\mathrm{F}_{2}=16,984$, $\mathrm{p} \leq 0,001$ ), principalmente após a defoliação (Figura 7). A gramínea exótica Urochloa brizantha proporcionou efeito significativamente mais negativo que a gramínea nativa Paspalum atratum (ANOVA, $\mathrm{F}_{2}=16,984, \mathrm{p}<0,001$ ), sendo que, após 14 meses do início do experimento, menos de 5\% das plantas submetidas à defoliação conseguiram sobreviver junto à gramínea exótica comparado a aproximadamente $50 \%$ nos locais onde não havia gramíneas e $30 \%$ nas parcelas com Paspalum atratum (Figura 7).

É quase um consenso entre diversos pesquisadores que a competição com gramíneas deve exercer forte efeito negativo no estabelecimento inicial e na sobrevivência de plântulas de lenhosas (Kambatuku et al., 2011; Ward \& Esler, 2011; Grellier et al., 2012).

Diversos pesquisadores sugerem que a remoção da cobertura graminosa, seja através do fogo ou pela herbivoria, promove um aumento do recrutamento das espécies lenhosas (Kraaij \& Ward, 2006; Sankaran et al., 2008; Ward \& Esler, 2010). A influência negativa da cobertura 
graminosa no crescimento inicial de plântulas de Acacia spp. também foi observado por Ward e Kraaij e Ward (2006) e Esler (2010), em savanas da África. De acordo com Kraaij e Ward (2006), as gramíneas exercem uma competição subterrânea por água e nutrientes maior que a competição aérea por luz.

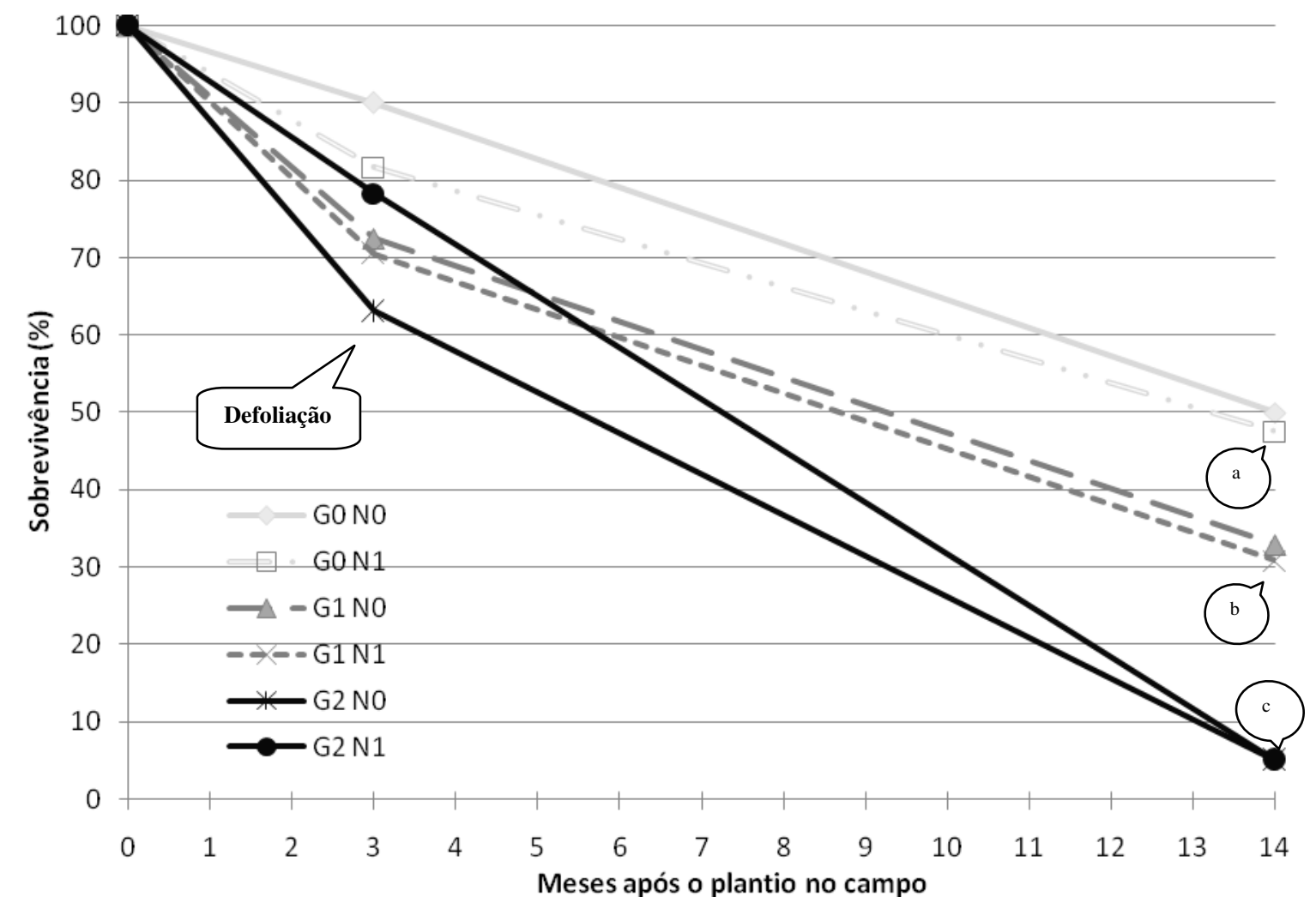

Figura 7. Porcentagem de sobrevivência de plantas de lenhosas nos diferentes tratamentos, ao longo do tempo. Experimento conduzido em área experimental do Laboratório de Termobiologia, UnB/Brasília, entre fevereiro de 2011 e abril de 2012. (Obs.: letras diferentes entre tratamentos indicam a existência de diferenças significativas). G0=sem gramíneas; G1=com Paspalum atratum; G2=com Urochloa brizantha; N0 = sem adição de nutrientes; $\mathrm{N} 1$ = com adição de nutrientes.

A adição de nutrientes não mostrou efeito significativo na sobrevivência das plantas de lenhosas, após 14 meses do plantio no campo (ANOVA, $\mathrm{F}_{1}=0,303$, p=0,586) (Figura 7, Tabela 6). Após a defoliação, somente plantas das espécies Eriotheca pubescens e Eugenia dysenterica conseguiram sobreviver nos tratamentos contendo a gramínea exótica Urochloa brizantha (Tabela 7). Todas as plantas das outras espécies morreram ou apenas um indivíduo sobreviveu (Tabela 7). 
Tabela 7. Sobrevivência $(\%)$ e biometria média (média \pm desvio padrão) de mudas de lenhosas plantadas na área experimental, nos diferentes tratamentos, após 11 meses da defoliação. Plantas das espécies: Copaifera langsdorffii, Dalbergia miscolobium, Eriotheca pubescens, Eugenia dysenterica, Myracrodruon urundeuva e Stryphnodendron adstringens. Obs. Plantas com aproximadamente 540 dias de vida.

\begin{tabular}{|c|c|c|c|c|c|c|}
\hline Espécie & Tratamento & $\mathbf{N}$ & $\begin{array}{l}\text { Sobrevi- } \\
\text { Vencia }\end{array}$ & $\begin{array}{c}\text { Comprimento } \\
\text { caule }(\mathbf{m m})\end{array}$ & $\begin{array}{c}\text { Diametro } \\
\text { caule }(\mathbf{m m})\end{array}$ & $\begin{array}{c}\text { Biomassa aérea } \\
(\mathrm{g})\end{array}$ \\
\hline \multirow{7}{*}{$\begin{array}{l}\text { Copaifera } \\
\text { langsdorffii }\end{array}$} & G0 N0 & 20 & 30 & $56,600 \pm 30,631$ & $2,477 \pm 0,498$ & $1,147 \pm 0,975$ \\
\hline & G0 N1 & 20 & 25 & $106,328 \pm 34,666$ & $2,858 \pm 1,048$ & $1,531 \pm 0,862$ \\
\hline & G1 N0 & 20 & 15 & $39,533 \pm 7,533$ & $1,627 \pm 0,569$ & $0,295 \pm 0,211$ \\
\hline & G1 N1 & 20 & 15 & $67,163 \pm 30,280$ & $1,803 \pm 0,544$ & $0,556 \pm 0,329$ \\
\hline & G2 N0 & 20 & 0 & $*$ & $*$ & $*$ \\
\hline & G2 N1 & 20 & 0 & $*$ & $*$ & $*$ \\
\hline & Todos Trats & 120 & 14,17 & $67,406 \pm 28,335$ & $2,191 \pm 0,576$ & $0,882 \pm 0,561$ \\
\hline \multirow{7}{*}{$\begin{array}{l}\text { Dalbergia } \\
\text { miscolobium }\end{array}$} & G0 N0 & 20 & 45 & $195,112 \pm 119,470$ & $3,904 \pm 1,582$ & $3,721 \pm 3,078$ \\
\hline & G0 N1 & 20 & 25 & $432,305 \pm 266,116$ & $6,825 \pm 2,860$ & $19,868 \pm 17,420$ \\
\hline & G1 N0 & 20 & 15 & $40,750 \pm 24,174$ & $2,283 \pm 1,393$ & $0,862 \pm 1,099$ \\
\hline & G1 N1 & 20 & 10 & $124,435 \pm 83,120$ & $1,520 \pm 0,113$ & $0,295 \pm 0,213$ \\
\hline & G2 N0 & 20 & 0 & $*$ & $*$ & $*$ \\
\hline & G2 N1 & 20 & 5 & 136,420 & 1,850 & 0,292 \\
\hline & Todos Trats & 120 & 16,67 & $185,804 \pm 148,404$ & $3,277 \pm 2,185$ & $5,008 \pm 8,428$ \\
\hline \multirow{7}{*}{$\begin{array}{l}\text { Eriotheca } \\
\text { pubescens }\end{array}$} & G0 N0 & 20 & 65 & $20,265 \pm 14,541$ & $2,394 \pm 1,639$ & $1,660 \pm 2,816$ \\
\hline & G0 N1 & 20 & 85 & $117,728 \pm 92,193$ & $7,136 \pm 1,582$ & $7,481 \pm 8,062$ \\
\hline & G1 N0 & 20 & 60 & $28,742 \pm 19,659$ & $1,792 \pm 1,226$ & $0,471 \pm 0,911$ \\
\hline & G1 N1 & 20 & 55 & $21,695 \pm 17,668$ & $1,345 \pm 0,786$ & $0,245 \pm 0,264$ \\
\hline & G2 N0 & 20 & 10 & $23,350 \pm 13,364$ & $1,210 \pm 0,976$ & $0,083 \pm 0,050$ \\
\hline & G2 N1 & 20 & 5 & 27,280 & 0,380 & 0,064 \\
\hline & Todos Trats & 120 & 46,67 & $39,843 \pm 38,293$ & $2,376 \pm 2,425$ & $1,667 \pm 2,910$ \\
\hline \multirow{7}{*}{$\begin{array}{l}\text { Eugenia } \\
\text { dysenterica }\end{array}$} & G0 N0* & 20 & 85 & $27,365 \pm 12,278$ & $1,274 \pm 0,437$ & $0,321 \pm 0,301$ \\
\hline & G0 N1 & 20 & 50 & $32,365 \pm 15,520$ & $1,124 \pm 0,394$ & $0,258 \pm 0,301$ \\
\hline & G1 N0 & 20 & 75 & $26,284 \pm 10,572$ & $0,936 \pm 0,460$ & $0,109 \pm 0,082$ \\
\hline & G1 N1 & 20 & 30 & $41,282 \pm 23,434$ & $0,998 \pm 0,488$ & $0,380 \pm 0,351$ \\
\hline & G2 N0 & 20 & 20 & $32,213 \pm 5,561$ & $1,163 \pm 0,291$ & $0,065 \pm 0,022$ \\
\hline & G2 N1 & 20 & 20 & $31,903 \pm 10,496$ & $0,953 \pm 0,239$ & $0,133 \pm 0,141$ \\
\hline & Todos Trats & 120 & 46,67 & $31,902 \pm 5,300$ & $1,074 \pm 0,134$ & $0,211 \pm 0,127$ \\
\hline \multirow{7}{*}{$\begin{array}{l}\text { Myracroduron } \\
\text { urundeuva }\end{array}$} & G0 N0 & 20 & 40 & $171,983 \pm 200,164$ & $3,587 \pm 2,667$ & $0,712 \pm 0,696$ \\
\hline & G0 N1 & 20 & 45 & $937,891 \pm 50,788$ & $11,829 \pm 3,965$ & $45,160 \pm 59,539$ \\
\hline & G1 N0 & 20 & 40 & $59,603 \pm 26,959$ & $1,443 \pm 0,794$ & $0,218 \pm 0,154$ \\
\hline & G1 N1 & 20 & 20 & $65,665 \pm 6,773$ & $1,398 \pm 0,738$ & $0,310 \pm 0,244$ \\
\hline & G2 N0 & 20 & 0 & $*$ & $*$ & $*$ \\
\hline & G2 N1 & 20 & 0 & $*$ & $*$ & $*$ \\
\hline & Todos Trats & 120 & 24,17 & $308,785 \pm 422,567$ & $4,564 \pm 4,950$ & $11,600 \pm 22,374$ \\
\hline \multirow{7}{*}{$\begin{array}{l}\text { Stryphnodendron } \\
\text { adstringens }\end{array}$} & G0 N0 & 20 & 35 & $39,081 \pm 12,933$ & $4,283 \pm 2,070$ & $5,137 \pm 3,944$ \\
\hline & G0 N1 & 20 & 55 & $50,679 \pm 23,591$ & $3,014 \pm 1,447$ & $5,542 \pm 6,740$ \\
\hline & G1 N0 & 20 & 5 & 17,400 & 1,390 & 1,201 \\
\hline & G1 N1 & 20 & 10 & $68,405 \pm 6,824$ & $1,975 \pm 1,280$ & $1,207 \pm 0,792$ \\
\hline & G2 N0 & 20 & 0 & $*$ & $*$ & $*$ \\
\hline & G2 N1 & 20 & 0 & $*$ & $*$ & $*$ \\
\hline & Todos Trats & 120 & 17,5 & $43,891 \pm 21,385$ & $2,665 \pm 1,270$ & $3,272 \pm 2,393$ \\
\hline
\end{tabular}

* G0=sem gramíneas; G1=com Paspalum atratum; G2=com Urochloa brizantha; N0 = sem adição de nutrientes; N1 = com adição de nutrientes 
É interessante notar que, em menos de ano após a defoliação, Urochloa brizantha já foi capaz de reduzir drasticamente a sobrevivência das lenhosas. Isso demonstra um forte potencial competitivo desta invasora que, mesmo tendo sido cortada a dois centímetros do solo, em pouco tempo cresceu vigorosamente e foi capaz de eliminar várias espécies lenhosas concorrentes.

Plantas invasoras, como é o caso da Urochloa brizantha, apresentam características que as tornam melhores competidoras, como altas taxas de crescimento, alta taxa fotossintética, alta eficiência no uso de nutrientes, tolerância ao desfolhamento e ao sombreamento e alta capacidade de rebrota (Rejmanek \& Richardson, 1996; Williamson \& Fitter, 1996; Everett, 2000; Matos \& Pivello, 2009). Hoffmann \& Haridasan (2008) também observaram efeito negativo de outra gramínea invasora Melinis minutiflora na sobrevivência de plântulas de lenhosas do Cerrado.

Com relação às plantas que conseguiram rebrotar após à defoliação, a presença das gramíneas nativa e exótica também inibiu seu crescimento e o desenvolvimento (Tabela 7, Figura 8). Foi possível verificar diferenças significativas entre os tratamento com e sem cobertura graminosa, em todos os parâmateros biométricos analisados (Tabela 6, Figura 8).

Como a maior parte das lenhosas já havia morrido nos tratamentos contendo braquiária, não foi possível observar diferenças significativas entre a gramínea exótica e a nativa no crescimento aéreo das plantas de lenhosas (Tabela 6, Figura 8).

De acordo com Vadigi e Ward (2014), espécies de savanas úmidas são mais vulneráveis à competição com gramíneas e à defoliação que espécies de savanas mais secas, já que tem seu crescimento reduzido em relação às outras espécies. Em competição com gramíneas e após defoliação, as plantas de savanas úmidas apresentaram menores valores de biomassa seca total, diâmetro basal do caule e razão folha/parte aérea, do que as espécies características de savanas mais secas (Vadigi \& Ward, 2014). 

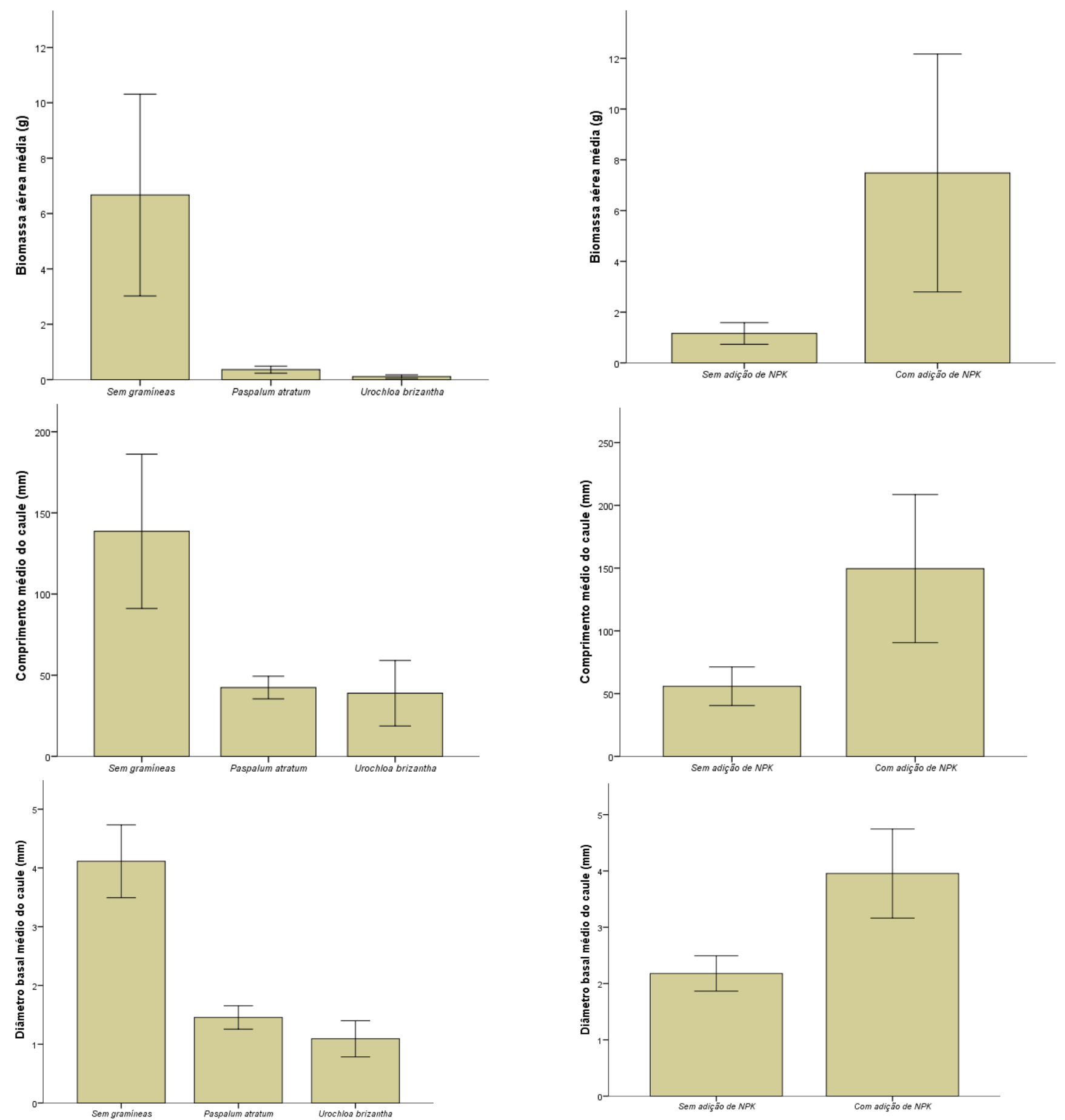

Figura 8. Biometria média dos indivíduos de espécies de lenhosas plantados nos diferentes tratamentos, após 11 meses da defoliação. Barras de erros indicam o intervalo de confiança de $95 \%$. Obs. Plantas com aproximadamente 540 dias de vida.

De maneira geral, a adição de nutrientes influenciou o crescimento aéreo das plantas de lenhosas. Além do incremento em biomassa aérea $\left(\mathrm{F}_{1}=5,804, \mathrm{p}=0,001\right)$, a adição de nutrientes ao solo promoveu respostas positivas no crescimento da parte aérea das plantas, sendo possível 
observar maiores valores no diâmetro basal do caule e na altura do caule das lenhosas $\left(\mathrm{F}_{1}=3,941\right.$, $\mathrm{p}=0,049$ e $\mathrm{F}_{1}=7,144, \mathrm{p}=0,008$, respectivamente) (Figura 8, Tabela 6).

Vadigi e Ward (2014) também encontraram efeitos positivos da adição de nutrientes ao solo contendo gramíneas na biomassa das plantas jovens de lenhosas em algumas espécies de lenhosas de savanas.

Também foi possível verificar a influência de interações entre os fatores nutrientes e gramíneas (Tabela 6). A presença de nutrientes só influencia positivamente no desenvolvimento aérea da planta de lenhosa, quando esta não está na presença das gramíneas (Figura 9). Desta forma, a planta de lenhosa é beneficiada pela adição de nutrientes, mas se as gramíneas estiverem presentes, elas irão competir diretamente pelos recursos, evitando um incremento no desenvolvimento das lenhosas.

De fato, Mangla et al. (2011) afirmam que o acréscimo de nitrogênio ao solo favorece o crescimento de espécies de gramíneas invasoras em detrimento das espécies nativas. Aparentemente, as invasoras, que em geral possuem crescimento mais rápido que as nativas, estabelecem uma relação positiva entre tamanho da planta e captação de recursos (Mangla et al., 2011).

A teoria da separação vertical de nichos prevê que as espécies de lenhosas não competem diretamente por recursos com as gramíneas já que, com raízes mais profundas, ocupariam nichos de captação de recursos diferentes daqueles explorados pelas gramíneas, mais superficiais (Kambatuku et al., 2011; Rossatto et al., 2014). Segundo Hoffmann (2000) e Franco (2002), o crescimento de espécies arbóreas nativas do Cerrado é bastante lento. Sendo assim, é possível que as plântulas de lenhosas do presente estudo, ainda eram muito jovens para terem produzido raízes profundas o suficiente a ponto de evitar a competição com as gramíneas.

Este fato demonstra a susceptibilidade das mudas de espécies lenhosas que, mesmo com aproximadamente 550 dias de vida, ainda perdem na competição por recursos tanto com a gramínea, como com a gramínea exótica. 

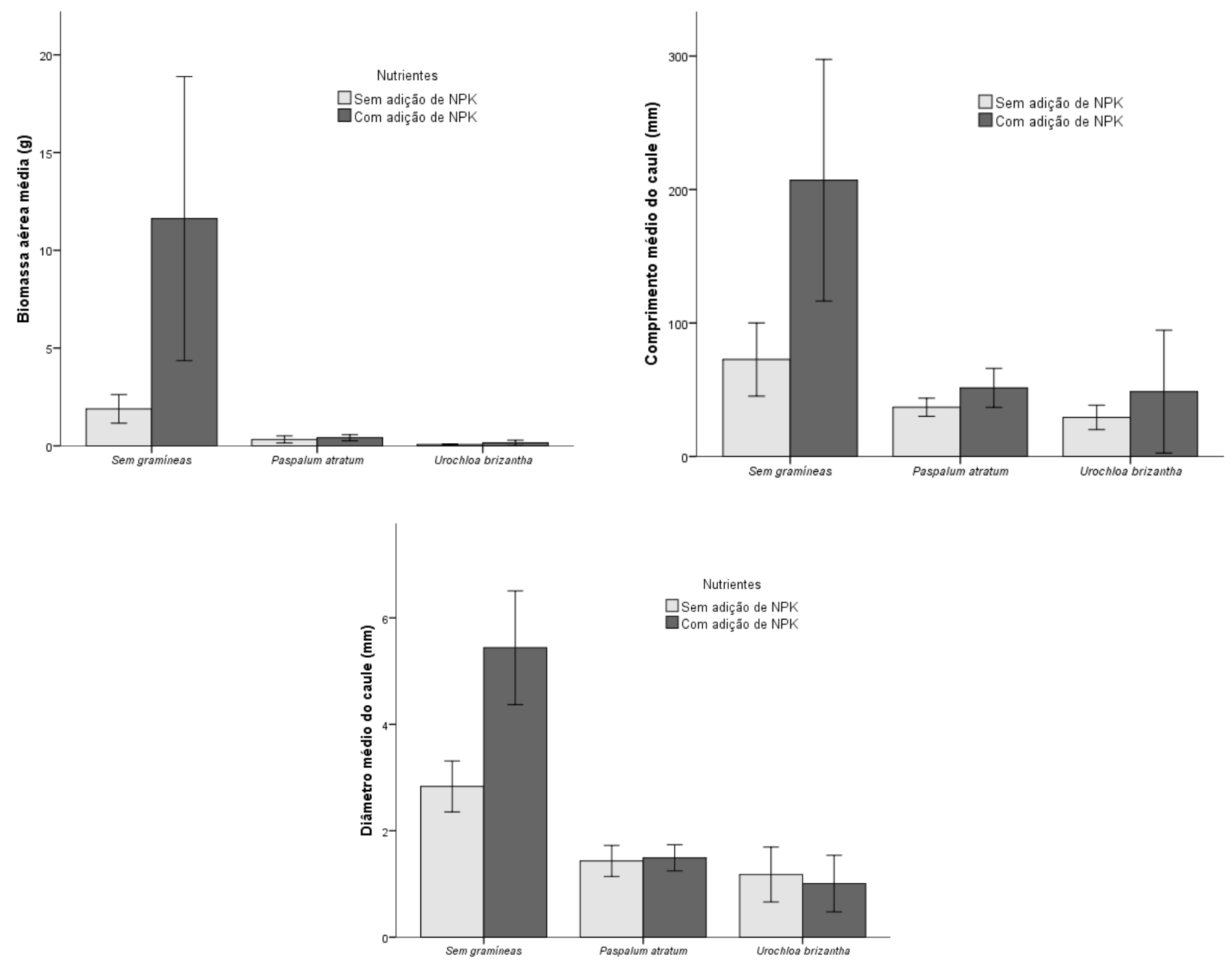

Figura 9. Biometria média dos indivíduos de espécies de lenhosas plantados nos diferentes tratamentos, após 11 meses da defoliação. Barras de erros indicam o intervalo de confiança de 95\%. Obs. Plantas com aproximadamente 540 dias de vida.

Gramíneas conseguem aproveitar estes recursos mais eficientemente que as plantas de lenhosas, deixando os nutrientes indisponíveis para estas (Kraaij \& Ward, 2006). Kraaij e Ward (2006) também observaram que a ausência das gramíneas (através da poda) promove maior aumento da biomassa das plantas de lenhosas que a adição de nutrientes ao solo.

De fato, apesar das diferenças intrínsecas das espécies lenhosas e da existência de variação interespecífica na habilidade de captação de recursos, a influência negativa das gramíneas, 
principalmente da gramínea exótica braquiária, foi bastante evidente e comum entre as diferentes espécies lenhosas.

\section{Conclusão}

Foi possível verificar a existência de uma relação positiva entre a biomassa aérea das plantas de lenhosa, antes do plantio no campo, e sua sobrevivência após 3 meses de cultivo no campo. Uma correlação negativa entre biomassa inicial e biomassa após três meses no campo também foi observada.

Com base nos dados encontrados, pode-se dizer também que a defoliação aumentou a vulnerabilidade das espécies à competição com gramíneas. De maneira geral, a sobrevivência e o crescimento das plantas das espécies lenhosas foram inibidos pela presença das gramíneas, sendo que a gramínea exótica exerceu a maior inibição. A adição de nutrientes não influenciou na sobrevivência das lenhosas, mas afetou positivamente o desenvolvimento daquelas que conseguiram rebrotar.

Nos primeiros meses de crescimento das lenhosas, apenas a presença das gramíneas afeta negativamente desenvolvimento das mudas, não havendo distinção entre os efeitos promovidos pelas gramíneas exótica ou nativa. O efeito competitivo maior da gramínea exótica frente à gramínea nativa só foi possível de ser visto, após algum tempo, visto que houve a defoliação de todas as gramíneas no momento do plantio.

Mesmo assim, em menos de ano após a defoliação, Urochloa brizantha já foi capaz de reduzir drasticamente a sobrevivência e o desenvolvimento das lenhosas. Quase nenhuma espécie de lenhosa conseguiu sobreviver nos tratamentos contendo braquiária. Das seis espécies utilizadas, apenas duas, Eriotheca pubescens e Eugenia dysenterica, conseguiram sobreviver nos tratamentos contendo braquiária. 
O poder inibitório desta gramínea invasora tão frequiente nos cerrados leva a uma grande preocupação com a conservação da biodiversidade da região. Ações de manejo destas invasoras devem ser tomadas com urgência, visto que as características do ambiente são favoráveis à espécie e a novas invasões. Incêndios contantes, formações de mais pastagens, crescimento urbano, com seu grande efeito de borda, e a quase completa ausência de áreas de conservação permanente, põem em risco toda a estrutura da comunidade vegetal.

\section{REFERÊNCIAS BIBLIOGRÁFICAS}

Almeida-Neto, M.; Prado, P. I.; Kubota, U.; Bariani, J. M.; Aguirre, G. H. \& Lewinsohn, T. M., 2010. Invasive grasses and native Asteraceae in the Brazilian Cerrado. Plant Ecology, 209: 109-122.

Almeida, S. P.; Proença, C. E. B.; Sano, S. M. \& Ribeiro, J. F., 1998. Cerrado: espécies vegetais úteis. Embrapa, CPAC, Planaltina, 464 p.

Andrade, C. M. S. de; Valentim, J. F.; Carneiro, J. C. \& Vaz, F. A., 2004. Crescimento de gramíneas e leguminosas forrageiras tropicais sob sombreamento. Pesquisa Agropecuária Brasileira, 39 (3): 263-270.

Barbosa, E. G.; Pivello, V. R. \& Meirelles, S. T., 2008. Allelopathic Evidence in Brachiaria decumbens and its potential to invade the Brazilian Cerrados. Brazilian Archives of Biology and Technology, 51 (4): 825-831.

Baudena, M.; D’Andrea, F. \& Provenzale, A., 2010. An idealized model for tree-grass coexistence in savannas: the role of life stage structure and fire disturbances. Journal of Ecology, 98: 7480 .

Beckage, B.; Gross, L. J. \& Platt, W. J., 2011. Grass feedbacks on fire stabilize savannas. Ecological Modelling, 222: 2227-2233.

Bond, W. J., 2008. What limits trees in $\mathrm{C}_{4}$ grasslands and savannas? Annual Review of Ecology, Evolution and Systematics, 39: 641-659.

Bond, W. J.; Woodward, F. I. \& Midgley, G. F., 2005. The global distribution of ecosystems in a world without fire. The New Phytologist, 165, 525-538. 
Brooks, K. J.; Setterfield, S. A. \& Douglas, M. M., 2010. Exotic Grass invasions: Applying a Conceptual Framework to the Dynamics of Degradation and Restoration in Australia's Tropical Savannas. Restoration Ecology, 18 (2): 188-197.

Brown, J. R. \& Archer, S. 1999. Shrub invasion of grassland: recruitment is continuous and not regulated by herbaceous biomass or density. Ecology 80: 2385-2396.

D’Antonio, C. M.; Hugles, R. F.; Mack, M.; Hitchcock, D \& Vitousek, P. M., 1998. The response of native species to removal of invasive exotic grasses in a seasonally dry Hawaiian woodland. Journal of Vegetation Science, 9 (5): 699-712.

D’Antonio, C. M. \& Vitousek, P. M., 1992. Biological invasions of alien grasses, the grass/fire cycle and global change. Annual review of ecology and Systematics, 23: 63-87.

Davis, M. A.; Wrage, K. J. \& Reich, P. B. 1998. Competition between tree seedlings and herbaceous vegetation: support for a theory of resource supply and demand. Journal of Ecology 86: 652-661.

Dohn, J.; Dembélé, F.; Karembé, M.; Moustakas, A.; Amévor, K. A. \& Hanan, N. P., 2013. Tree effects on grass growth in savannas: competition, facilitation and the stress-gradient hypothesis. Journal of Ecology, 101: 202-209.

Duarte E. F.; Naves, R. V.; Borges, J. D. \& Guimarães, N. N. R., 2006. Germinação e vigor de sementes de Cagaita (Eugenia dysenterica MART. ex DC.) em função do seu tamanho e tipo de coleta. Pesquisa Agropecuária Tropical, 36 (3): 173-179.

Everett, R. A., 2000. Patterns and pathways of biological invasions. Trends in Ecology \& Evolution, 15: $177-178$.

Fagg, C. W. \& Felfili, J. M., 2008. Coleta, armazenamento, beneficiamento de sementes e produção de mudas. In: Felfili, J.M.; Sampaio, J.C. \& Correia, C. R. M. A. (Org.). Bases para recuperação de áreas degradadas na Bacia do São Francisco. $1^{\circ}$ Edição. Centro de Referência em conservação da Natureza e Recuperação de Áreas Degradadas - CRAD, Brasília, DF. pp. 7 17.

Felfili, J. M.; Sousa-Silva, J. C. \& Scariot, A., 2005. Biodiversidade, ecologia e conservação do Cerrado: avanços no conhecimento. In: Cerrado: ecologia, biodiversidade e conservação. A. Scariot; J. C. Sousa-Silva \& J. Felfili (orgs). Brasília, Ministério do Meio Ambiente. p. 25-44.

Ferreira, A. G. \& Borghetti, F. (Orgs.), 2009. Germinação: do básico ao aplicado. Porto Alegre: Artmed, 399 p.

Fonseca, F. O. (org.). 2008. Águas Emendadas. Brasília, Seduma. 542p. 
Foxcroft, L. C.; Richardson, D. M.; Rejmanek, M. \& Pysek, P., 2010. Alien plant invasions in tropical and sub-tropical savannas: patterns, processes and prospects. Biological Invasion, 12: 3913-3933.

Franco, A. C., 2002. Ecophysiology of woody plants. In: Oliveira, P. S. \& Marquis, R. J. (Eds). The Cerrados of Brazil: Ecology and Natural History of a Neotropical Savanna. Columbia University Press, NewYork, pp. 178-197.

Freitas, G. K. \& Pivello, V. R., 2005. A ameaça das gramíneas exóticas à biodiversidade. In: Pivello, V. R. \& Varanda, E. M. (Eds). O Cerrado Pé-de Gigante, ecologia e conservação. São Paulo, pp. 283-296.

Gorgone-Barbosa, E.; Pivello, V. R.; Bautista, S.; Zupo, T.; Rissi, M. N. \& Fidelis, A., 2014. How can an invasive grass affect fire behavior in a tropical savanna? A community and individual plant level approach. Ecological Invasions, 17. Disponível em: http://link.springer.com/article/10.1007/s10530-014-0740-z

Grellier, S.; Barot, S.; Janeau, J. L. \& Ward, D., 2012. Grass competition is more important than seed ingestion by livestock for Acacia recruitment in South Africa. Plant Ecology, 213: 899908.

Hanan, N.; Sea, W.; Dangelmayr, G. \& Govender, N., 2008. Do fires in savannas consume woody biomass? A comment on approaches to modelling savanna dynamics. American Naturalist, 171: $851-856$.

Higgins, S. I.; Bond, W. J. \& Trollope, W. S. W., 2000. Fire, resprouting and variability: a recipe for grass-tree coexistence in savanna. Journal of Ecology, 88: 213-229.

Hoffmann, W. A. 1999. Fire and population dynamics of woody plants in a neotropical savanna: matrix model projection. Ecology, 80: 1354-1369.

Hoffmann, W. A., 2000. Post-establishment seedling success in the Brazilian cerrado: a comparison of savanna and forest species. Biotropica, 32: 62-69.

Hoffmann, W. A. \& Solbrig, O. T., 2003. The role of topkill in the differential response of savanna woody species to fire. Forest Ecology and Management, 180: 273-286.

Hoffmann, W. A.; Lucatelli, V. M. P. C.; Silva, F. J. Azeuedo, I. N. C.; Marinho, M. S.; Albuquerque, A. M. S.; Lopes, A. O. \& Moreira, S. P., 2004. Impact of the invasive grass Melinis minutiflora at the savanna-forest ecotone in the Brazilian Cerrado. Diversity and Distributions, 10: 99-103. 
Hoffmann, W. A. \& Haridasan, M., 2008. The invasive grass, Melinis minutiflora, inhibits tree regeneration in a Neotropical savanna. Australian Ecology, 33: 29-36.

Hoffmann, W. A.; Jaconis, S.; Mckinley, K. 1.; Geiger, E. L.; Gotsch, S. G. \& Franco, A. C., 2012. Fuels or microclimate? Understanding the drivers of fire feedbacks at savanna-forest boundaries. Australian Journal of Ecology, 37: 634-643.

Holmgren, M.; Scheffer, M. \& Huston, M. A., 1997. The interplay of facilitation and competition in plant communities. Ecology, 78: 1966-1975.

Jeltsch, F., Weber, G. E. \& Grimm, V., 2000. Ecological buffering mechanisms in savannas: a unifying theory of long-term tree-grass coexistence. Plant Ecology, 161: 161-171.

Kambatuku, J. R.; Cramer, M. D. \& Ward, D., 2011. Savanna tree-grass competition is modified by substrate type and herbivory. Journal of Vetation Science, 22: 225-237.

Karia, C. T. \& Andrade, R. P., 2001 Cultivo do Capim Pojuca. Recomendação Técnica Embrapa Cerrados, 50: 1-2.

Kitajima, K., 1992. Relationship between photosynthesis and thickness of cotyledons for tropical tree species. Functional Ecology, 6: 582-589.

Kitajima, K. \& Fenner, M., 2000. Ecology of seedling regeneration. In: Fenner, M. (ed.) Seeds: the ecology of regeneration in plant communities. Wallingford, UK, CABI Publishing. pp. 331359.

Klink, C. A. \& Joly, C. A., 1989. Identification and Distribution of $\mathrm{C}_{3}$ and $\mathrm{C}_{4}$ grasses in open and shades habitats in São Paulo State, Brazil. Biotropica, 21 (1): 30-34.

Kozovits, A. R.; Bustamante, M. M. C.; Silva, L. F.; Duarte, G. F.; Castro, A. A. \& Magalhães, J. R., 1996. Nitrato e amônio no solo e sua assimilação por espécies lenhosas em uma área de cerrado submetida a queimadas prescritas. In: Miranda, H. S.; Saito, C. H. \& Dias, B. F. S. Impacto de queimadas em áreas de cerrado e restinga. Anais do Simpósio Impacto de queimadas sobre os ecossistemas e mudanças globais, Brasília, p. 137-147.

Kraaij, J. \& Ward, D., 2006. Effects of rain, nitrogen, fire and grazing on tree recruitment and early survival in bush-encroached savanna, South Africa. Plant Ecology, 186: 235-246.

Lannes, L. S.; Bustamante, M. M. C.; Edwards, P. J. \& Venterink, H. O., 2012. Alien and endangered plants in the Brazilian Cerrado exhibit contrasting relationships with vegetation biomass and N: p stoichiometry. The New Phytologist, 196: 816-823.

Larcher, W., 2000. Ecofisiologia vegetal. São Carlos: Rima, 531 p. 
Laris, P., 2011. Humanizing Savanna Biogeography: Linking Human Practices with Ecological Patterns in a Frequently Burned Savanna of Southern Mali. Annals of the Association of American Geographers, 101 (5): 1067-1088.

Leite, G. G.; Silveira, L. F.; Fernandes, F. D. \& Gomes, A. C., 2001. Crescimento e composição química do capim Paspalum atratum cv Pojuca. Boletim pesquisa e desenvolvimento (Embrapa cerrados), 19: 1-22.

Levine, J. M.; Vila, M.; D’Antonio, C. M.; Dukes, J. S.; Grigulis, K. \& Lavorel, S., 2003. Mechanisms underlying the impacts of exotic plant invasions. Proceedings of The Royal Society of London B, 270: 775-781.

LLoret, F.; Casanovas, C. \& Peñuelas, J., 1999. Seedling survival of Mediterranean shrubland species in relation to root: shoot ratio, seed size and water and nitrogen use. Functional Ecology, 13: 210-216.

Lopes, S. F.; Vale, V. S.; Oliveira, A. P. \& Schiavini, I., 2011. Análise Comparativa da estrutura e composição florística de Cerrado no Brasil Central. Interciência, 36(1): 8-15.

Lorenzi, H., 2008. Árvores Brasileiras: manual de identificação e cultivo de plantas arbóreas do Brasil. Instituto Plantarum, Nova Odessa, 383p.

Ludwig, F.; De Kroon, H.; Berendse, F. \& Prins, H. H. T., 2004. The influence of savanna trees on nutrient, water and light availability and the understory vegetation. Plant Ecology, 170: 93-105.

Macedo, M. C. M., 2005. Pastagens no ecossistema Cerrados: evolução das pesquisas para o desenvolvimento sustentável. In: Anais da $42^{\mathrm{a}}$. Reunião Anual da Sociedade Brasileira de Zootecnia. Goiânia, Sociedade Brasileira de Zootecnia. p.56-84.

Maciel, J. R.; Oliveira, R. C. de \& Alves, M., 2009. Paspalum L. (Poaceae: Panicoideae: Paniceae) no estado de Pernambuco, Brasil. Acta Botanica Brasilica, 23 (4): 1145-1161.

Mangla, S.; Sheley, R. L.; James, J. J. \& Radosevich, S. R., 2011. Intra and interspecific competition among invasive and native species during early stages of plant growth. Plant Ecology, 212 (4): 531-542.

Martins, D.; Martins, C. C. \& Costa, N. V., 2006. Potencial alelopático de soluções de solo cultivado com Brachiaria brizantha: efeitos sobre a germinação de gramíneas forrageiras e plantas daninhas de pastagens. Planta Daninha, 24 (1): 61-70.

Matos, R. B. M., 1994. Efeito do fogo sobre regenerantes de Blepharocalyx salicifolius (H. B. K.) Berg. (Myrtaceae) em Cerrado aberto, Brasília, DF. Dissertação de Mestrado, Universidade de Brasília, Brasília. 105p. 
Matos, D. M. S. \& Pivello, V. R., 2009. O impacto das plantas invasoras nos recursos naturais de ambientes terrestres - alguns casos brasileiros. Ciência e Cultura, 61 (1): 27-30.

Miranda, A. C.; Miranda, H. S.; Dias, I. O. \& Dias, B. F., 1993. Soil and air temperatures during prescribed Cerrado fires in Central Brazil. Journal of Tropical Ecology, 9: 313-320.

Miranda, H. S.; Bustamante, M. M. C. \& Miranda, A. C., 2002. The Fire factor. In: Oliveira, P. S. \& Marquis, R. J. (Eds). The Cerrados of Brazil: Ecology and Natural History of a Neotropical Savanna. Columbia University Press, NewYork, pp. 51-68.

Moreira, A .G., 2000. Effects of fire protection on savanna structure in Central Brazil. Journal of Biogeography. 27:1021-1029.

Pivello, V. R. \& Coutinho, L. M., 1996. A qualitative successional model to assist in the management of Brazilian cerrados. Forest Ecology and Management, 87: 127-138.

Pivello, V. R., 2011. The use of fire in the Cerrado and Amazonian rainforests of Brazil: past and present. Fire Ecology, 7(1): 24-39.

Pivello, V. R.; Carvalho, V. M. C.; Lopes, P. F. Peccinini A. A. \& Rosso, S., 1999a. Abundance and distribution of native and alien grasses in a "Cerrado" (Brazilian savanna) biological reserve. Biotropica, 31: 71- 82 .

Pivello, V. R.; Shida, C. N. \& Meirelles, S. T. 1999b. Alien grasses in Brazilian savannas: a threat to the biodiversity. Biodiversity and Conservation, 8: 1281- 1294.

Ramos, A. E., 1990. Efeito da queima sobre a vegetação lenhosa do Cerrado. Dissertação de Mestrado, Universidade de Brasília, Brasília.

Rejmánek, M. \& Richardson, D. M., 1996. What attributes make some plant species more invasive? Ecology, 77: 1655- 1661.

Riginos, C., 2009. Grass competition suppresses savanna tree growth across multiple demographic stages. Ecology, 90: 335-340.

Riginos, C. \& Young, T. P., 2007. Positive and negative effects of grass, cattle, and wild herbivores on Acacia saplings in an East African savanna. Oecologia, 153: 985-995.

Rocha e Silva, E. P., 1999. Efeito do regime de queima na taxa de mortalidade e estrutura de vagetação lenhosa de campo sujo de Cerrado. Dissertação de Mestrado, universidade de Brasília, Brasília, 113p. 
Roques, K. G.; O'Connor, T. G. \& Watkinson, A. R., 2001. Dynamics of shrub encroachment in an African savanna: relative influences of fire, herbivory, rainfall and density dependence. Journal of Applied Ecology, 38: 268-280.

Rossatto, D. R.; Silva, L. C. R; Sternberg, L. S. L. \& Franco, A. C., 2014. Do woody and herbaceous species compete for soil water across topographic gradients? Evidence for niche partitioning in a Neotropical savanna. South African Journal of Botany, 91: 14-18.

Rossiter, N. A.; Setterfield, S. A.; Douglas, M. M. \& Hutley, L. B., 2003. Testing the grass-fire cycle: alien grass invasion in the tropical savannas of northern Australia. Diversity and Distributions, 9:169-176.

Sankaran, M.; Ratnam, J. \& Hanan, N. P., 2004. Tree-grass coexistence in savannas revisited Insights from an examination of assumptions and mechanisms invoked in existing models. Ecological Letters, 7: 480-490.

Sankaran, M.; Hanan, N. P.; Scholes, R. J.; Ratnam, J.; Augustine, D. J.; Cade, B.S.; Gignoux, J.; Higgins, S. I.; Le Roux, X.; Ludwig, F.; Ardo, J.; Banyikwa, F.; Bronn, A.; Bucini, G.; Caylor, K. K.; Coughenour, M. B.; Diouf, A.; Ekaya, W.; Feral, C. J.; February, E. C., Frost, P. G. H., Hiernaux, P., Hrabar, H., Metzger, K. L.; Prins, H. H. T.; Ringrose, S.; Sea, W.; Tews, J.; Worden, J. \& Zambatis, N., 2005. Determinants of woody cover in African savannas. Nature, 438: 846-849.

Sankaran, M.; Ratnam, J. \& Hanan, N. P., 2008. Woody cover in African savannas: the role of resources, fire and herbivory. Global Ecology and Biogeography, 17: 236-245.

Sato, M. N. \& Miranda, H. S., 1996. Mortalidade de plantas lenhosas do cerrado sensu stricto submetidas a diferentes regimes de queima. In: H. S. Miranda; C. H. Saito \& B. F. S. de Souza Dias (eds). Impactos de queimadas em áreas de cerrado e restinga. Brasília, Depto de Ecologia, Universidade de Brasília. pp. 102-111.

Scholes, R. J. \& Archer, S.R., 1997. Tree-Grass interactions in savannas. Annual Review of Ecology and Systematics, 28: 517-544.

Setterfield, S. A., 2002. Seedling establishment in an Australian tropical savanna: effects of seed supply, soil disturbance and fire. Journal of Applied Ecology, 39: 949-959.

Seymour, C., 2008. Grass, rainfall and herbivores as determinants of Acacia erioloba (Meyer) recruitment in an African savanna. Plant Ecology, 197; 131-138. 
Silva, I. A. \& Batalha, M. A., 2011a. Plant functional types in Brazilian savannas: The niche partitioning between herbaceous and woody species. Perspectives in Plant Ecology, Evolution and Systematics, 13 (3): 201-206.

Silva, D. M. \& Batalha, M. A., 2011b. Defense syndromes against herbivory in a cerrado plant community. Plant Ecology, 212:181-193.

Silva, L. O; Costa, D. A.; Santo Filho, K. E.; Ferreira, H. D. \& Brandão, D., 2002. Levantamento florístico e fitossociológico em duas áreas de cerrado sensu stricto no Parque Estadual da Serra de Caldas Novas, Goiás. Acta Botânica Brasilica,16: 43-53.

Silva Júnior, M. C.; Santos, G. C.; Nogueira, P. E.; Munhoz, C. B. R. \& Ramos, A. E., 2005. 100 Árvores do Cerrado - Guia de campo. Rede de sementes do Cerrado, Brasília, 278p.

Sousa-Silva, J. C. \& Fagg, C. W., 2011. Viveiros: produção de mudas nativas do Bioma Cerrado. In: Fagg, C. W.; Munhoz, C. B. R. \& Sousa-Silva, J. C. Conservação de áreas de preservação permanente do Cerrado. Caracterização, educação ambiental e manejo. Centro de Referência em Conservação da Natureza e Recuperação de Áreas Degradadas - CRAD, Brasília. pp. 115 148.

Tilman, D., 1987. Secondary sucession and the pattern of plant dominance along experimental nitrogen gradients. Ecological Monographs, 57 (3): 189-214.

Tilman, D., 1988. Plant strategies and the dynamics and structure. Princeton University Press, Princeton.

Tomlinson, K. W.; Sterck, F. J.; Bongers, F.; Silva, D. A.; Barbosa, E. R. M.; Ward, D.; Bakker, F. T.; Van Kaauwen, M.; Prins, H. T.; de Bie, S. \& Van Langevelde, F., 2012. Biomass partitioning and root morphology of savanna trees across a water gradient. Journal of Ecology, 100 (5): $1113-1121$.

Vadigi, S. \& Ward, D., 2014. Herbivory effects on saplings are influenced by nutrients and grass competition in a humid South African savanna. Perspectives in Plant Ecology, Evolution and Systematics, 16: 11- 20.

Van Langevelde, F.; Van De Vijver, C. A. D. M.; Kumar, L., Van De Koppel, J., De Ridder, N., Van Andel, J., Skidmore, A. K., Hearne, J.W., Stroosnijder, L., Bond, W. J., Prins, H. H. T. \& Rietkerk, M., 2003. Effects of fire and herbivory on the stability of savanna ecosystems. Ecology, 84: 337-350.

Wakeling, J. L.; Cramer, M. D. \& Bond, W. J., 2012. The savanna-grassland 'treeline': why don't savanna trees occur in upland grasslands? Journal of Ecology, 100: 381-391. 
Walker, B. H. \& Knoop, W. T., 1987. The response of the herbaceous layer in a dystrophic Burkea africana savanna to increased levels of nitrogen, phosphate and potassium. Journal of the Grassland Society of South Africa, 4: 31-34.

Walker, B. H.; Ludwig, D.; Holling, C. S. \& Peterman, R. M., 1981. Stability of semi-arid savanna grazing systems. Journal of Ecology, 69: 473-498.

Ward, D. \& Esler, K. J., 2010. What are the effects of substrate and grass removal on recruitment of Acacia mellifera seedlings in a semi-arid environment? Plant Ecology, 212: 245-250.

Williams, D. G. \& Baruch, Z., 2000. African grass invasion in the Americas: ecosystem consequences and the role of ecophysiology. Biological Invasions, 2: 123-140.

Williamson, M. H. \& Fitter, A., 1996. The characters of successful invaders. Biological conservation, 78: 163-170. 